\title{
Community \\ cohesion and \\ PREVENT: how have \\ schools responded?
}

\section{Chris Phillips, Daniel Tse, Fiona Johnson}

\section{Ipsos Mori}

Department for Education 
This research report was commissioned before the new UK Government took office on 11 May 2010. As a result the content may not reflect current Government policy and may make reference to the Department for Children, Schools and Families (DCSF) which has now been replaced by the Department for Education (DFE).

The views expressed in this report are the authors' and do not necessarily reflect those of the Department for Education. 


\section{Contents}

Tables and figures....................................................................... 3

Executive summary...................................................................6

Introduction .........................................................................17

Background to the research ...................................................... 17

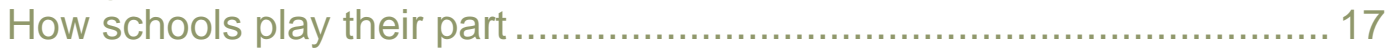

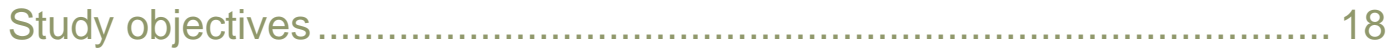

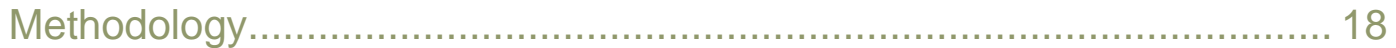

Quantitative survey sample design and weighting ............................. 20

Achieved sample profile ............................................................... 21

Glossary of analysis variable terms............................................... 23

Statistical reliability ................................................................... 24

Main findings: promoting community cohesion .......................27

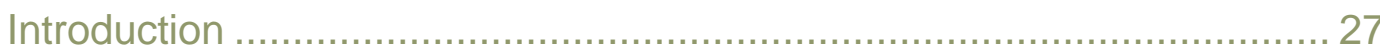

What "community cohesion" means for schools ................................. 28

Knowledge and confidence about the statutory duty to promote community

cohesion ................................................................................... 30

Knowledge of schools' community cohesion context .......................... 38

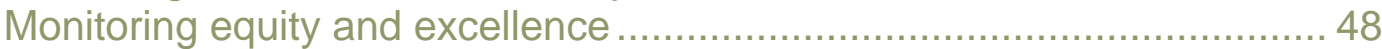

What are schools doing to promote community cohesion? .................... 56

Who are schools' partners in promoting community cohesion? ..............66 62

How structured is what schools are doing? ........................................ 64

Measuring impact........................................................................... 66

Main findings: preventing violent extremism ...........................73

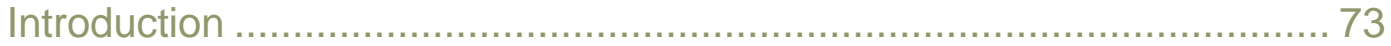

Awareness and understanding of policy on schools' role in preventing violent

extremism .................................................................................. 74

Awareness and understanding of schools' role in preventing violent extremism

How are schools building their pupils' resilience to violent extremism? ... 82

Information and support: how much and what have schools received? ... 85

Training: who has received it and how much have they received? ......... 91

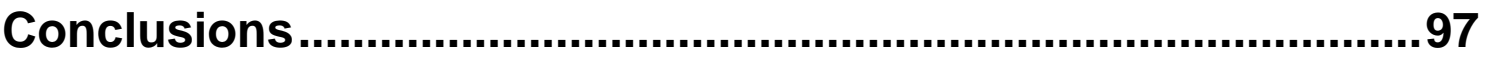

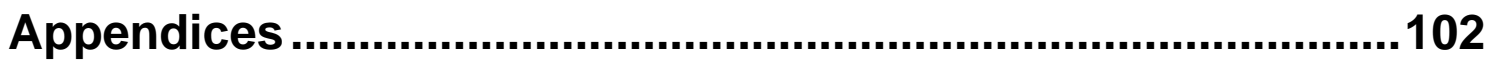

Review of materials to support the implementation of the duty ............ 103

Topline findings ........................................................................ 106

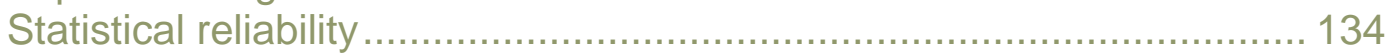

Key driver analysis ................................................................. 136 


\section{Tables and figures}

\begin{tabular}{|c|c|}
\hline TABLE & Page \\
\hline CC1: Words and phrases associated with the term "community cohesion" & 29 \\
\hline CC2: Impact of introducing the statutory duty to promote community cohesion & 35 \\
\hline CC3: Primary schools' knowledge of the community cohesion context & 40 \\
\hline CC4: Secondary schools' knowledge of the community cohesion context & 42 \\
\hline CC5: Special schools' knowledge of the community cohesion context & 45 \\
\hline CC6: Sources of information on cohesion groups & 46 \\
\hline $\begin{array}{l}\text { CC7: Primary schools' cohesion group equity and excellence - knowledge, } \\
\text { monitoring and action }\end{array}$ & 51 \\
\hline $\begin{array}{l}\text { CC8: Secondary schools' cohesion group equity and excellence - knowledge, } \\
\text { monitoring and action }\end{array}$ & 53 \\
\hline $\begin{array}{l}\text { CC9: Special schools' cohesion group equity and excellence - knowledge, } \\
\text { monitoring and action }\end{array}$ & 55 \\
\hline CC10: Means of promoting community cohesion (all responses 10\%+) & 58 \\
\hline $\begin{array}{l}\text { CC11: Curriculum subjects used to promote community cohesion (all } \\
\text { responses 2\%+) }\end{array}$ & 60 \\
\hline CC12: Activities used to promote community cohesion & 61 \\
\hline $\begin{array}{l}\text { CC13: Schools' partiners in promoting community cohesion (all responses } \\
5 \%+\text { - developed links since statutory duty }\end{array}$ & 62 \\
\hline $\begin{array}{l}\text { CC14: Schools' partners in promoting community cohesion - currently have } \\
\text { links }\end{array}$ & 64 \\
\hline $\begin{array}{l}\text { CC15: Community cohesion's inclusion in school and local authority policies } \\
\text { and planning }\end{array}$ & 65 \\
\hline $\begin{array}{l}\text { Cc16: Monitoring school effectiveness in promoting community cohesion (all } \\
\text { responses } 10 \%+\text { ) }\end{array}$ & 67 \\
\hline $\begin{array}{l}\text { CC17: Recipients of community cohesion statutory duty continuing } \\
\text { professional development - significant differences by phase }\end{array}$ & 69 \\
\hline VE1: Words or phrases associated with the term "community cohesion" & 79 \\
\hline $\begin{array}{l}\text { VE2: Formal/named/lead responsibility for work related to promoting } \\
\text { community cohesion and preventing violent extremism }\end{array}$ & 81 \\
\hline VE3: Resillience-building activities for pupils - significant differences by phase & 83 \\
\hline VEA: Sources of information and or/support & 86 \\
\hline $\begin{array}{l}\text { VE5: Secondary school sources of information and/or support about } \\
\text { preventing violent extremism }\end{array}$ & 87 \\
\hline $\begin{array}{l}\text { VE6: Additional help in developing approaches - significant differences by } \\
\text { phase }\end{array}$ & 89 \\
\hline VE7: Additional help in developing approaches - primary schools & 90 \\
\hline VE8: Additional help in developing approaches - special schools & 91 \\
\hline VE9: Recipients of PREVENT-related training & 92 \\
\hline
\end{tabular}




\begin{tabular}{l|c}
\hline Figures & Page \\
\hline 1: Knowledge of policy: duty to promote community cohesion & 31 \\
\hline 2: Understanding of policy: duty to promote community cohesion & 32 \\
\hline 3: Knowledge of ethnic origins and cultures (secondary schools) & 43 \\
\hline 4: Schools' promotion of community cohesion & 57 \\
\hline 5: Volume of training received & 70 \\
\hline 6: Knowledge of policy: schools' role in preventing violent extremism & 75 \\
\hline 7: Understanding of policy: schools' role in preventing violent extremism & 76 \\
\hline 8: Understanding of role in preventing violent extremism & 78 \\
\hline 9: Importance of role in preventing violent extremism & 80 \\
\hline 10: Volume of information received & 88 \\
\hline 11: Volume of training received & 93 \\
\hline 12: Key driver analysis: Knowledge of duty (primary schools) & 138 \\
\hline 13: Key driver analysis: Confidence about duty (primary schools) & 139 \\
\hline 14: Key driver analysis: Knowledge of duty (secondary schools) & 140 \\
\hline 15: Key driver analysis: Confidence about duty (secondary schools) & 140 \\
\hline 16: Key driver analysis: Knowledge of duty (special schools) & 141 \\
\hline 17: Key driver analysis: Confidence about duty (special schools) & 141 \\
\hline $18:$ Key driver analysis: Change in understanding (primary schools) & 142 \\
\hline 19: Key driver analysis: Change in activity (primary schools) & 143 \\
\hline 20: Key driver analysis: Change in understanding (secondary schools) & 144 \\
\hline 21: Key driver analysis: Change in activity (secondary schools) & 144 \\
\hline 22: Key driver analysis: Change in understanding (special schools) & 145 \\
\hline 23: Key driver analysis: Change in activity (special schools) & 145 \\
\hline
\end{tabular}


 \\ (n)}

Executive summary

Executive sum mary

Executive summary

Executive sum mary

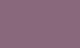

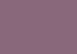

E

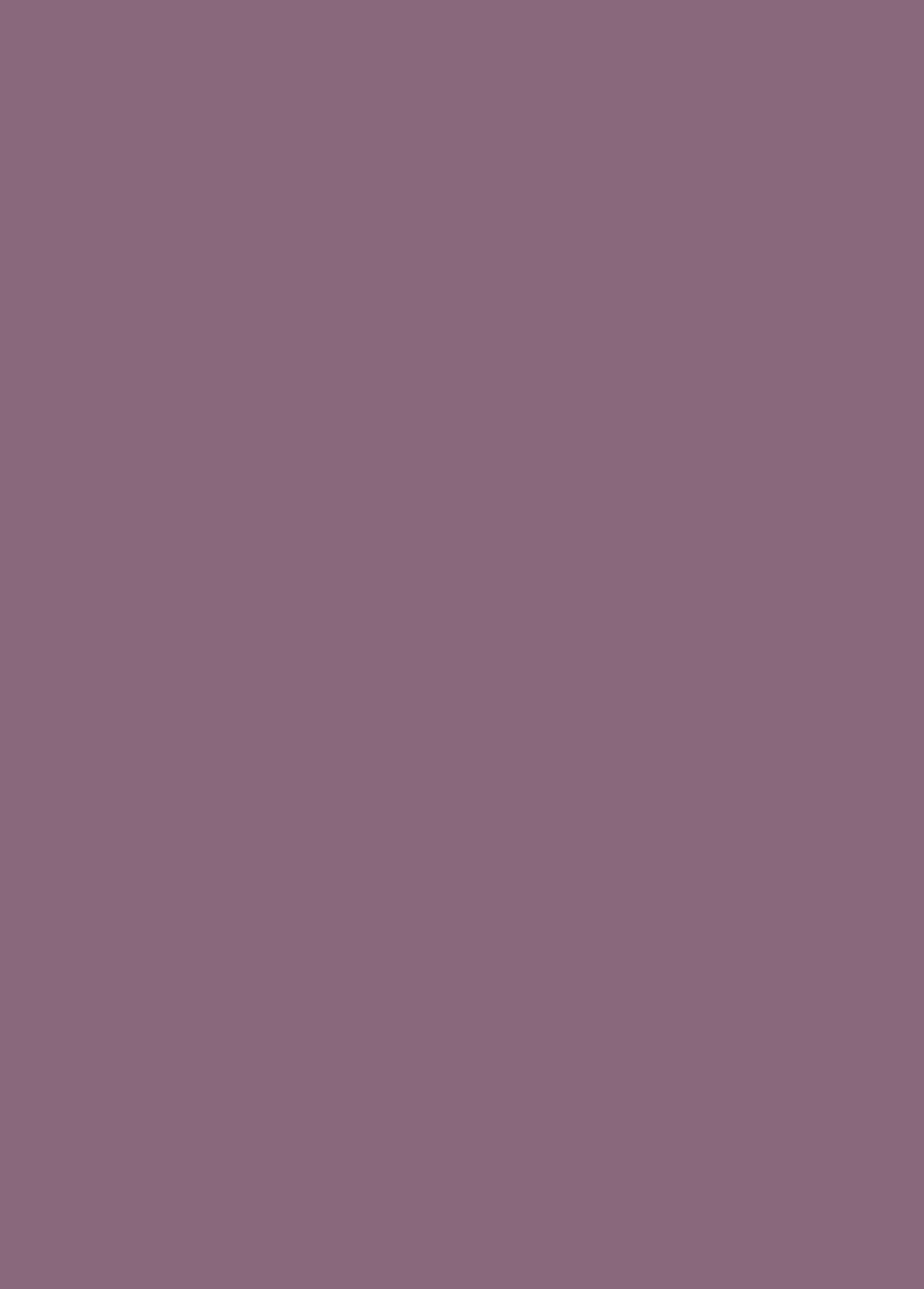




\section{Executive summary}

This report presents the findings from research commissioned by the Department for Education (then the Department for Children, Schools and Families) to assess the effect on schools and local authorities of implementing the duty to promote community cohesion and the extent to which schools are aware of, and undertaking activities to contribute to, the Government's PREVENT strategy.

\section{Study objectives}

Specifically, the aims of this study were to:

- investigate how schools and local authorities have implemented the duty to promote community cohesion, particularly the impact of policy on practices;

- $\quad$ assess the level of awareness and activity within schools regarding the prevention of violent extremism;

- compare the variation in response for: different types of schools (faith, non-faith; those in different settings (rural, urban, mono-culture, diverse etc.); and those in different phases (primary, secondary, special); and

- $\quad$ identify promising practice among schools and local authorities.

\section{Methodology}

The research used the following mixed methods approach to address the key research objectives:

\section{Literature review}

This was a collation, synthesis and critical examination of material which has been produced to support the implementation of the duty to promote community cohesion and the application of PREVENT strategy guidance, in order to begin to identify the main themes and approaches (or models) being used by schools, and to inform the development of the quantitative research questionnaire and qualitative discussion guides and materials.

\section{Quantitative survey}

We adopted a mixed-mode methodology, combining postal and telephone approaches. This comprised:

- An initial self-completion questionnaire mailed to sampled schools: respondents were advised that they could complete and return the questionnaire or refer to it during a later telephone interview;

- One postal questionnaire reminder sent to those who did not complete and return the self-completion questionnaire; and

- A telephone follow-up survey among non-respondents to both the initial and reminder postal mailout.

During the telephone fieldwork, postal questionnaires continued to be received; as soon as this occurred, they were removed from the telephone sample. 
Overall, 492 schools responded to the survey by post and 312 schools responded by telephone, yielding a total of 804 interviews. Fieldwork took place between 10 February and 14 May 2010. Telephone interviews were conducted by Ipsos MORI's in-house telephone centre using Computer-Assisted Telephone Interviewing (CATI). The questionnaire was developed jointly by the Department and Ipsos MORI. The survey allowed for robust statistical analysis of differences in views and practice across different types of school, both between and within phases.

\section{Quantitative survey sample design and weighting}

Edubase, DfE's database of all schools, was used as the survey sampling frame, supplemented by DfE-supplied data relating to the ethnic profile of schools (not held on the public-facing version of Edubase). The research universe was defined as all maintained primary and secondary schools, and all local authority maintained and non-maintained special schools, in England. Within this universe, the majority of schools are primary schools. To ensure that robust numbers of all three types of school were interviewed, and to make possible an analysis of results by key sub-groups within the secondary and special phases, a disproportionately large number of secondary and special schools were included in the survey. This was done through an initial stratification of the universe (by phase, Government Office Region and school size) before selections were made using the method of random start and fixed interval. A total of 1,621 leads was drawn: 555 primary, 829 secondary and 237 special. The random selection meant that the sample selected within each phase was broadly representative of the profile for all schools in that phase in terms of:

- $\quad$ Government Office Region (GOR)

- Location (whether urban/rural)

- Percentage of Black and Minority Ethnic (BME)/white pupils

- Diversity of the school roll (measured in terms of the degree of ethnic fractionalisation)

We interviewed 804 schools (321 primary, 348 secondary and 135 special). This represents an unadjusted aggregate response rate of $50 \%$, and unadjusted response rates of $58 \%, 42 \%$ and $57 \%$ for primary, secondary and special schools respectively. At the analysis stage, the datasets for primary, secondary and special schools were weighted to match each phase's profile in terms of: level of deprivation (IMD) ${ }^{1}$, proportion of white/BME pupils, ethnic diversity (or "fractionalisation") of the school roll and settlement type (urban or rural, town and fringe) please see the glossary of analysis variable terms below (see Page 19) for more details. Primary school data were also weighted to the profile of faith and non-faith schools. An additional weight based on the numbers of primary, secondary and special schools was applied to the aggregated "all schools" data to make it representative of all schools in England.

When interpreting the findings, it is important to remember that the quantitative results are based on a sample (not the entire population of) maintained primary and secondary schools, and local authority-maintained and non-maintained special schools, in England.

Consequently, results are subject to sampling tolerances and not all differences between sub-groups are statistically significant. At the same time, it should be noted that statistically significant differences in the data need to be interpreted to see whether they make reasonable sense.

\footnotetext{
${ }^{1}$ IMD is the Index of Multiple Deprivation, which combines indicators across seven 'domains' - income deprivation, employment deprivation, health deprivation and disability, education, skills and training deprivation, barriers to housing and services, living environment deprivation, and crime - into a single deprivation score and rank at small area level. Each area is given a percentage score, with those closest to 0 the least deprived and those closest to 100 the most deprived. We then link the school's postcode to the IMD score for the small area in which it is located.
} 


\section{Key findings - Community Cohesion}

\section{What "community cohesion" means for schools}

- Schools view "community cohesion" as cutting across several issues.

- Primary, secondary and special schools all often view "community cohesion" in terms of citizenship, multiculturalism, faith and race/ethnicity: more than three quarters mention each of these.

- Special schools also frequently see it as encompassing disability: nine out of ten (90\%) do so.

- Secondary schools also view cohesion in terms of socio-economic status (85\%), deprivation (75\%) and anti-social behaviour (76\%): over three quarters mention these.

\section{Knowledge and confidence about the statutory duty}

- $\quad$ Almost all schools (95\%) claim at least a fair amount of knowledge about the duty.

- $\quad$ Secondary schools are more likely than primary or special schools to say they know a great deal (54\% of secondary schools say this, compared with $46 \%$ of primary schools and $44 \%$ of special schools).

- $\quad$ Almost all schools say they are confident about their understanding of the duty, but secondary and special schools are the most confident: half of secondary schools (51\%) and special schools (50\%) say they are very confident.

\section{Changes since the introduction of the statutory duty}

- $\quad$ Almost all primary (89\%), secondary (93\%) and special (89\%) schools say their understanding of community cohesion is better since the introduction of the duty to promote community cohesion. Well over half say it is a lot better.

- $\quad$ Almost all schools say they are doing more (87\% of primary, $91 \%$ of secondary and $82 \%$ of special schools), but around half of these are doing a little more; it seems that understanding has increased more than activity.

\section{Knowledge of schools' community cohesion context}

- $\quad$ School senior leadership teams are seen as having the most knowledge about their community cohesion context, followed by teaching staff, support staff and finally governors. In secondary schools, there is a particularly noticeable gap in perceived knowledge between the senior leadership team and other staff members and governors. For example, when it comes to knowledge about ethnic origin and culture in secondary schools, $64 \%$ say their senior leadership team knows a great deal, compared with $34 \%$ for teaching staff, $28 \%$ for support staff and $31 \%$ for governors.

- Most schools think that their staff and/or governors know at least a fair amount about the different ethnic origins and cultures, socio-economic groups, and faiths and religions in their school and the area it serves.

- In primary schools, knowledge of all three strands is seen as broadly similar. The same is true in special schools. In secondary schools, knowledge is most well-developed 
about socio-economic groups and ethnic origins and cultures and least developed when it comes to faiths and religions. For example, among secondary senior leadership teams, $70 \%$ are thought to know a great deal about socio-economic groups, $64 \%$ about ethnic origins and cultures, but only $51 \%$ about faiths and religions.

- Perceived knowledge of faiths and religions is greater in faith schools than in their nonfaith counterparts. This is the case for both primary and secondary schools: for example, $69 \%$ of faith primary senior leadership teams are thought to know a great deal about faiths and religions in the school and local area, compared with 51\% of nonfaith primary senior leadership teams.

- Amongst secondary schools, perceived knowledge of ethnic origins and cultures appears greatest in both the most ethnically diverse schools (where presumably it is seen as a particularly pressing issue) and in the least ethnically diverse schools (perhaps reflecting a view that in a homogenous school there is little complexity to understand). Schools that are neither very diverse nor very homogenous tend to claim the least knowledge.

- Schools use a variety of information sources to understand the profile of their school and the local community. Most commonly these are school roll data, local authority guidance/training, guidance from DfE/Teachernet and consultations or surveys with parents or pupils.

- Differences in use of information sources are linked more to school phase than to the particular cohesion group about which information is being sought.

\section{Monitoring equity and excellence}

- Primary and secondary school knowledge of differences in outcomes between different cohesion groups tends to be greatest for academic results, followed by rates of exclusion and bullying. Perceived knowledge about variations in applications for places is considerably lower than knowledge of the other three issues. For example, the proportions of secondary schools saying they know a great deal about variations between different ethnic groups are $69 \%$ for academic results, $64 \%$ for exclusion rates, $48 \%$ for bullying and only $31 \%$ for applications.

- Special schools claim broadly similar levels of knowledge about variations in academic results, rates of exclusion and bullying, although perceived levels of knowledge about these issues are mostly below the levels claimed by primary or secondary schools. Most special schools do not give a rating of their knowledge of differences in likelihood of applying: they see this as not applicable.

- $\quad$ The same patterns apply to knowledge of variation by pupils from different ethnic origins/cultures, socio-economic groups and faiths/religions.

- In primary and secondary schools, perceived knowledge of variations by socioeconomic group is similar to knowledge of variations by ethnic origin and culture. Both primary and secondary schools claim least knowledge about variations by faith and religion. For example, the proportions of primary schools saying they know a great deal about variations in academic results is only $43 \%$ for different faith and religious groups, but $61 \%$ for different socio-economic groups and $67 \%$ for different ethnic origins. 
- Use of the curriculum to promote community cohesion is widespread: half or more of all types of school say they are using the curriculum and enrichment activities in equal measure (51\% of primary, $52 \%$ of secondary and $57 \%$ of special schools). Upwards of a third say they are using the curriculum more than enrichment activities (39\% of primary, $37 \%$ of secondary and $33 \%$ of special). Only one in twenty (6\% among primary, secondary and special schools) say they are mainly using one-off enrichment activities.

- Almost all schools promote cohesion through the school's ethos and values (97\%), the pastoral curriculum (94\%), curriculum subjects (94\%) and assemblies (93\%). In addition, most use one-off enrichment activities (85\%) and extended school activities (84\%). Use of English as an additional language (EAL) support is more widespread in more deprived areas.

- $\quad$ The large number of subjects used to promote cohesion suggests that most schools have cohesion activities embedded across their curriculum.

- The opportunities schools most widely offer pupils to promote cohesion are school councils (94\%) and after-school activities (89\%). Mentoring, volunteering and exchange visits are used more widely by secondary schools than by primary or special schools.

Mentoring is also used more widely by secondary schools in more deprived areas and urban areas.

\section{Who are schools' partners in promoting community cohesion?}

- Most schools have links with local charities or community groups (86\%), the police (83\%) or another school (or schools) with a different demographic profile (70\%). Slightly fewer have links with training partners (60\%) or their locality partnerships $(52 \%)$.

- Most links have been developed since the duty became statutory: for any given partnership organisation, no more than one in five schools say they already had a link established before the duty became statutory.

- Schools in deprived areas appear more likely to have developed links with other schools or partnership organisations since the duty became statutory.

\section{How structured is what schools are doing?}

- $\quad$ Community cohesion is very frequently part of the school improvement plan (SIP): this is the case for $82 \%$ of primary, $84 \%$ of secondary and $84 \%$ of special schools. Written policies for promoting community cohesion are widespread in primary $(75 \%)$ and secondary schools (68\%), but less so in special schools (61\%).

- Links to local authority children and young people's plans (CYPP) are more common (and found in $64 \%$ of all schools) than the inclusion of promoting community cohesion in school safeguarding policies (found in $53 \%$ of schools).

\section{Measuring impact}

- $\quad$ Almost all schools (91\%) measure the impact of their cohesion-related work through self-evaluation. 
- Contextual and demographic data is widely used in primary (74\%) and secondary schools $(87 \%)$, but rather less so in special schools (50\%).

- Ofsted inspections and feedback are widely cited as monitoring tools for secondary (71\%) and special schools (70\%).

- Parent and carer consultations are also used, particularly in secondary schools (67\%).

\section{Do schools want more training?}

- Respondents themselves (usually headteachers and deputy headteachers) are the most likely to have received training or continuing professional development (CPD) on the statutory duty: $74 \%$ have received such training.

- In three fifths of all schools, senior leadership teams (59\%) have received cohesion training. School governor and teaching staff training has been less widespread: training for these groups has taken place in $50 \%$ and $46 \%$ of schools respectively.

- Support staff appear least likely to have received training: this has happened in only $27 \%$ of schools.

- Most schools would welcome more training, especially for teaching staff.

\section{Key findings - PREVENT}

PREVENT is part of the broader UK counter-terrorism strategy (CONTEST). PREVENT'S overall aim is to stop people becoming or supporting terrorists. Learning together to be safe: A toolkit to help schools contribute to the prevention of violent extremism ${ }^{2}$ provided schools with guidance about extending and enhancing their existing work to incorporate the PREVENT strategy. A key objective of the research was to establish baseline measures of PREVENT activity in schools.

\section{Awareness and understanding of policy on schools' role in preventing violent extremism}

- Schools' awareness of PREVENT is lower than their awareness of the statutory duty to promote community cohesion, perhaps reflecting the fact there is no statutory duty to engage in PREVENT-related work and the relatively recent publication of Department guidance. Half of schools (50\%) say they know a fair amount or more about the policy compared with $95 \%$ claiming at least a fair amount of knowledge about the statutory duty.

- Awareness is considerably higher in secondary schools (67\% know a fair amount or more) than in primary or special schools (47\% and 54\%).

- $\quad$ Faith-status primary schools are more aware of PREVENT than non-faith primary schools (54\% versus $43 \%)$; no such difference exists amongst secondary or special schools.

- Schools appear less confident in their understanding of the PREVENT strategy than they are about the statutory duty to promote community cohesion (48\% are fairly

\footnotetext{
${ }^{2}$ DEPARTMENT FOR CHILDREN, SCHOOLS AND FAMILIES (2008). Learning together to be safe: A toolkit to help schools contribute to the prevention of violent extremism. DCSF-00804-2008BKT-EN. London: DCSF.
} 
confident or better about their understanding of PREVENT, compared with 93\% saying they are fairly confident or better about their understanding of the community cohesion duty). Confidence appears to be linked to the amount of training received.

- Secondary school knowledge of and confidence about PREVENT is higher in more deprived areas and urban centres, particularly London. Schools with an ethnically diverse school roll or a large proportion of BME pupils are likely to know more and feel more confident.

- $\quad$ Almost all schools that know a great deal about PREVENT also say they know a great deal about the statutory duty to promote community cohesion. However, only a small proportion of the schools that say they know a great deal about the statutory duty also say they know a great deal about PREVENT.

\section{Awareness and understanding of schools' role in preventing violent extremism}

- Encouragingly, most schools (84\%) say they know at least something about their role in preventing violent extremism, and only a minority (20\%) regard this role as unimportant.

- Secondary schools associate "community cohesion" with several other issues much more widely than they associate it with violent extremism or radicalisation. But a sizeable minority of secondary schools do associate the issue of "community cohesion" with violent extremism (39\%) or radicalisation (34\%) (more than is the case for primary or special schools).

- A sizeable minority of schools have no-one with formal, named or lead responsibility for their work in preventing violent extremism (35\% of primary, $35 \%$ of secondary and $44 \%$ of special schools). By contrast, hardly any schools (less than $5 \%$ ) do not have a specific person responsible for their work relating to community cohesion.

\section{How are schools building their pupils' resilience to violent extremism?}

- Schools most widely say that they build pupils' resilience to violent extremism through their ethos and values (75\%), internet safety policies or processes $(67 \%)$ and through the pastoral curriculum or PSHE (67\%).

- Only half (49\%) of schools use the curriculum to build resistance to violent extremism. By contrast almost all (94\%) use the curriculum to promote community cohesion.

\section{Information and support: how much and what have schools received?}

- Three quarters of schools (74\%) have obtained information about preventing violent extremism. Secondary schools are slightly more likely to have obtained information than primary or special schools.

- The three most widely used information sources are: DfE guidance, local authority guidance and the media (respectively used by $48 \%, 32 \%$ and $30 \%$ of all schools). The police are another important source of information for secondary schools - almost half $(48 \%)$ have used them.

- $\quad$ Secondary schools appear to be accessing more information than primary or special schools: a larger proportion of secondary schools has used almost every given source. 
- $\quad$ Primary schools in areas of low deprivation are particularly likely not to have accessed any information.

- Secondary schools in urban areas (especially London) and those with the highest BME populations or the most ethnically diverse school rolls are particularly likely to have used each of the information sources.

- Most schools (70\%) would like a little or a lot more information about preventing violent extremism (though the proportion of special schools which want more information $(60 \%)$ is smaller). Preferred sources of information are the local authority, DfE and the police.

\section{Continuing professional development/training: who has received it and how much have they received?}

- In two thirds of schools (65\%), no-one has received continuing professional development or training related to preventing violent extremism in the past year. In secondary schools, this figure is a little lower $(58 \%)$ than primary $(66 \%)$ or special schools (74\%).

- Three quarters of schools (74\%) say both their senior leadership team and teaching staff need more training related to preventing violent extremism. For teaching staff, this is less than the proportion of schools saying they need more training about promoting community cohesion (80\%), but there are more schools which want a lot more training about preventing violent extremism for their teaching staff (39\%) than say the same about community cohesion (32\%).

- Secondary schools in more deprived areas are more likely to want a lot more training for their staff.

\section{Conclusions}

\section{Impact of the statutory duty to promote community cohesion}

- $\quad$ Schools generally say that they understand community cohesion better and are doing more since the duty to promote community cohesion was introduced. Almost all schools say their understanding of community cohesion is better since the statutory duty was introduced. Well over half say it is a lot better.

- $\quad$ Almost all schools say they are doing more, but around half of these are doing a little more - perhaps understanding has increased more than activity.

- $\quad$ Almost all schools measure impact of their cohesion-related work through selfevaluation. Contextual and demographic data is widely used in primary and secondary schools, but rather less so in special schools. Ofsted inspections and feedback are widely cited as monitoring tools for secondary and special schools. Parent and carer consultations are also used, particularly in secondary schools.

\section{Awareness and activity related to PREVENT}

- Schools' awareness of PREVENT is lower than their awareness of the statutory duty to promote community cohesion, perhaps reflecting the fact that there is no statutory duty 
to engage in PREVENT-related work and the relatively recent publication of Department guidance. However, half $(50 \%)$ say they know a fair amount or more about the policy compared with $95 \%$ claiming at least a fair amount of knowledge about the statutory duty.

- Schools also appear less confident in their understanding of the PREVENT strategy than of the statutory duty. Confidence appears to be linked to the amount of training received. Three quarters of schools would like more information about preventing violent extremism, ideally from their local authority, the DfE or the police.

- $\quad$ Although many schools are active on PREVENT, the survey findings suggest it is seen as a lower priority than implementing the statutory duty to promote community cohesion. A sizeable minority of schools have no-one with formal, named or lead responsibility for PREVENT (35\% of both primary and secondary and $44 \%$ of special schools). By contrast, hardly any schools (3\% of both primary and special and $5 \%$ of special schools) do not have a specific person responsible for their work relating to community cohesion. Some schools point out that they have deliberately recruited someone to have this responsibility.

\section{Which schools are more active on community cohesion and PREVENT?}

- Differences between faith and non-faith schools are limited: perhaps more so than might be expected. Unsurprisingly, issues of faith and religion appear more of a concern for faith schools than for their non-faith counterparts. However, the approaches used to promote cohesion, monitor effectiveness and involve the broader community do not differ dramatically between faith and non-faith schools.

- $\quad$ Attitudes to PREVENT and approaches used appear broadly similar between faith schools and non-faith schools, except that faith-status primary schools are more likely than their non-faith counterparts to say they know a fair amount or more about the PREVENT-related schools policy; no similar difference emerges amongst secondary or special schools.

- To some extent, more ethnically diverse schools are more active on community cohesion but the picture is complex. For example, secondary schools' perceived knowledge of ethnic origins and cultures appears greatest in both the most ethnically diverse schools (where presumably it is seen as a particularly pressing issue) and in the least ethnically diverse schools (perhaps reflecting a view that in a homogenous school there is little complexity to understand). Schools with 'middling' levels of ethnic diversity tend to claim the least knowledge.

- Schools with an ethnically diverse school roll or a large proportion of BME pupils are likely to know more about PREVENT and feel more confident about PREVENT.

- Local factors other than the make-up of the school roll are often associated with bigger variations in approach. Schools in deprived areas and those in urban centres appear most active in promoting community cohesion: there is more variation associated with these factors than with the degree of ethnic diversity in a school.

- In primary schools, understanding and activity around community cohesion appear to have increased whatever the school's ethnic mix: there are no statistically significant differences between schools with different degrees of ethnic diversity or those with different proportions of white and BME pupils. 
- $\quad$ Secondary schools from different types of areas and with different ethnic mixes report similar levels of improved understanding. Differences in the extent to which schools are doing more are more associated with whether the school is in an urban area than with whether it is mono-cultural.

\section{Identifying promising practice}

- Much published guidance refers to individual (apparently stand-alone) activities, rather than detailed case studies of "whole school" approaches to promoting community cohesion. Findings from the quantitative survey suggest that schools are promoting community cohesion in a much more broad and "whole school" way than the picture derived from the review of the literature. Half of schools say they mostly promote community cohesion through curriculum subjects and one-off enrichment activities in roughly equal measure; a further four in ten say that they are doing so more through curriculum subjects than through one-off enrichment activities. Only one in twenty schools say that they are promoting community cohesion more through one-off enrichment activities than through curriculum subjects. The picture is similar for primary, secondary and special schools.

- Almost all schools say they are using the curriculum to promote community cohesion. Typically this appears to be across a range of subjects. Use of the curriculum to build resistance to violent extremism is significantly less widespread: half of all schools say they use it (though this varies between phases from nearer two fifths of special schools to three fifths of secondary schools). To an extent this reflects the fact that schools are less active on preventing violent extremism than on promoting community cohesion. But use of the curriculum also appears to be relatively less important: it is the third most-cited means of promoting community cohesion, but the sixth or seventh mostcited means for pursuing the PREVENT agenda.

- Training is happening but schools would generally like more of it. In most schools, the senior leadership team has received training or continuing professional development on the statutory duty. School governors and teaching staff training are less likely to have received training than senior leadership teams, and support staff are the least likely to have received training.

- In two thirds of schools, no-one has received continuing professional development or training related to preventing violent extremism in the past year. In secondary schools this figure is a little lower.

- Most schools would welcome more training on community cohesion, especially for teaching staff. Only slightly fewer think they need more training related to preventing violent extremism, but schools are more likely to want a lot more training about preventing violent extremism than about community cohesion.

- Most schools have developed links since the duty became statutory. Most commonly these are with local charities or community groups, the police or another school. Fewer have links with training partners or their locality partnerships. Schools in more deprived areas appear more likely to have developed links. Secondary schools are more likely than primary and special schools to say they've developed links with the police since the introduction of the statutory duty. 
 \\ Introduction

Introduction

(1)

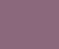

dod




\section{Introduction}

This report presents the findings from research commissioned by the Department for Education (then the Department for Children, Schools and Families) to assess the effect on schools and local authorities of implementing the duty to promote community cohesion and the extent to which schools are aware of, and undertaking activities to contribute to, the Government's PREVENT strategy.

\section{Background to the research}

The Education and Inspections Act 2006 placed a new duty on the governing bodies of maintained schools in England to promote community cohesion. The Act set schools at the heart of an aim to generate greater community cohesion, and charged them with responsibility for developing a bespoke approach reflecting their school and their community.

While a number of studies have been carried out to report on various interventions in schools, much of this work is either small-scale or of a more qualitative and subjective nature. Previously, there was little, if any, robust quantitative evidence about the extent to which schools, and their supporting local authorities, have applied the duty to promote community cohesion, nor how the duty has evolved so as to inform further policy development and identify good and promising practice. A further research need related directly to the PREVENT strategy. In 2008, guidance was published on how schools can contribute to the prevention of violent extremism, but as with community cohesion, there was little robust evidence on how the guidance is being applied, nor how effective current methods for raising awareness at school level have been.

Therefore, the aim of this study was to plug an important gap in the evidence base regarding the implementation of the duty to promote community cohesion and the application of PREVENT strategy guidance in schools.

\section{How schools play their part}

The coming-together of young people from different backgrounds in a 'neutral' school setting provides a platform for encouraging cohesion and stimulating discussion that will create better understanding and promote shared values. In turn, it might be hoped that work carried out within the school setting would promote positive activities and foster better relations outside the school setting, in the wider community.

Recognising this crucial "focal point" role and the important opportunity which schools provide in broadening pupils' horizons and challenging prejudice, the Education and Inspections Act 2006 placed schools at the heart of an aim to generate greater community cohesion.

It is the duty of schools to promote community cohesion through the school ethos (therefore creating a whole school approach), through teaching and learning, through narrowing gaps in outcomes and through their external engagement and extended services. Ofsted explains that "all schools, whatever the mix of pupils they serve, are responsible for equipping those pupils to live and thrive alongside people from many different backgrounds" ${ }^{3}$. Each school should develop a bespoke approach that reflects their school and their community, considering the faith, ethnicity, culture and socio-economic status of their pupils.

\footnotetext{
${ }^{3}$ Ofsted, Inspecting maintained schools' duty to promote community cohesion: a guide for inspectors 2007, p4
} 
In turn, Ofsted evaluates the efforts of schools to carry out their duty by assessing what schools know about the context of their school in respect of community cohesion, whether the school has planned a set of appropriate actions to promote community cohesion and what impact these plans are having.

\section{Study objectives}

Specifically, the aims of this study were to:

- investigate how schools and local authorities have implemented the duty to promote community cohesion, particularly the impact of policy on practices;

- $\quad$ assess the level of awareness and activity within schools regarding the prevention of violent extremism;

- compare the variation in response for: different types of schools (faith, non-faith, etc.); those in different settings (rural, urban, mono-culture, diverse etc.); and those in different phases (primary, secondary, special); and

- $\quad$ identify promising practice among schools and local authorities.

\section{Methodology}

This research used a mixed methods approach to address the key research objectives, as set out in the diagram below ${ }^{4}$ :

\section{Preliminary review of materials}<smiles>C1CCCC1</smiles>

Survey instrument development

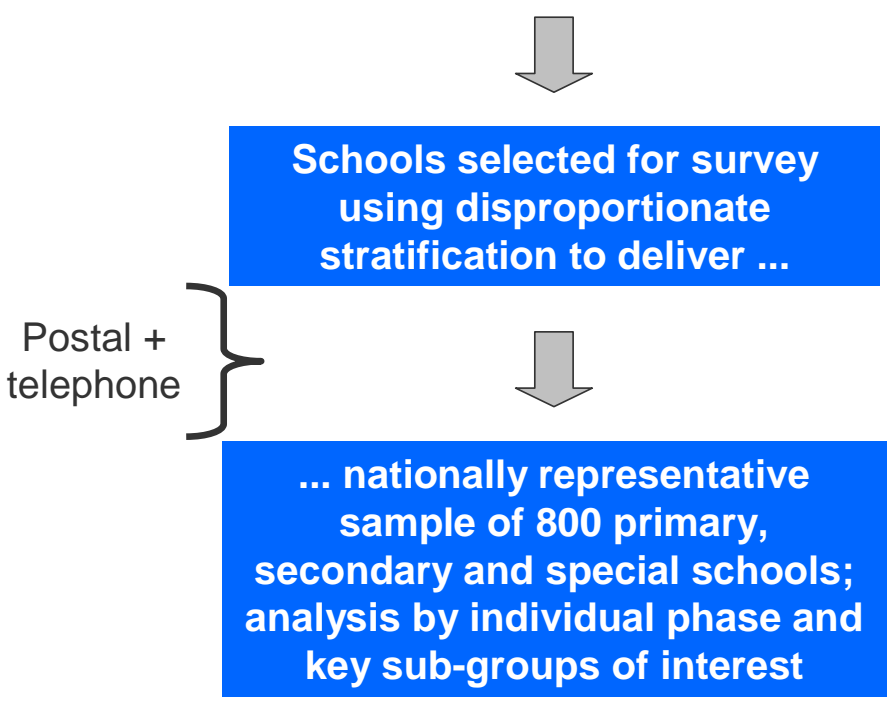

\footnotetext{
${ }^{4}$ The initial design of the project included a qualitative stage. Fieldwork was planned to be conducted by Ipsos MORI researchers in the second half of 2010. However, in light of changed ministerial priorities, a decision was made in August 2010 to not go ahead with the qualitative stage of the research.
} 


\section{Literature review}

This was a collation, synthesis and critical examination of material which has been produced to support the implementation of the duty to promote community cohesion and the application of PREVENT strategy guidance, in order to begin to identify the main themes and approaches (or models) being used by schools, and to inform the development of the quantitative research questionnaire. Key findings from this stage of this research (best described as a rapid evidence review) may be found in the appendices.

When conducting the literature review, we were unable to find detailed case studies of "whole school" approaches taken to promoting community cohesion. Much guidance from local authorities, and many publically available examples of schools' work, referred to individual, seemingly standalone, activities. There was little or no information on whether and how these activities were integrated with anything else that schools might be doing to meet their obligations under the legislation.

In short, the available evidence did not make it possible to say whether schools are adopting coherent and multi-faceted, whole-school approaches to community cohesion-related work; taken purely at face value, the available evidence suggested they were not. Therefore, one of the key questions to be addressed by the quantitative research was: does the literature "do justice" to what is actually happening in schools?

\section{Quantitative survey}

We adopted a mixed-mode methodology, combining postal and telephone approaches. This comprised:

- An initial self-completion questionnaire mailed to sampled schools: respondents were advised that this could be treated as a stand-alone postal questionnaire, or as a reference during a later telephone interview.

- One postal questionnaire reminder sent to those who did not complete and return the self-completion questionnaire.

- A telephone follow-up survey among non-respondents to both the initial and reminder postal mailout.

During the telephone fieldwork, postal questionnaires continued to be received; as soon as this occurred, they were removed from the telephone sample.

Overall, 492 schools responded to the survey by post and 312 schools responded by telephone, yielding a total of 804 interviews. Fieldwork took place between 10 February and 14 May 2010. Telephone interviews were conducted by Ipsos MORI's in-house telephone centre using Computer-Assisted Telephone Interviewing (CATI). The questionnaire was developed jointly by the Department and Ipsos MORI (a marked-up version of which, showing the topline findings, may be found in the appendices). The survey allowed for robust statistical analysis of differences in views and practice across different types of school, both between and within phases. 


\section{Quantitative survey sample design and weighting}

Edubase, DfE's database of all schools, was used as the survey sampling frame, supplemented by DfE-supplied data relating to the ethnic profile of schools (which is not held on the public-facing version of Edubase). The research universe was defined as all maintained primary and secondary schools, and all local authority-maintained and nonmaintained special schools, in England. Within this universe, the majority of schools are primary schools. To ensure that robust numbers of all three types of school were interviewed, and to make possible an analysis of results by key sub-groups within the secondary and special phases, a disproportionately large number of secondary and special schools were included in the survey. The universe was initially stratified by phase, Government Office Region and school size. Selections were then made using the method of random start and fixed interval. A total of 1,621 leads was drawn: 555 primary, 829 secondary and 237 special. The random selection meant that the sample selected within each phase was broadly representative of the profile for all schools in that phase in terms of:

- Government Office region (GOR);

- Location (whether urban/rural);

- Percentage of BME/white pupils; and

- Diversity of the school roll (measured in terms of the degree of ethnic fractionalisation).

We interviewed 804 schools (321 primary, 348 secondary and 135 special), giving an aggregate unadjusted response rate of $50 \%$, and unadjusted response rates of $58 \%, 42 \%$ and $57 \%$ for primary, secondary and special schools respectively. At the analysis stage, the datasets for primary, secondary and special schools were weighted to match the profile for each phase in terms of: level of deprivation (IMD) ${ }^{5}$, proportion of white/BME pupils, ethnic diversity (or "fractionalisation") of the school roll and settlement type (urban or rural, town and fringe) - please see the glossary of analysis variable terms below for more details. Primary school data were also weighted to the profile of faith and non-faith schools. An additional weight based on the numbers of primary, secondary and special schools was applied to the aggregated "all schools" data to make it representative of all schools in England.

When interpreting the findings, it is important to remember that the quantitative results are based on a sample (not the entire population of) maintained primary and secondary schools, and local authority-maintained and non-maintained special schools, in England.

Consequently, results are subject to sampling tolerances and not all differences between sub-groups are statistically significant. At the same time, it should be noted that statistically significant differences in the data need to be interpreted to see whether they make reasonable sense.

A note setting out the weighting design effect ${ }^{6}$, and confidence intervals, for this study is included in the appendices.

\footnotetext{
${ }^{5}$ IMD is the Index of Multiple Deprivation, which combines indicators across seven 'domains' - income deprivation, employment deprivation, health deprivation and disability, education, skills and training deprivation, barriers to housing and services, living environment deprivation, and crime - into a single deprivation score and rank at small area level. Each area is given a percentage score, with those closest to 0 the least deprived and those closest to 100 the most deprived. We then link the school's postcode to the IMD score for the small area in which it is located.

${ }^{6}$ The design effect $(\mathrm{DE})$ is defined as the ratio of the true variance of a statistic under the actual design divided by the variance that would have been obtained from a simple random sample of the same size. The DE represents the cumulative effect of sample design components such as stratification, unequal weighting and clustering, and will differ for each design.
} 


\section{Achieved sample profile}

The tables below show the achieved sample profile for schools that responded to the survey, and the profile of the respondents within schools who responded to the survey.

Achieved sample of schools

\begin{tabular}{|lcc|cc|cc|cc|}
\hline & \multicolumn{2}{c|}{ Primary } & \multicolumn{2}{c|}{ Secondary } & \multicolumn{2}{c|}{ Special } & \multicolumn{2}{|c|}{ Total } \\
\hline Pupil ethnicity quartiles & $\mathbf{N}$ & $\%$ & $\mathbf{N}$ & $\%$ & $\mathbf{N}$ & $\%$ & $\mathbf{N}$ & $\%$ \\
Q1/2 highest white population & 146 & 45 & 162 & 47 & 60 & 44 & 368 & 46 \\
Q3 & 59 & 18 & 80 & 23 & 33 & 24 & 172 & 21 \\
Q4 highest BME population & 102 & 32 & 90 & 26 & 31 & 23 & 223 & 28 \\
Information not supplied & 14 & 4 & 16 & 5 & 11 & 8 & 41 & 5 \\
\hline Ethnic diversity quartiles & & & & & & & & \\
Q1/2 least ethnically diverse or & & & & & & & & \\
fractionalised (i.e. most homogenous) & 155 & 48 & 168 & 48 & 59 & 44 & 382 & 48 \\
Q3 & 59 & 18 & 82 & 24 & 33 & 24 & 174 & 22 \\
Q4 most ethnically diverse or & & & & & & & & \\
fractionalised & 93 & 29 & 88 & 25 & 32 & 24 & 213 & 26 \\
Information not supplied & 14 & 4 & 10 & 3 & 11 & 8 & 35 & 4 \\
\hline Status & & & & & & & & \\
Faith & 90 & 28 & 82 & 24 & 2 & 1 & 174 & 22 \\
Not faith & 231 & 72 & 266 & 76 & 133 & 99 & 630 & 78 \\
\hline Index of Multiple Deprivation & & & & & & & & \\
High (most deprived) & 88 & 27 & 83 & 24 & 40 & 30 & 211 & 26 \\
Medium & 158 & 49 & 191 & 55 & 57 & 42 & 406 & 50 \\
Low (least deprived) & 68 & 21 & 72 & 21 & 33 & 24 & 173 & 22 \\
Information not supplied & 7 & 2 & 2 & 1 & 5 & 4 & 14 & 2 \\
\hline Location & & & & & & & & \\
Town and fringe & 23 & 7 & 36 & 10 & 18 & 13 & 77 & 10 \\
Urban & 265 & 83 & 291 & 84 & 95 & 70 & 651 & 81 \\
Rural & 19 & 6 & 14 & 4 & 22 & 16 & 55 & 7 \\
Information not supplied & 14 & 4 & 4 & 1 & 135 & 100 & 153 & 19 \\
\hline Total schools & 321 & & 348 & & 135 & & $\mathbf{8 0 4}$ & \\
\hline
\end{tabular}

Achieved sample of respondents within schools

\begin{tabular}{|lcc|cc|cc|cc|}
\hline & \multicolumn{2}{c|}{ Primary } & \multicolumn{2}{|c|}{ Secondary } & \multicolumn{2}{|c|}{ Special } & \multicolumn{2}{|c|}{ Total } \\
\hline Respondent & $\mathbf{N}$ & $\mathbf{9}$ & $\mathbf{N}$ & $\mathbf{\%}$ & $\mathbf{N}$ & $\mathbf{\%}$ & $\mathbf{N}$ & $\mathbf{\%}$ \\
Headteacher & 264 & 82 & 147 & 42 & 85 & 63 & 496 & 62 \\
Deputy/assistant head teacher & 17 & 5 & 140 & 40 & 28 & 21 & 185 & 23 \\
Other (all) & 35 & 11 & 57 & 16 & 18 & 13 & 110 & 14 \\
$\quad$ of which on senior leadership team & 24 & 7 & 26 & 7 & 11 & 8 & 61 & 8 \\
$\quad$ of which not on senior leadership team & 10 & 3 & 22 & 6 & 4 & 3 & 36 & 4 \\
$\quad$ of which not known whether on senior & & $*$ & & & & & & \\
$\quad$ leadership team & 1 & $*$ & 9 & 3 & 3 & 2 & 13 & 2 \\
Not stated & 5 & 2 & 4 & 1 & 4 & 3 & 13 & 2 \\
\hline Total schools & $\mathbf{3 2 1}$ & & $\mathbf{3 4 8}$ & & $\mathbf{1 3 5}$ & & $\mathbf{8 0 4}$ & \\
\hline
\end{tabular}

\footnotetext{
${ }^{7}$ The DfE was unable to provide these data for some schools, because they are too small and the values are suppressed.
} 
The following table shows the make-up of achieved interviews alongside the profile of all schools. Comparing the population and achieved figures within each phase reveals that the schools which responded were broadly representative of schools as a whole. The most notable exception to this was a slight over-representation of urban primary schools, accompanied by a corresponding under-representation of faith-status primary schools. The dataset was weighted to the profile of "all schools" to correct for this and other small differences between the profile of the interviewed schools and that of all schools.

Profile of interviewed schools compared with all schools

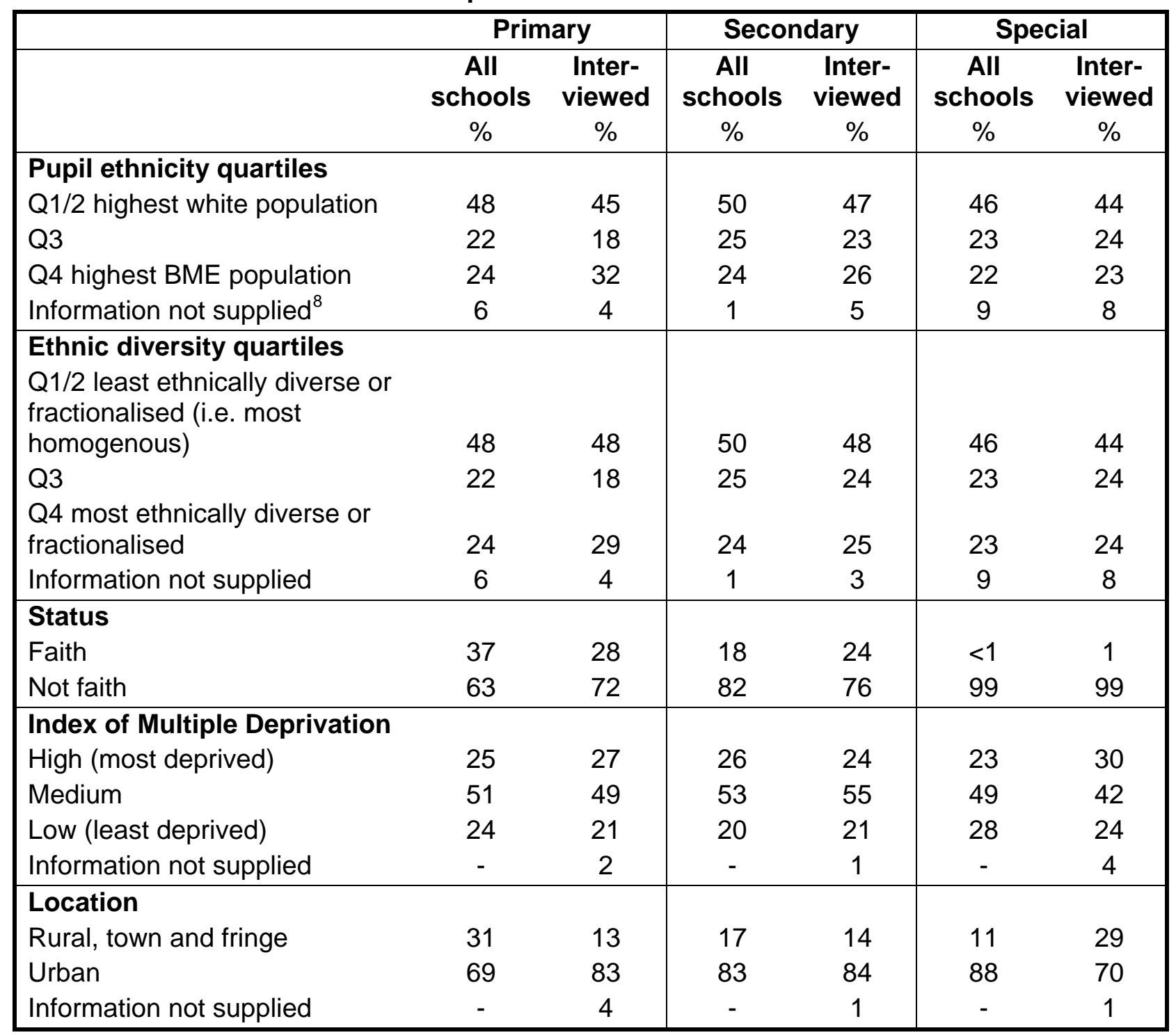

\footnotetext{
${ }^{8}$ The DfE was unable to provide these data for some schools, because they are too small and the values are suppressed.
} 


\section{Glossary of analysis variable terms}

It was important to examine whether contextual factors play a role in schools' approaches to implementing the duty to promote community cohesion, and to their engagement with the PREVENT strategy. For this reason, the findings have been analysed in terms of various factors related to the school and its local area. Ofsted guidance emphasises the need for schools to consider cohesion in terms of ethnic or cultural groups, socio-economic groups and faith and religious groups. The factors used in analysis were selected with these specific groups in mind and include:

- faith or non-faith status;

- $\quad$ indices of multiple deprivation. These measure how deprived a small local area is. Areas have been split into the most deprived quartile of areas in England, the least deprived and the $50 \%$ in between these two groups ("areas with medium levels of deprivation");

- $\quad$ settlement type. Survey findings have been compared for schools located in urban centres (with a further sub-division into London and non-London urban settlements) and those in "rural, town and fringe" settlements;

- the white/BME profile of the school. Schools have been classified based on the relative balance of white and BME pupils on the school roll. Schools have been split into quartiles and the quartiles of schools with the highest white populations ("highest white population quartiles Q1/2") have been compared with the quartile with the highest proportion of BME pupils ("highest BME population quartile Q4");

- degree of ethnic diversity of the school roll. Schools have been classified based on the degree of homogeneity of their pupils. A more ethnically diverse school contains a larger number of different ethnic groups. Schools have been split into quartiles and the most fractionalised quartile (i.e. the least ethnically homogenous) has been compared with the least fractionalised quartile (i.e. the most ethnically homogenous) ("most ethnically diverse" versus "least ethnically diverse"); and

- $\quad$ perceived community cohesion in the local area. Local authorities have been required to collect this information as part of the national indicator set. National Indicator 1 (the proportion of local residents who believe people from different backgrounds get on well in the local area) has been appended to each school's data. Comparisons have then been made between schools in local authorities with the highest levels of perceived cohesion, those with the lowest levels and schools that are in the $50 \%$ of local authorities that lie in between.

The factors listed above each capture a subtly different aspect of the broader environment in which schools operate. However, when interpreting findings it is important to note a high degree of overlap between several of the factors. For example, the most ethnically diverse schools and the most deprived areas are usually found in densely populated parts of the country. Similarly, schools with a large proportion of BME pupils are often, but not always, highly ethnically diverse as well. Where possible, this report offers suggestions for which one of several overlapping characteristics might offer an explanation for an emerging finding. 


\section{Ofsted data}

In addition to the variables listed above, the research findings were also analysed (where possible) by the Ofsted inspection rating for each school (this was available for 393 of the schools in the achieved sample, which is just under half of the total interviewed). The Ofsted ratings were used to provide an external benchmark for schools' own assessments of their activity related to the statutory duty. Broadly speaking the results of this analysis were as might be expected: namely that confidence, self-assessed knowledge and reported activity are higher among schools receiving outstanding or good ratings from Ofsted. The fact that Ofsted data was only available for around half of the schools interviewed means that comparisons based on the Ofsted ratings can only be viewed as indicative, rather than statistically robust. For this reason, they are not included in the body of the report.

\section{Interpretation of the data}

Caution should be exercised when comparing percentages derived from base sizes of 99 respondents or fewer, and particularly those derived from base sizes of 50 respondents or fewer. In the reporting which follows, percentages which derive from base sizes of 30-99 respondents should be regarded as indicative. Where bases fall below 30 respondents, we give actual numbers (Ns), not percentages, when appropriate.

Where percentages do not sum to $100 \%$, this may be due to computer rounding, the exclusion of "don't know"/"not stated"/"not applicable" categories, or multiple responses. An asterisk $(*)$ denotes a value of less than $0.5 \%$ but greater than zero.

References may be made in the text to "net" figures. These represent the balance of opinion on attitudinal questions, and provide a useful means for comparing the results for a number of variables. For example, in the case of a "net agree" figure, this represents the percentage of respondents agreeing with something, less the percentage not agreeing. Thus, if $40 \%$ of respondents agree with a statement and $25 \%$ disagree, the "net agree" figure is +15 percentage points.

\section{Statistical reliability}

Respondents represent only samples of total populations, so we cannot be certain that the figures obtained are exactly those we would have if everybody had taken part ("true values"). However, we can predict the variation between the sample results and the true values from a knowledge of the size of the samples on which results are based and the number of times a particular answer is given. The confidence with which we make this prediction is usually chosen to be $95 \%$ - that is, the chances are 95 in 100 that the true value will fall within a specified range (the "95\% confidence interval").

When results are compared between separate groups within a sample, the difference may be "real" or it may occur by chance (because not everyone in the population has been interviewed). In the text, differences are identified as being "statistically significant" (i.e. a real, not just apparent, difference). This is based on significance tests performed with a 95\% confidence interval. Where sample sizes are too small for reliable significance testing, results are reported as being indicative only. More information about statistical reliability and confidence intervals is attached as an appendix. 


\section{Acknowledgements}

It is clear that schools are increasingly working under great pressure from a number of different sources. They also receive numerous requests to participate in surveys such as this. Consequently, we wish to record our gratitude to the many schools that took part and we are indebted to all the staff who made this research possible.

Ipsos MORI would also like to thank Ghulam Abbas, Hannah Sheehan, Richard White and Sarah Butt at the Department for Education for all their assistance with this project. 


\section{Main findings: promoting community cohesion}

\section{Introduction}

Schools have had a duty to eliminate unlawful racial discrimination and to promote equality of opportunity and good relations between people of different groups since $2000^{9}$ and this was reinforced by the Education Act 2002 which states that "The curriculum for all maintained schools should promote the spiritual, moral, cultural, mental and physical development of pupils at the school and of society, and prepare pupils at the school for the opportunities, responsibilities and experiences of later life". However, the Education and Inspections Act 2006 placed a new duty on the governing bodies of maintained schools in England to promote community cohesion.

In line with the legislation, Ofsted inspection guidance explains that "all schools, whatever the mix of pupils they serve, are responsible for equipping those pupils to live and thrive alongside people from many different backgrounds"10. As a result, it is expected that every school should develop a bespoke approach to promoting cohesion which reflects their school and their community, considering the faith, ethnicity, culture and socio-economic status of their pupils.

The coming-together of young people from different backgrounds in a 'neutral' school setting provides a platform for encouraging cohesion and stimulating discussion that creates better understanding. In turn, it is hoped that work carried out within the school setting will then promote positive activities outside the school setting, in the wider community.

"Race and faith are often seen as the most frequent friction points between communities, and the most visible sources of tension. However, discrimination and prejudice can be experienced by other groups - including the disabled, Lesbian, Gay, Bisexual, and Transgender communities and different age and gender groups. Schools should therefore design their programmes to recognise where other strands of the equalities agenda - including gender, sexual orientation, disability and age - are interconnected with the aspiration to promote community cohesion, but should note that the main focus of the duty is cohesion across different cultures, ethnic, religious or non-religious and socio-economic groups."

\section{Guidance on the duty to promote community cohesion}

Department for Children, Schools and Families, July 2007

At the time this research project was commissioned (October 2009), there was little robust evidence about what schools are doing to promote community cohesion and how much they know and understand about community cohesion. The survey therefore provided an opportunity to provide reliable statistical evidence on:

\footnotetext{
${ }^{9}$ Race Relations Amendment Act 2000

${ }^{10}$ Ofsted, Inspecting maintained schools' duty to promote community cohesion: a guide for inspectors 2007, p4
} 
- Schools' knowledge and understanding of community cohesion at a general level;

- Depth of knowledge regarding different ethnic and cultural groups, different socioeconomic groups and different faiths and religions;

- Issues they have reviewed and felt the need to take action on in regard to these cohesion groups;

- How that action is structured - whether it is stand-alone enrichment activity or delivered through curriculum subjects - and how it intersects with school policies, such as the school's safeguarding policy, and improvement planning;

- Whether and how schools have changed since the introduction of the statutory duty;

- Who they partner with to promote community cohesion; and

- What training needs that they have in relation to community cohesion.

\title{
What "community cohesion" means for schools
}

\author{
Summary \\ Schools view "community cohesion" as cutting across several issues. \\ Primary, secondary and special schools all widely view "community cohesion" in terms of \\ citizenship, multiculturalism, faith and race/ethnicity: more than three quarters mention each \\ of these.
}

Special schools frequently also see it as encompassing disability: nine out of ten (90\%) do so.

Secondary schools also view cohesion in terms of socio-economic status (85\%), deprivation $(75 \%)$ and anti-social behaviour (76\%): over three quarters mention these.

Department guidance on the statutory duty emphasises the need for schools to view community cohesion as more wide-reaching than just the possible frictions over race and faith that may most readily spring to mind. While the main focus is likely to be cohesion across different cultural, ethnic, religious and non-religious or socio-economic groups, the guidance encourages schools to view cohesion as an issue that cuts across all aspects of the equalities agenda.

Perceptions in schools reflect both the broad-based view and the emphasis on three key areas that is encouraged by the guidance. For primary, secondary and special schools, the words most commonly associated with "community cohesion" are citizenship, multiculturalism, faith and race/ethnicity. As the table below shows (Table CC1), over three quarters associate these with the term "community cohesion."

There are some differences by school phase. In the table, words that are used more widely within a particular phase are shaded dark grey.

As might be expected, disability is more likely to be seen as a cohesion issue by special schools than by primary or secondary schools. Secondary schools are the most likely to view community cohesion as involving deprivation, anti-social behaviour or sexual identity. One of the key strands identified in the guidance, socio-economic status is the aspect of "community 
cohesion" most often mentioned by secondary schools. It is less likely to be linked by primary or special schools to cohesion (although it is still mentioned by more than seven in ten).

\begin{tabular}{|c|c|c|c|c|}
\hline $\begin{array}{l}\text { Thinking about your school and the local } \\
\text { area it serves, which of the following words } \\
\text { or phrases do you associate with the term } \\
\text { "community cohesion", if any? }\end{array}$ & $\begin{array}{c}\text { All } \\
\text { schools }\end{array}$ & $\begin{array}{l}\text { Primary } \\
\text { schools }\end{array}$ & $\begin{array}{l}\text { Secondary } \\
\text { schools }\end{array}$ & $\begin{array}{l}\text { Special } \\
\text { schools }\end{array}$ \\
\hline Base: All respondents & $\begin{array}{c}(804) \\
\%\end{array}$ & $\begin{array}{c}(321) \\
\%\end{array}$ & $\begin{array}{c}(348) \\
\%\end{array}$ & $\begin{array}{c}(135) \\
\%\end{array}$ \\
\hline Citizenship & 87 & 87 & 85 & 89 \\
\hline Multiculturalism & 85 & 85 & 84 & 84 \\
\hline Faith & 82 & 83 & 81 & 76 \\
\hline Race/ethnicity & 82 & 81 & 84 & 79 \\
\hline Disability & 74 & 74 & 73 & 90 \\
\hline Socio-economic status & 73 & 71 & 85 & 71 \\
\hline Gender & 68 & 68 & 70 & 72 \\
\hline Tradition & 64 & 66 & 60 & 51 \\
\hline Age & 64 & 63 & 66 & 59 \\
\hline Deprivation & 63 & 61 & 75 & 67 \\
\hline Anti-social behaviour & 62 & 59 & 76 & 59 \\
\hline Sexual identity & 46 & 43 & 60 & 49 \\
\hline Britishness & 41 & 41 & 43 & 28 \\
\hline Violent extremism & 31 & 30 & 39 & 27 \\
\hline Radicalisation & 27 & 26 & 34 & 21 \\
\hline
\end{tabular}

To some extent, primary or secondary school interpretations of "community cohesion" vary in line with the characteristics of the local area and of the school roll. By contrast, most special schools make similar interpretations whatever the nature of the local area or of the school roll. Looking at this is more detail:

- Primary schools: Primary schools in the most deprived areas are more likely than those in the least deprived areas to associate multiculturalism (92\%), deprivation (73\%), anti-social behaviour (71\%), Britishness (58\%), and violent extremism (38\%) with "community cohesion"11. Meanwhile, urban (including London) primary schools are more likely than average to make an association between these words - together with citizenship (88\%), race/ethnicity (85\%), faith (84\%), disability (76\%) and sexual identity (45\%) - and community cohesion.

- Secondary schools: London secondary schools are more likely than average to make an association between "community cohesion" and multiculturalism (96\%), tradition (79\%), violent extremism (55\%) and radicalisation (48\%) ${ }^{12}$. Perhaps surprisingly,

\footnotetext{
${ }^{11}$ Indicative finding: small base sizes for primary schools in high $(n=88)$ and low $(n=68)$ IMD areas

12 Indicative finding: small base size for London secondary schools $(n=48)$.
} 
schools in the most deprived areas are not any more likely to associate deprivation with community cohesion than are schools in the least deprived areas. Instead, settlement type appears to be a factor: urban secondary schools (including those in London) are more likely than average to associate deprivation with community cohesion (77\%). Schools in the most deprived areas more frequently associate radicalisation with community cohesion than those in the least deprived areas (45\% versus $27 \%)^{13}$. Views differ for schools with different ethnic mixes on their rolls: schools in the 'highest BME population' quartile Q4, and those with the most ethnically diverse school roll, are both more likely than average to identify multiculturalism, faith, violent extremism and radicalisation with "community cohesion"14.

- Special schools: Special schools in the most deprived areas (27\%) are three times more likely than those in the least deprived areas (9\%) to associate radicalisation with community cohesion.

\section{Knowledge and confidence about the statutory duty to promote community cohesion}

\section{Summary}

Almost all schools (95\%) claim at least a fair amount of knowledge about the statutory duty.

Secondary schools are more likely than primary or special schools to say they know a great deal: $54 \%$ of secondary say this, compared with $46 \%$ of primary and $44 \%$ of special schools.

Almost all schools say they are confident about their understanding of the duty, but secondary and special schools are the most confident: half of secondary (51\%) and special $(50 \%)$ say they are very confident.

Almost all primary, secondary and special schools say they know at least a fair amount about schools' duty to promote community cohesion. In each phase, there is a fairly even split between those that say they know a great deal and those that say they know a fair amount. On balance, though, secondary schools are the most likely to say they know a great deal: just over half $(54 \%)$ do so, compared with just under half of primary (46\%) and special (44\%) schools.

\footnotetext{
${ }^{13}$ Indicative finding: small base sizes for high $(n=83)$ and low $(n=72)$ IMD secondary schools.

${ }^{14}$ Indicative finding: small base sizes for pupil ethnicity Quartile $4(n=90)$ and fractionalisation Quartile $4(n=88)$ secondary schools.
} 


\section{Knowledge of policy:}

\section{duty to promote community cohesion}

Q1. Before today, how much, if anything, would you say you knew about each of the following education policies?

Schools' duty to promote community cohesion

- \% A great deal $\quad \%$ A fair amount $\quad \%$ Not very much $\quad \%$ Nothing at all

\begin{tabular}{r|c|c|} 
All schools & 47 & 48 \\
Primary school & 46 & 50 \\
Secondary schools & 54 & 41 \\
Special schools & 44 & 50 \\
\% Fair amount or more & \% Not very much or less \\
All schools & 96 & 3 \\
Primary school & 96 & 4 \\
Secondary schools & 95 & 4 \\
Special schools & 94 & 4 \\
\hline
\end{tabular}

Base: 804 schools in England (321 primary, 348 secondary, 135 special); 10 February-14 May 2010 for DfE

Within phases, the following differences in response emerge:

- Primary schools: Primary schools in areas of medium (49\%) and low (53\%) deprivation are more likely to say that they know a great deal about schools' duty to promote community cohesion than schools in highly deprived (34\%) areas ${ }^{15}$.

- A later section of the report examines the extent to which school understanding and activity have changed since the duty became statutory. Primary schools which say their understanding has improved since the introduction of the statutory duty cohesion are also more likely than average to say they know a fair amount or more about the duty. Similarly, those which say they are doing more to promote community cohesion since the introduction of the statutory duty are also more likely than average to say they know a fair amount or more about the duty.

- Secondary schools: London secondary schools $(77 \%)^{16}$, and those with the highest BME populations $(69 \%)^{17}$ and most ethnically diverse school rolls $(72 \%)^{18}$, are more likely than average to say that they know a great deal about schools' duty to promote community cohesion.

Almost all primary, secondary and special schools say they are at least fairly confident about their understanding of the duty, with a fairly even split between those that feel very confident and those that feel fairly confident. Among secondary and special schools, more feel very confident than feel fairly confident. For primary schools, the reverse is true.

\footnotetext{
${ }^{15}$ Indicative finding: small base sizes for high $(\mathrm{n}=88)$ and low $(\mathrm{n}=68)$ IMD primary schools.

${ }^{16}$ Indicative finding: small base size for London secondary schools $(n=48)$.

${ }^{17}$ Indicative finding: small base size for pupil ethnicity Quartile $4(n=90)$ secondary schools.

18 Indicative finding: small base size for fractionalisation Quartile $4(n=88)$ secondary schools.
} 


\section{Understanding of policy:}

\section{duty to promote community cohesion}

Q2. And how confident, if at all, would you say you feel about your understanding of each of the following education policies?

Schools' duty to promote community cohesion

- \% Very confident $\quad \%$ Fairly confident $\quad \%$ Not very confident $\quad \%$ Not at all confident

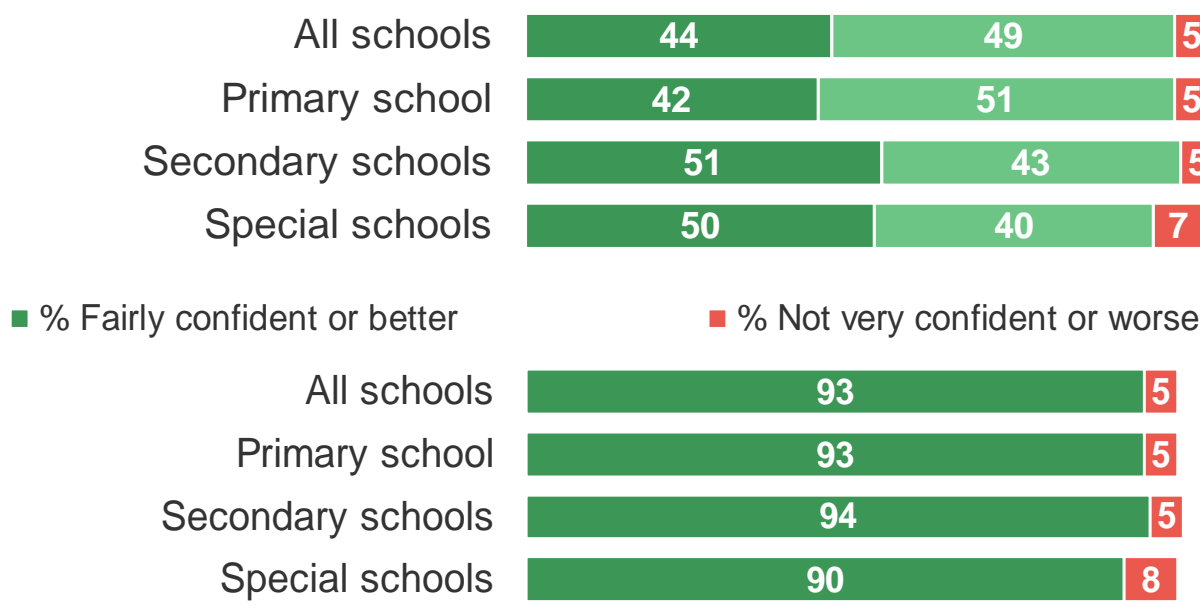

Base: 804 schools in England (321 primary, 348 secondary, 135 special); 10 February-14 May 2010 for DfE

When we look at findings within phases:

- $\quad$ Primary and secondary schools: Levels of confidence are broadly similar and do not vary in different types of local area or with different ethnic mixes on the school roll.

- Special schools: Special schools in the most deprived areas are markedly more likely than those in the least deprived areas to express confidence in their understanding of community cohesion policy $(97 \% \text { versus } 82 \%)^{19}$.

\section{Key drivers of knowledge and confidence}

Throughout the report comparisons are made between different sub-groups of schools. However, as discussed earlier, different factors can tend to overlap: for example, many schools with ethnically diverse school rolls are located in large urban areas.

In order to unpick this overlap, four key questions were examined using multiple regression analysis. This is a statistical technique which identifies the unique impact of different factors and identifies the most important factors or "key drivers".

This section uses this approach to examine:

- knowledge about community cohesion; and

- confidence about community cohesion.

Later in the report the same approach is used to look at:

\footnotetext{
${ }^{19}$ Indicative finding: small base sizes for high $(n=40)$ and low $(n=33)$ IMD special schools.
} 
- $\quad$ understanding since the duty became statutory; and

- $\quad$ activity since the duty became statutory.

Findings are included in the main report for each of these questions for primary, secondary and special schools. More detail about the models and the method used to produce them is attached as an appendix. It is also important to note that multiple regression analysis highlights correlations, but this does not necessarily mean that there is a causal link from the factors in the model to the question being analysed.

Before discussing the findings in more detail, it is worth noting several broad patterns that apply across the modelling of all four questions for primary, secondary and special schools:

- It has not been possible to construct models where a small number of factors explain a large amount of the variation in outcomes ${ }^{20}$. This suggests that many factors are at work: for example, variations in confidence about community cohesion cannot be largely explained by differences in one or two local factors, attitudes or behaviours.

- $\quad$ Some of the key drivers for a particular question are similar for primary, secondary and special schools.

- $\quad$ Some of the same factors are key drivers for primary schools across several of the questions (and the same is true for both secondary and special schools), in particular, senior leadership team knowledge of socio-economic groups in the school and local area.

- $\quad$ The models are generally stronger and contain fewer drivers in special schools than in primary or secondary schools.

- School and local area contextual factors (such as perceptions of community cohesion in the local area, ethnic fractionalisation and profiles in the school, settlement type/ location, levels of deprivation and attainment measured through Contextual Value Added or CVA scores ${ }^{21}$ ) have been included in the modelling, but are weaker drivers than might perhaps be expected.

\section{Drivers of knowledge and confidence - primary schools}

For primary schools' knowledge of the duty, many factors appear to be at work: it is not possible to construct a model where a small number of factors explain most of the variation. Senior leadership team knowledge about socio-economic groups emerges as the strongest individual driver (it is twice as strong as any of the other drivers), but still only accounts for $5 \%$ of the variation in knowledge. Contextual factors appear to be relatively weak drivers.

Confidence about the duty in primary schools can be broken down into a slightly smaller number of stronger factors. Senior leadership team knowledge of socio-economic groups is again the biggest driver, but the analysis also reveals the importance of the school having a plan or policy for promoting community cohesion. Similarly, primary schools which review effectiveness through pupil surveys and consultations tend to be more confident about the duty.

\footnotetext{
${ }^{20}$ In most cases the models have an $\mathrm{R}^{2}$ of approximately $36 \%$ or less, meaning that they explain around only a third or less of the variation in the dependent variable.

${ }^{21}$ CVA scores measure attainment of pupils in comparison to pupils with similar prior attainment and are discussed in more detail at http://www.standards.dfes.gov.uk/performance/1316367/CVAinPAT2005/
} 


\section{Drivers of knowledge and confidence of duty - secondary schools}

The pattern in drivers of knowledge and confidence in secondary schools is in many respects similar to that seen in primary schools. In particular, it is not possible to construct a model in which a small number of factors explain most of the variations in knowledge or confidence. Again, senior leadership team knowledge appears important for both knowledge and confidence. As was the case in primary schools the existence of a school plan for promoting community cohesion is a key driver of confidence in secondary schools. Finally, contextual factors are not significant drivers. Although CVA score appears, it is fairly far down the list of drivers. Faith status, levels of deprivation and settlement type do not appear as key drivers.

\section{Drivers of knowledge and confidence of duty - special schools}

The models for special schools are noticeably different from those just explored for primary and secondary schools. For primary and secondary schools, key drivers are senior leadership team knowledge and whether the school has a plan or policy for promoting cohesion. By contrast, in special schools senior leadership team knowledge is not a key driver, and a strategic approach seems more important than was the case for primary or secondary schools. Plans for promoting cohesion, and integration into the school improvement plan, are both key drivers of knowledge, while integration into the school improvement plan is a key driver of confidence.

\section{Changes since the introduction of the statutory duty}

\section{Summary}

Almost all primary (89\%), secondary (93\%) and special (89\%) schools say their understanding of community cohesion is better since the introduction of the duty to promote community cohesion. Well over half say it is a lot better.

Almost all say they are doing more (87\% of primary, $91 \%$ of secondary and $82 \%$ of special schools), but around half of these are doing a little more; it seems that understanding has increased more than activity.

The vast majority of primary, secondary and special schools say that their understanding of community cohesion is better, and that they are doing more to promote community cohesion, since the introduction of the statutory duty. As Table CC2 shows, understanding has perhaps increased more than activity. 


\begin{tabular}{|c|c|c|c|c|}
\hline $\begin{array}{l}\text { Since the introduction of the statutory duty, which } \\
\text { of the following best describes your school's } \\
\text { understanding of community cohesion in your } \\
\text { school and the local area it serves? }\end{array}$ & $\begin{array}{c}\text { All } \\
\text { schools }\end{array}$ & $\begin{array}{l}\text { Primary } \\
\text { schools }\end{array}$ & $\begin{array}{l}\text { Secondary } \\
\text { schools }\end{array}$ & $\begin{array}{l}\text { Special } \\
\text { schools }\end{array}$ \\
\hline Base: All respondents & $\begin{array}{c}(804) \\
\%\end{array}$ & $\begin{array}{c}(321) \\
\%\end{array}$ & $\begin{array}{c}(348) \\
\%\end{array}$ & $\begin{array}{c}(135) \\
\%\end{array}$ \\
\hline Our understanding is a lot better & 57 & 56 & 64 & 54 \\
\hline Our understanding is a little better & 32 & 33 & 29 & 35 \\
\hline $\begin{array}{l}\text { There has been no change in our } \\
\text { understanding }\end{array}$ & 8 & 9 & 5 & 9 \\
\hline Our understanding is a little worse & * & - & * & - \\
\hline Our understanding is a lot worse & * & - & - & 1 \\
\hline Understanding is better (a lot + a little) & 89 & 89 & 93 & 89 \\
\hline $\begin{array}{l}\text { Since the introduction of the statutory duty, which } \\
\text { of the following best describes how much your } \\
\text { school is doing to promote community cohesion? }\end{array}$ & $\begin{array}{c}\text { All } \\
\text { schools }\end{array}$ & $\begin{array}{l}\text { Primary } \\
\text { schools }\end{array}$ & $\begin{array}{l}\text { Secondary } \\
\text { schools }\end{array}$ & $\begin{array}{l}\text { Special } \\
\text { schools }\end{array}$ \\
\hline Base: All respondents & $\begin{array}{c}(804) \\
\%\end{array}$ & $\begin{array}{c}(321) \\
\%\end{array}$ & $\begin{array}{c}(348) \\
\%\end{array}$ & $\begin{array}{c}(135) \\
\%\end{array}$ \\
\hline We are doing a lot more & 42 & 41 & 45 & 43 \\
\hline We are doing a little more & 46 & 46 & 46 & 39 \\
\hline $\begin{array}{l}\text { There has been no change in how much we } \\
\text { are doing }\end{array}$ & 11 & 11 & 7 & 17 \\
\hline We are doing a little less & - & - & - & - \\
\hline We are doing a lot less & - & - & - & - \\
\hline Doing more (a lot + a little) & 88 & 87 & 91 & 82 \\
\hline
\end{tabular}

Focusing just on primary schools, nine in ten say their understanding is better (a lot + a little) and the same proportion say they are doing more (a lot + a little). However, significantly more say that their understanding is a lot better than say that they are doing a lot more. The same pattern can be seen for secondary and special schools. Indeed, the contrast is particularly noticeable among secondary schools, where two thirds (64\%) say their understanding is a lot better, but less than half (45\%) say they are doing a lot more.

Breaking down these findings by phase:

- Primary schools: Primary schools in the least deprived areas $(98 \%)^{22}$ are more likely than average to be doing more to promote community cohesion since the introduction of the duty. Whatever the school's ethnic mix, understanding and activity appear to have increased; there are no statistically significant differences between schools with different proportions of white and BME pupils or different degrees of ethnic diversity.

There is no notable difference between faith primary schools and their non-faith

\footnotetext{
${ }^{22}$ Indicative finding: small base size for low IMD primary schools $(n=68)$.
} 
counterparts in terms of whether their understanding is better or they are doing more to promote cohesion since the duty became statutory.

- Secondary schools: Secondary schools from different types of areas and with different ethnic mixes report similar levels of improved understanding. By contrast, the amount by which they are doing more varies. In particular urban (including London) secondary schools (48\%), and London secondary schools in particular (55\%), are more likely than rural, town and fringe secondary schools (29\%) to say that they are doing a lot more to promote community cohesion since the introduction of the statutory duty ${ }^{23}$.

Faith and non-faith secondary schools report similar amounts of change in understanding and the same is true for changes in activity.

- $\quad$ Special schools: Special schools in the most deprived areas (93\%) are more likely than their counterparts in the least deprived areas (70\%) to say they are doing more to promote community cohesion since the statutory duty was introduced ${ }^{24}$.

This sense that the increase in understanding has been bigger than the increase in activity comes through when schools are asked to explain the reasons behind their answers to these two questions:

We were already doing most of the things but we are more structured and overt now.

Primary school, urban with a high BME pupil population

We analyse data more closely.

Primary school, urban with a high BME pupil population

Through the work of Extended Schools, the whole school has gained a better understanding of community cohesion. The school was doing a lot of work originally, but the duty has helped focus the school to fill gaps and to celebrate the areas it was successful at.

Secondary school, urban with an above average BME pupil population

We have a better understanding of what "community cohesion" is. It has always been a strength but the context needed clarifying.

Secondary school, urban with a high BME pupil population

Opportunities are planned to discuss [community cohesion] and action plan ... in a way we had not done in the past.

Primary school, urban with a high BME pupil population

\footnotetext{
${ }^{23}$ Indicative finding: small base sizes for London $(n=48)$ and rural, town and fringe $(n=53)$ secondary schools.

${ }^{24}$ Indicative finding: small base sizes for high $(n=40)$ and low $(n=33)$ IMD special schools.
} 
For some, the change has involved them developing a clearer sense of the community, while others feel that they have been engaging with the community for the first time:

Has prompted us to define our 'community" with greater clarity.

Special school, urban, with an above average BME population

We have actually started to engage with our community - something we weren't doing a year and a half ago.

Special school, rural, with an above average or high white pupil population

We had been complacent as a near white monoculture in an impoverished area. Our view is very different now and we understand our duty has special relevance in this area.

Secondary school, urban with an above average or high white pupil population

\section{Key drivers of changes since the duty}

This section provides a summary of the key driver analysis of changes since the duty became statutory. More detail about the statistical models used is attached as an appendix.

\section{Primary schools}

For primary schools, it is difficult to single out individual factors to explain changes in understanding and activity since the duty became statutory. The key driver analysis suggests that many factors are at work.

\section{Secondary schools}

The same is true for secondary schools: it is not possible to single out individual key influencers which explain much of the variation in changes since the duty became statutory. The previous section showed how most schools had experienced a change since the duty became statutory and this was not confined to particular groups of schools. The findings of the key driver analysis confirm this.

\section{Special schools}

Changes in knowledge since the duty became statutory vary most with knowledge of bullying rates for different faith or religious groups. Special schools which are faith schools are less likely to feel their understanding has improved. The same is true of special schools which use parent/carer surveys to obtain their knowledge of faith and religious groups.

The special schools most likely to be doing more since the duty became statutory are those which use community consultations or surveys, those which integrate promotion of cohesion into the school improvement plan and those where there is good senior leadership knowledge of faith and religion in the school and local area. Relatively speaking these three factors are stronger drivers than those identified for primary or secondary schools: between them, these three factors are associated with around a fifth of the change in activity since the duty became statutory. 


\section{Knowledge of schools' community cohesion context}

Department guidance on the statutory duty ${ }^{25}$ suggests that the main focus is likely to be on promoting cohesion across communities comprising a variety of different:

- cultures and ethnic groups;

- religious and non-religious groups; and

- socio-economic groups.

In order to develop an appropriate local approach, schools are seen as needing to know their local context. Ofsted guidance for inspectors ${ }^{26}$ presents the requirements in the following terms:

\begin{tabular}{|l|l|}
\hline Key question to ask the school & Minimum expectations \\
\hline $\begin{array}{l}\text { What do you know about the context of your } \\
\text { school in respect of community cohesion? }\end{array}$ & $\begin{array}{l}\text { Schools must show that they have } \\
\text { considered the context in all three strands of } \\
\text { faith, ethnicity and culture, and socio- } \\
\text { economic factors. }\end{array}$ \\
& $\begin{array}{l}\text { As a minimum, they must have contrasted } \\
\text { the school community with local and } \\
\text { national communities. }\end{array}$ \\
\hline
\end{tabular}

This section examines schools' views of their own knowledge of these three strands within their school and the area it serves. It also compares the extent to which knowledge is seen to vary between the senior leadership teams, teaching staff, support staff and school governors.

\footnotetext{
${ }^{25}$ Guidance on the duty to promote community cohesion http://www.teachernet.gov.uk/ doc/11635/Guidance\%20on\%20the\%20duty\%20to\%20promote\%20community\%20cohesion\%2 $\frac{0 \text { pdf.pdf }}{26}$

${ }^{26}$ Inspecting maintained schools' duty to promote community cohesion: guidance for inspectors

http://www.ofsted.gov.uk/Media/Ofsted/Forms-and-guidance2/Education-schools/s5/Community-Cohesion-Guidance-oninspecting.doc
} 


\title{
Staff knowledge
}

\begin{abstract}
Summary
Senior leadership teams are seen as having the most knowledge about their community cohesion context, followed by teaching staff, support staff and finally governors. In secondary schools, there is a particularly noticeable gap in perceived knowledge between the senior leadership team and other staff members and governors. For example, when it comes to knowledge about ethnic origin and culture in secondary schools, $64 \%$ say their senior leadership team knows a great deal, compared with $34 \%$ for teaching staff, $28 \%$ for support staff and $31 \%$ for governors.
\end{abstract}

Most schools think that their staff and/or governors know at least a fair amount about the different ethnic origins and cultures, socio-economic groups, and faiths and religions in their school and the area it serves.

In primary schools, knowledge of all three strands is seen as broadly similar. The same is true in special schools. In secondary schools, knowledge is most well-developed about socio-economic groups and ethnic origins and cultures and least developed when it comes to faiths and religions. For example, among secondary senior leadership teams, $70 \%$ are thought to know a great deal about socio-economic groups, $64 \%$ about ethnic origins and cultures, but only $51 \%$ about faiths and religions.

Perceived knowledge of faiths and religions is greater in faith schools than in their non-faith counterparts. This is the case for both primary and secondary schools.

Amongst secondary schools, perceived knowledge of ethnic origins and cultures appears greatest in both the most ethnically diverse schools (where presumably it is seen as a particularly pressing issue) and in the least ethnically diverse schools (perhaps reflecting a view that in a homogenous school there is little complexity to understand). Schools that are neither very diverse nor very homogenous tend to claim the least knowledge.

Schools use a variety of information sources to understand the profile of their school and the local community. At a national level school roll data, local authority guidance/training, guidance from DfE/Teachernet and consultations or surveys with parents or pupils tend to be the most widely used.

Differences in use of information sources are linked more to school phase than to the particular cohesion group about which information is being sought.

\section{Primary schools}

Senior leadership teams (SLTs) in around three fifths of primary schools are seen as knowing a great deal about each of the three strands (see Table CC3). Teaching staff are the next most likely to be seen as knowing a great deal. Support staff and governors are least likely to be seen as knowing a great deal.

More primary schools think their senior leadership teams know a great deal than think they know a fair amount. For teaching staff, support staff and governors the reverse is true: the perception in most primary schools is that these groups know a fair amount. One exception to this is teaching staff knowledge of faith and religions: in just over half of primary schools, teachers are thought to know a great deal about this. Support staff knowledge of different socio-economic groups is lower than that recorded for other types of staff. 
Across all staff types, perceived knowledge of any one strand is not consistently higher than that of the other two strands.

\begin{tabular}{|c|c|c|c|c|}
\hline $\begin{array}{l}\text { On the whole, how much, if anything, would } \\
\text { you say your school's <staff group }>\text { know } \\
\text { about the different }<\text { strand }>\text { in your school } \\
\text { and the local area it serves? }\end{array}$ & $\begin{array}{c}\text { A great } \\
\text { deal }\end{array}$ & $\begin{array}{c}\text { A fair } \\
\text { amount }\end{array}$ & $\begin{array}{l}\text { Not very } \\
\text { much }\end{array}$ & $\begin{array}{c}\text { Nothing at } \\
\text { all }\end{array}$ \\
\hline Base: All primary respondents (321) & $\%$ & $\%$ & $\%$ & $\%$ \\
\hline \multicolumn{5}{|l|}{ Ethnic origins and cultures } \\
\hline Senior leadership team & 58 & 37 & 2 & - \\
\hline Teaching staff & 44 & 51 & 3 & - \\
\hline Support staff & 35 & 54 & 8 & * \\
\hline Governors & 36 & 52 & 9 & - \\
\hline \multicolumn{5}{|l|}{ Socio-economic groups } \\
\hline Senior leadership team & 62 & 35 & 1 & - \\
\hline Teaching staff & 43 & 51 & 3 & - \\
\hline Support staff & 27 & 56 & 13 & - \\
\hline Governors & 38 & 52 & 7 & - \\
\hline \multicolumn{5}{|l|}{ Faiths and religions } \\
\hline Senior leadership team & 58 & 37 & 2 & - \\
\hline Teaching staff & 52 & 41 & 5 & - \\
\hline Support staff & 32 & 54 & 10 & - \\
\hline Governors & 34 & 50 & 10 & * \\
\hline
\end{tabular}

Some variations in response by different types of primary school emerge:

- Ethnic origins and cultures: Knowledge varies most notably by settlement type, with teaching and support staff knowledge apparently better developed in primary schools in rural, town and fringe locations than in urban centres. Respondents in rural, town and fringe schools are more likely than average to say that teaching staff know a great deal about the different ethnic origins and cultures in their school and the local area it serves $(60 \%)^{27,28}$. Meanwhile, those working in urban (including London) schools are more likely than average to say their colleagues know a fair amount about this (57\%). Exactly the same pattern of response also emerges for support staff.

Perceived knowledge does not vary notably with primary schools' ethnic mix, faith status or local deprivation.

- Socio-economic groups: There is less variation in perceived knowledge than for the other two strands, and where there are differences they tend to be smaller. In particular, there is little variation in knowledge between schools in more deprived and less deprived local areas. Senior leadership teams in urban (excluding London) primary

\footnotetext{
${ }^{27}$ Indicative finding: small base size for rural, town and fringe $(n=53)$ primary schools.

${ }^{28}$ This is true, too, of primary schools in the 'highest white population' Quartiles 1/2 (49\%).
} 
schools are more frequently felt to know a fair amount or more about the different socio-economic groups in their school and the local area it serves than their counterparts in London primary schools (98\% versus $91 \%)^{29,30}$. Likewise, respondents in the 'highest white population' quartiles Q1/2 are more likely than those in the 'highest BME population' quartile Q4 to say the senior leadership team knows a fair amount or more about this (99\% versus 93\%). Perceived knowledge does not vary notably with schools' faith status.

- $\quad$ Faiths and religions: The biggest contrast in primary schools' perceived knowledge of faith and religious groups is between faith and non-faith schools. Senior leadership teams, teaching staff, support staff and governors in faith schools are all more likely than their counterparts in non-faith schools to be seen as knowing a great deal. Seven in ten faith primary senior leadership teams (69\%) are seen as knowing a great deal, compared with $51 \%$ of those in non-faith primary schools. There are similar patterns in the proportions that assess their school knowledge as a great deal for teaching staff ( $64 \%$ in faith versus $44 \%$ in non faith), support staff (42\% versus $27 \%$ ) and governors $(44 \% \text { versus } 29 \%)^{31}$.

Variations in perceived knowledge are much less pronounced for schools in different settlement types, more and less deprived areas, or with different ethnic mixes on the school roll. An exception is that senior leadership teams working in the most ethnically diverse primary schools are also more likely than those in the least ethnically diverse primary schools to be thought to know a great deal about this issue (66\% versus $52 \%)^{32,33}$.

\section{Secondary schools}

Perceptions in secondary schools follow the same broad pattern as in primary schools (see Table CC4). More think that their senior leadership teams know a great deal about the three strands than think they know a fair amount. For teaching staff, support staff and governors, the reverse is true: the perception in most secondary schools is that these groups know a fair amount.

However, in some respects the picture is slightly different for secondary schools where perceived knowledge is a little lower than was the case for primary schools. This comes out in the way that the proportions of schools where teaching staff, support staff and governors know only a fair amount are slightly higher in secondary than in primary. Or, viewing it from a slightly different perspective, for all three strands, the difference in perceived knowledge between the senior leadership team and the other staff/governors is bigger in secondary than in primary schools.

For all types of staff and for governors, perceived knowledge is lowest when it comes to faiths and religions.

\footnotetext{
${ }^{29}$ Indicative finding: small base size for London $(\mathrm{n}=39)$ primary schools.

30 The same pattern of response can be see, too, in regard to teaching staff (95\% versus $83 \%$ ).

${ }^{31}$ Indicative finding: small base size for faith status $(n=90)$ primary schools.

32 Indicative finding: small base size for pupil fractionalisation Quartile $4(n=93)$ primary schools.

${ }^{33}$ As are their colleagues on the teaching staff (59\% versus $45 \%$ ) and the support staff (43\% versus $29 \%$ ). [Indicative finding: small base size for pupil fractionalisation Quartile $4(n=93)$ primary schools.]
} 
Table CC4: Secondary schools' knowledge of the community cohesion context

On the whole, how much, if anything, would you say your school's <staff group > know about the different <strand $>$ in your school and the local area it serves?

Base: All secondary respondents (348)

Ethnic origins and cultures

Senior leadership team

Teaching staff

Support staff

Governors

Socio-economic groups

Senior leadership team

Teaching staff

Support staff

Governors

Faiths and religions

Senior leadership team

Teaching staff

Support staff

Governors

\begin{tabular}{|c|c|c|c}
$\begin{array}{c}\text { A great } \\
\text { deal }\end{array}$ & $\begin{array}{c}\text { A fair } \\
\text { amount }\end{array}$ & $\begin{array}{c}\text { Not very } \\
\text { much }\end{array}$ & $\begin{array}{c}\text { Nothing at } \\
\text { all }\end{array}$ \\
$\%$ & $\%$ & $\%$ & $\%$ \\
64 & 32 & 1 & $*$ \\
34 & 58 & 6 & $*$ \\
28 & 58 & 12 & $*$ \\
31 & 58 & 8 & 1 \\
\hline 70 & 27 & 2 & - \\
32 & 57 & 9 & - \\
26 & 58 & 14 & $*$ \\
35 & 55 & 8 & - \\
\hline 51 & 41 & 7 & $*$ \\
26 & 56 & 16 & 1 \\
21 & 51 & 24 & 1 \\
26 & 50 & 21 & 1 \\
\hline & & &
\end{tabular}

Looking across different types of secondary school:

- Ethnic origins and cultures: Perceived knowledge of different ethnic origins and cultures varies in line with the extent to which the school's roll is ethnically diverse.

Across all types of staff, and governors, perceived knowledge is generally highest in very ethnically diverse schools and in the most ethnically homogenous $50 \%$ of schools. This is illustrated in the following chart, which also shows how perceived knowledge tends to be greatest in both the most homogenous and the most diverse schools, and tends to be lowest where extremes of homogeneity or diversity are not seen (i.e. in the second most fractionalised quartile). 


\section{Knowledge of ethnic origins and cultures (secondary schools)}

Q4. On the whole, how much, if anything, would you say your school's $<$ staff group> know about the different ethnic origins and cultures in your school and the local area it serves?

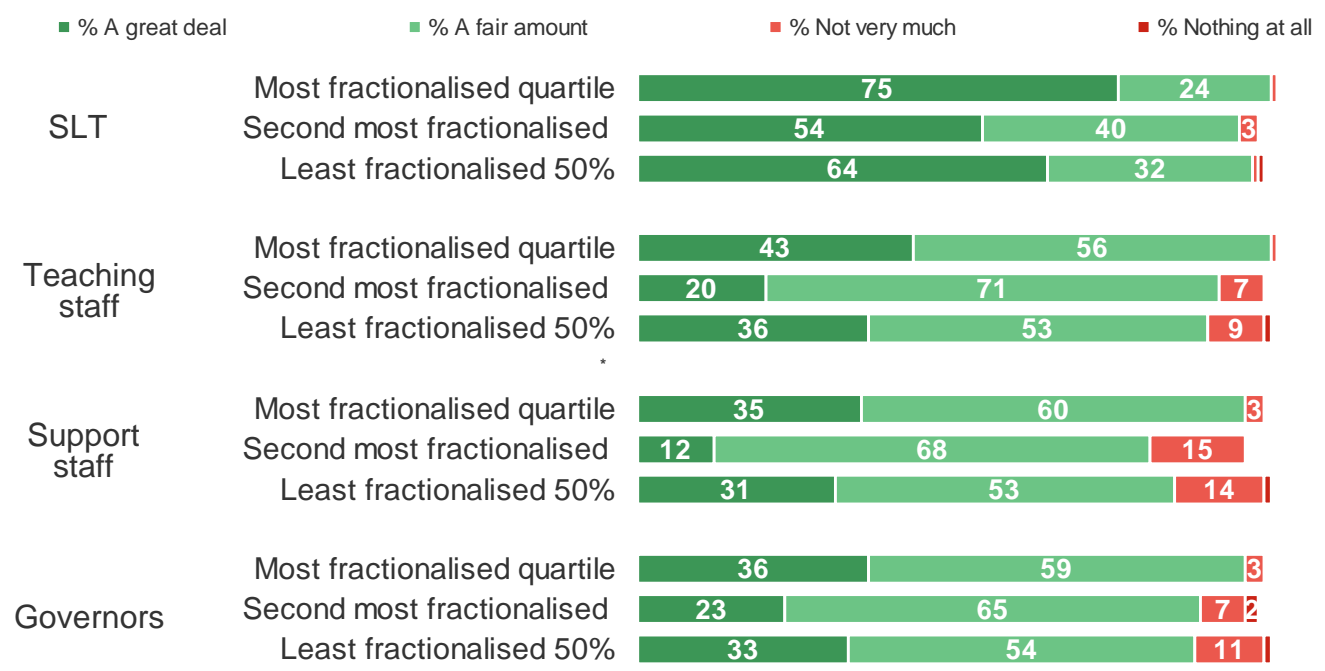

Base: 348 secondary schools in England; 10 February-14 May 2010 for DfE

A possible explanation could be that very ethnically diverse schools see knowledge of ethnic origins as a priority (as we note later in the report, the most diverse schools are considerably more likely to have found the need to take action to address academic underperformance by certain ethnic groups). For the least diverse schools (i.e. the most homogenous) there is perhaps less for the school to understand and it is more likely they will make the judgement that their staff know a great deal.

Perceived knowledge also varies in line with the proportion of white and BME pupils on the roll and the settlement type. However, these variations perhaps reflect the extent to which the most ethnically diverse schools usually (though not always) tend to have the highest proportions of BME pupils and are located in urban areas.

For example, in secondary schools with the highest proportions of BME pupils, three quarters (75\%) of senior leadership teams are seen as knowing a great deal about the ethnic origins and cultures in their schools and the local area. Similarly, in schools with the highest proportions of white pupils, two thirds (66\%) of senior leadership teams are thought to know a great deal. By contrast, only half (51\%) of senior leadership teams in the third quartile say they know a great deal about the different ethnic origins and cultures in their schools and the local areas they serve.

Other variations also perhaps reflect the different degrees of school roll ethnic diversity in different areas. For example, teaching staff in London secondary schools are more likely than average to reportedly know a great deal about the different ethnic origins and cultures in their schools and the local areas they serve (49\%), as are governors in urban (including London) schools (31\%). There are no notable differences in perceived knowledge between faith and non-faith secondary schools.

- Socio-economic groups: Perceived knowledge differs most between teaching staff in schools with different local area characteristics. In particular, secondary schools in the 
most deprived areas are more likely to say their teaching staff know a great deal (46\%) than their counterparts in areas with low or medium levels of deprivation (25\% and $28 \%$ respectively) ${ }^{34}$. There is a smaller contrast between perceived teaching staff knowledge in urban and rural, town and fringe areas, but the smaller size of the contrasts suggests this is more a reflection of the local relative level of deprivation than of something related to settlement type per se. Otherwise, perceived knowledge differs little between sub-groups of secondary schools.

- $\quad$ Faiths and religions: As noted earlier, perceived secondary school knowledge of faiths and religions is considerably lower than for socio-economic groups or ethnic origins and cultures. As well as being lower, it is also rather more variable, with the most notable variations by faith status (as for this strand in primary schools) and ethnic mix on the school roll.

Specifically, senior leadership teams in faith-status secondary schools are more likely to reportedly know a great deal (63\%) than senior leadership teams in non-faith schools $(48 \%)^{35}$. Among the quartile of schools with the biggest proportion of BME pupils, $37 \%$ say their teaching staff know a great deal about faiths and religions in the school and local area. For the two quartiles with the largest proportion of white pupils, only $23 \%$ say this. This is also the only one of the three strands where a sub-group of secondary schools says that its teachers know not very much: among the quartile with the second biggest proportion of BME pupils, $26 \%$ of schools make this assessment of their teaching staff's knowledge.

\section{Special schools}

Perceptions in special schools follow the same broad pattern as in primary and secondary schools (see Table CC5). More think that their senior leadership teams know a great deal about the three strands than think they know a fair amount; for teaching staff, support staff and governors the reverse is true: the perception in most special schools is that these groups know a fair amount.

\footnotetext{
${ }^{34}$ Indicative finding: small base sizes for high $(n=83)$ and low $(n=72)$ IMD secondary schools

${ }^{35}$ This pattern of response also emerges for teaching staff in faith status secondary schools where $40 \%$ are said to know a great deal compared with $26 \%$ in non-faith schools, for support staff (34\% versus $18 \%$ ), and for governors (43\% versus $21 \%$ ). [Indicative finding: small base size for faith status $(n=82)$ secondary schools.]
} 
Table CC5: Special schools' knowledge of the community cohesion context

On the whole, how much, if anything, would you say your school's <staff group > know about the different <strand $>$ in your school and the local area it serves?

Base: All special respondents (348)

Ethnic origins and cultures

Senior leadership team

Teaching staff

Support staff

Governors

Socio-economic groups

Senior leadership team

Teaching staff

Support staff

Governors

Faiths and religions

Senior leadership team

Teaching staff

Support staff

Governors

\begin{tabular}{c|c|c|c}
$\begin{array}{c}\text { A great } \\
\text { deal }\end{array}$ & $\begin{array}{c}\text { A fair } \\
\text { amount }\end{array}$ & $\begin{array}{c}\text { Not very } \\
\text { much }\end{array}$ & $\begin{array}{c}\text { Nothing at } \\
\text { all }\end{array}$ \\
$\%$ & $\%$ & $\%$ & $\%$ \\
65 & 33 & 1 & - \\
45 & 54 & 1 & - \\
39 & 53 & 7 & - \\
32 & 50 & 15 & - \\
\hline 67 & 30 & 3 & - \\
44 & 50 & 6 & - \\
36 & 53 & 10 & - \\
33 & 52 & 12 & - \\
\hline 52 & 43 & 3 & - \\
42 & 51 & 4 & - \\
28 & 60 & 9 & - \\
26 & 51 & 17 & - \\
\hline
\end{tabular}

\section{Sources of information}

This section examines how schools have obtained information about the ethnic and cultural, religious and faith, and socio-economic groups in their community, both within the school and the local area it serves.

Schools use a variety of information sources to understand the profile of their school and the local community. At a national level, for each cohesion group, school roll data, local authority guidance/training, guidance from DfE/Teachernet and consultations or surveys with parents or pupils tend to be the most widely used.

Table CC6 shows a mixture of similarities and differences between phases. An information source that is used more widely within a particular phase is shaded dark grey. An information source that is used significantly less widely within a particular phase is shaded light grey.

Looking at the top of the table, it is clear that contextual/demographic school roll data is the most widely used source for ethnic/cultural or socio-economic information. Almost all primary and secondary schools, and three quarters of special schools, have used school roll data for this purpose. In primary and secondary schools, it is the most widely used source of information about faiths/religions, and in special schools it is one of the two most widely used sources (along with parent and carer surveys or consultations). 
However, the table also demonstrates some clear differences by phase in the types of information used. For example, secondary schools tend to be more likely than primary and special schools to use information on each cohesion group derived from consultation with/ surveys of pupils. They are also more frequently utilising consultation with/surveys of other members of the local community as a source of information than other schools. Meanwhile, special schools are much less likely than primary and secondary schools to be using contextual/demographic data such as PLASC.

From even a quick glance at the columns on the table, it is noticeable that the pattern of shading for a particular phase is generally similar regardless of the cohesion group. This suggests that differences in use of information sources are linked more to school phases than to the particular cohesion group about which information is being sought.

\section{Table Cc6: Sources of information on cohesion groups}

Which of the following sources of information, if any, have you used to learn more or understand better about different ... in your school and the local area it serves?

the local area it serves?

Base: All respondents

Contextual/demographic data for pupils on the school roll (e.g. RAISEonline, PLASC)

\begin{tabular}{l}
\hline Local authority \\
guidance/training \\
\hline Consultation with/surveys of \\
parents and carers
\end{tabular}

Consultation with/surveys of pupils

Guidance from the DfE/on Teachernet

Guidance from/training by local community groups or local charities or voluntary organisations

Consultation with/surveys of other members of the local community

Guidance from/training by national charities or voluntary organisations

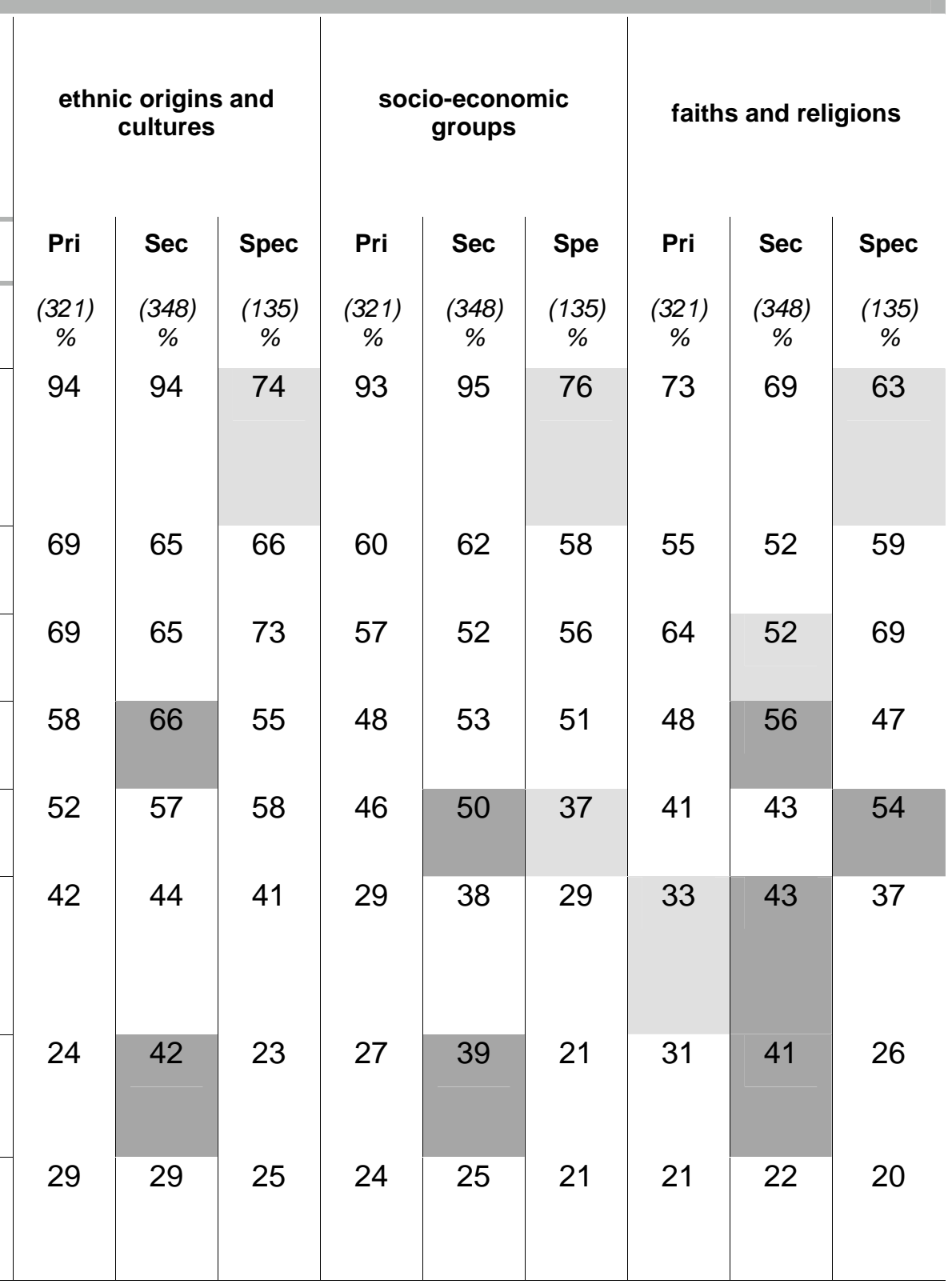


Within phases, some key differences emerge in the likelihood that these sources of information have been used by schools to learn more or understand better about the different ethnic origins and cultures in the communities they serve.

\section{Ethnic origins and cultures}

- $\quad$ Primary schools: Non-faith primary schools are more likely than faith-status primary schools to be using guidance from the DfE/on Teachernet and consultation with/surveys of other members of the local community as sources of information ${ }^{36}$. Urban (including London) primary schools tend to be more likely than average to use most of these potential sources of information, with London primary schools particularly likely to say they are using consultation with/surveys of pupils $(81 \%)^{37,38}$.

- Secondary schools: As with primary schools, urban (including London) secondary schools tend to be more likely than average to use most of these potential sources of information, with London secondary schools particularly likely to say they are using consultation with/surveys of parents and carers $(80 \%)^{39,40}$ alongside consultation with/surveys of pupils and guidance from/training by local community groups or local charities or voluntary organisations.

- Special schools: Special schools in the most deprived areas are more likely than average to be using consultation with/surveys of parents and carers (85\%) and local authority guidance/training (83\%) as sources of information ${ }^{41}$.

\section{Socio-economic groups}

- Primary schools: As with information about different ethnic origins and cultures, urban (including London) primary schools tend to be more likely than average to use most of these potential sources of information about different socio-economic groups in the communities they serve, with London primary schools particularly likely to say they are using guidance from/training by local community groups or local charities or voluntary organisations $(50 \%)^{42}$. This source is also more likely than average to be used by primary schools in the most deprived areas (43\%), as is guidance from/training by national charities or voluntary organisations $(35 \%)^{43}$.

- Secondary schools: Amongst secondary schools, both those in the most deprived areas, and urban (including London) secondary schools, tend to be more likely than average to use most of these potential sources of information.

- Special schools: Special schools in the most deprived areas are more likely than average to be using consultation with/surveys pupils (50\%) as a source of information ${ }^{44}$.

\footnotetext{
${ }^{36}$ The same finding emerges for primary schools in high IMD areas compared with those in low IMD areas. High IMD primary schools are also more likely than their low IMD counterparts to be using Consultation with/surveys of pupils as an information source. [Indicative finding: small base sizes for high $(n=88)$ and low $(n=68)$ IMD primary schools.]

37 Indicative finding: small base size for London primary schools $(n=35)$.

${ }^{38}$ Likewise, 'highest BME population' Quartile 4 (67\%) and 'most ethnically diverse' Quartile 4 (72\%) primary schools. [Indicative finding: small base size for fractionalisation Quartile $4(n=93)$ primary schools.]

39 Indicative finding: small base size for London $(n=48)$ secondary schools.

${ }^{40}$ Likewise, 'highest BME population' Quartile 4 (79\%) and 'most ethnically diverse' Quartile 4 (76\%) primary schools. [Indicative finding: small base sizes for pupil ethnicity Quartile $4(n=90)$ and fractionalisation Quartile 4 ( $n=88)$ secondary schools.]

${ }^{41}$ Indicative finding: small base size for high IMD special schools $(n=40)$.

42 Indicative finding: small base size for London primary schools $(n=35)$.

${ }^{43}$ Indicative finding: small base size for high IMD primary schools $(n=88)$

${ }^{44}$ Indicative finding: small base size for high IMD special schools $(n=40)$.
} 


\section{Faiths and religions}

- $\quad$ Primary schools: Again, urban (including London) primary schools tend to be more likely than average to use most of these potential sources of information, with London primary schools particularly likely to say they are using consultation with/surveys of pupils $(70 \%)^{45,46}$, and guidance from/training by local community groups or local charities or voluntary organisations $(49 \%)^{47}$.

- Secondary schools: In a pattern repeated elsewhere, urban (including London) secondary schools tend to be more likely than average to use most of these potential sources of information, with London secondary schools particularly likely to say they are using consultation with/surveys of pupils (74\%) ${ }^{48,49}$ alongside consultation with/surveys of parents and carers and consultation with/surveys of other members of the local community to guide them.

- Special schools: Special schools in the most deprived areas are more likely than their counterparts in the least deprived areas to be using contextual/demographic data for pupils on the school roll (80\% versus $57 \%)$, local authority guidance/training (75\% versus $46 \%$ ) and guidance from/training by local community groups or local charities or voluntary organisations (52\% versus $24 \%$ ) here ${ }^{50}$. Those in the 'most ethnically diverse' quartile Q4 are also more likely than average to be undertaking consultation with/surveys of other members of the local community (41\% versus $26 \%$ ) as a source of information ${ }^{51}$.

\section{Monitoring equity and excellence}

Department guidance ${ }^{52}$ emphasises the need for schools to develop an appropriate local approach to promoting community cohesion that encompasses teaching, learning and the curriculum, equity and excellence and engagement and extended services. It describes equity and excellence in terms of ensuring "equal opportunities for all to succeed at the highest level possible, striving to remove barriers to access and participation in learning and wider activities and working to eliminate variations in outcomes for different groups".

As detailed in the Ofsted guidance for inspectors ${ }^{53}$, schools are expected to have planned and taken appropriate action to promote community cohesion.

\begin{tabular}{|l|l|}
\hline Key question to ask the school & Minimum expectations \\
\hline $\begin{array}{l}\text { Have you planned and taken an appropriate } \\
\text { set of actions to promote community } \\
\text { cohesion? }\end{array}$ & $\begin{array}{l}\text { The school should have plans in place, } \\
\text { clearly based on its understanding or } \\
\text { analysis of the school's context and } \\
\text { priorities. It must include planned actions for } \\
\text { outreach. }\end{array}$ \\
\hline
\end{tabular}

\footnotetext{
${ }^{45}$ Indicative finding: small base size for London primary schools $(n=35)$.

${ }^{46}$ Likewise, 'highest BME population' Quartile 4 (60\%) and 'most ethnically diverse' Quartile 4 (64\%) primary schools.

[Indicative finding: small base size for fractionalisation Quartile $4(n=93)$ primary schools.]

${ }^{47}$ Indicative finding: small base size for London primary schools $(n=35)$.

48 Indicative finding: small base size for London secondary schools $(n=48)$.

${ }^{49}$ Likewise, 'highest BME population' Quartile 4 (73\%) and 'most ethnically diverse' Quartile 4 (75\%) primary schools.

[Indicative finding: small base sizes for pupil ethnicity Quartile $4(n=90)$ and fractionalisation Quartile 4 ( $n=88)$ secondary schools.]

${ }^{50}$ Indicative finding: small base size for high IMD special schools $(n=40)$.

51 Indicative finding: small base size for fractionalisation Quartile $4(n=32)$ special schools.

${ }^{52}$ Guidance on the duty to promote community cohesion

http://www.teachernet.gov.uk/ doc/11635/Guidance\%20on\%20the\%20duty\%20to\%20promote\%20community\%20cohesion\%2 Opdf.pdf

${ }^{53}$ Inspecting maintained schools' duty to promote community cohesion: guidance for inspectors

http://www.ofsted.gov.uk/Media/Ofsted/Forms-and-guidance2/Education-schools/s5/Community-Cohesion-Guidance-oninspecting.doc
} 
This section examines four specific equity and excellence issues:

- academic results;

- rates of exclusion;

- bullying; and

- applications for places.

The section looks at each in relation to the three key strands of differing ethnic origins and cultures, socio-economic groups, and faiths and religions.

For each, it examines schools' perceptions of their own knowledge of equity and excellence, whether they monitor variations in outcomes, and if they have found it necessary to take any action.

\section{Summary}

Primary and secondary school knowledge of differences in outcomes between different cohesion groups tends to be greatest for academic results, followed by rates of exclusion and bullying. Perceived knowledge about variations in applications for places is considerably lower than knowledge of the other three issues. For example, the proportions of secondary schools saying they know a great deal about variations between different ethnic groups are $69 \%$ for academic results, $64 \%$ for exclusion rates, $48 \%$ for bullying and only $31 \%$ for applications.

Special schools claim broadly similar levels of knowledge about variations in academic results, rates of exclusion and bullying, although perceived levels of knowledge about these are mostly below the levels claimed by primary or secondary schools. Most special schools do not give a rating of their knowledge of differences in likelihood of applying: they see this as not applicable.

The same patterns apply broadly to knowledge of variation by pupils from different ethnic origins/cultures, socio-economic groups and faiths/religions.

In primary and secondary schools, perceived knowledge of variations by socio-economic group is similar to knowledge of variations by ethnic origin and culture. Both primary and secondary schools claim least knowledge about variations by faith and religion. For example, the proportions of primary schools saying they know a great deal about variations in academic results is only $43 \%$ for different faith and religious groups, but $61 \%$ for different socio-economic groups and $67 \%$ for different ethnic origins.

As might be expected, schools which say they know a great deal about the statutory duty to promote community cohesion are slightly more likely to profess greater knowledge about any individual cohesion group in their school and local area or about variations in outcomes for a particular group.

\section{Primary schools}

\section{Knowledge}

As Table CC7 shows, for all three cohesion groups, most primary schools say they know at least a fair amount about variations in academic performance, rates of exclusion and bullying. A larger proportion say that rates of exclusion are not applicable than is the case for secondary schools. Considerably fewer say they know at least a fair amount about variations in applications for places: only around a half do so, with around a quarter saying they know 
not very much or nothing at all. Around one fifth say that variations in applications for places are not applicable (and there is no difference in the proportion saying this between faith status schools and non-faith schools).

Primary schools claim less knowledge of variations by faith and religion than of variations by ethnic origin and culture or by socio-economic group. It is not clear whether this reflects greater difficulty in obtaining information on the religious profile of the school and the community, difficulties in monitoring these factors by faith or religious group, or whether primary schools view this strand as less of a priority than the other two phases.

\section{Monitoring and action}

Across the three cohesion groups, primary schools are most likely to have reviewed academic under-performance, and least likely to have reviewed variations in applications for places; in fact, for each of the three cohesion groups, less than a third of primary schools have looked at the latter (see Table CC7). For each cohesion group, around a fifth of respondents say that variations in rates of exclusion or applications for places are not applicable to their school.

Reviews of socio-economic, and ethnic and cultural variations appear to be more widespread than reviews of variations by religious or faith group.

Of the issues examined, two have been reviewed by around four fifths of primary schools. The first of these is variation in academic performance by socio-economic group: four fifths $(81 \%)$ of primary schools have reviewed this. A little under half $(45 \%)$ of primary schools found that they needed to take action, meaning that a little over a third (36\%) reviewed it but judged that action was not required.

The second issue reviewed by around four fifths of primary schools is variations in academic performance by ethnic origin and culture: $78 \%$ have looked at this. A quarter (26\%) judged that action was needed while half $(52 \%)$ concluded that they did not need to take action.

Rather less widespread are reviews of academic performance by different faith and religious groups: half (53\%) say they have done this. Only one in ten (11\%) have taken action over variations in academic performance by religious or faith group; considerably more (42\%) have looked at this but judged that no action was necessary.

It is also perhaps worth noting that there seem to be similar levels of knowledge about variations in exclusion and bullying. This becomes clear when looking at the first column of figures in the table: for each of the three cohesion groups, the proportion saying they know a great deal about these two issues tends to be similar. But when it comes to monitoring these variations (shown two columns to the right) for each of the three groups, rather more primary schools have reviewed variations in bullying than have looked at exclusion rates. 
Table CC7: Primary schools' cohesion group equity and excellence - knowledge, monitoring and action

On the whole, how much, if anything, would you say you and your school know about whether its pupils from some different <groups> achieve/are <outcome> compared with other pupils ...?

In the last two or three years, has your school reviewed and found it necessary to take action to address $<$ group $><$ outcome $>$ ?

Base: All primary respondents (321)

Ethnic origins and cultures

... worse academic results

... more likely to be excluded

... more likely to be bullied

... less likely to apply for places

Socio-economic groups

... worse academic results

... more likely to be excluded

... more likely to be bullied

... are less likely to apply for places

Faiths and religions

... worse academic results

... more likely to be excluded

... more likely to be bullied

... less likely to apply for places

\begin{tabular}{c|c|c|c|c|c}
\multicolumn{3}{c|}{ Knowledge } & \multicolumn{2}{c}{ Monitoring and action } \\
$\begin{array}{c}\text { Great } \\
\text { deal }\end{array}$ & $\begin{array}{c}\text { Fair } \\
\text { amount } \\
\text { or more }\end{array}$ & $\begin{array}{c}\text { Not } \\
\text { applic- } \\
\text { able }\end{array}$ & $\begin{array}{c}\text { Review- } \\
\text { ed }\end{array}$ & $\begin{array}{c}\text { Action } \\
\text { needed }\end{array}$ & $\begin{array}{c}\text { Not } \\
\text { applic- } \\
\text { able }\end{array}$ \\
$\%$ & $\%$ & $\%$ & $\%$ & $\%$ & $\%$ \\
67 & 89 & 9 & 78 & 26 & 4 \\
58 & 78 & 14 & 51 & 2 & 20 \\
53 & 81 & 11 & 64 & 8 & 8 \\
29 & 48 & 20 & 32 & 2 & 21 \\
\hline & & & & & \\
61 & 90 & 2 & 81 & 45 & 4 \\
50 & 78 & 11 & 53 & 10 & 19 \\
46 & 78 & 6 & 64 & 9 & 10 \\
29 & 51 & 18 & 32 & 4 & 22 \\
\hline & & & & & \\
43 & 67 & 12 & 53 & 11 & 12 \\
39 & 75 & 17 & 37 & 2 & 24 \\
40 & 66 & 7 & 48 & 3 & 17 \\
24 & 43 & 28 & 30 & 4 & 24 \\
\hline
\end{tabular}

\section{Sub-groups within the primary phase}

There is a general tendency for primary schools in the most deprived areas to say they have reviewed, and found it necessary to take action, in regard to pupils' academic underperformance across each cohesion group. Conversely, schools in the least deprived areas tend to be more likely to say they reviewed this and did not need to take any action ${ }^{54}$.

A similar pattern emerges for urban (including London) schools ${ }^{55}$, compared with rural, town and fringe schools, and for schools with the highest proportions of BME pupils and most ethnically diverse school rolls ${ }^{56}$ compared with the highest proportion of white pupils and least ethnically diverse school rolls respectively. For example, primary schools in the "highest BME population' quartile Q4 are five times more likely than those in the 'highest white population' quartiles Q1/2 (50\% versus $10 \%)$ to say they reviewed academic underperformance by pupils from some different ethnic origins and cultures and needed to take action as a result. On the other hand, primary schools in the 'highest white population' quartiles Q1/2 are nearly twice as likely as their 'highest BME population' quartile Q4 counterparts to say they reviewed this and found no action to be necessary (62\% versus $34 \%)$.

\footnotetext{
${ }^{54}$ Indicative finding: small base size for high $(n=88)$ and low $(n=88)$ IMD primary schools.

${ }^{55}$ And for London schools in particular.

${ }^{56}$ Indicative finding: small base size for fractionalisation Quartile $4(n=93)$ primary schools.
} 


\section{Secondary schools}

\section{Knowledge}

The picture in secondary schools (see Table CC8) is broadly similar to that just discussed for primary schools. For all three strands, most secondary schools say they know at least a fair amount about variations in academic performance, rates of exclusion and bullying. Fewer say they know at least a fair amount about variations in applications for places, though the contrast between this and the previous three factors is not as large as it is for primary schools.

Focusing just on the first two of the strands (ethnic origin/culture and socio-economic group), well over half of secondary schools say they know a great deal about variations in academic performance or exclusion rates compared with less than half that say the same about variations in bullying.

Secondary schools claim less knowledge of variations by faith and religion than of variations by ethnic origin and culture or by socio-economic group. This echoes the earlier finding that staff knowledge is perceived to be lower when it comes to different faith and religious groups in their school and area than it is for ethnic origin and culture or socio-economic groups.

The extent to which knowledge of variation by faith and religion lags behind the other two strands is larger than was the case for primary schools. This may be due to a combination of better secondary school knowledge of the other two issues, and worse secondary school knowledge of variation by faith and religion.

\section{Monitoring and action}

Monitoring of variations related to socio-economic and ethnic origin/culture cohesion groups appears more widespread in secondary schools than in primary schools. Again, variations by socio-economic group and ethnic/cultural group are more widely investigated than those related to faith or religion. As was the case in primary schools, lack of equity in academic performance is the most widely monitored issue. Smaller proportions say that individual issues are not applicable than is the case for primary schools.

The issues most widely found to need action are variations by socio-economic group, then by ethnic origin and culture, and finally by faith and religious group. Three fifths (59\%) of secondary schools have found they needed to take action over variations in academic performance by socio-economic group. A smaller, but still substantial, proportion (41\%) have done so in relation to differences in performance by ethnic or cultural group.

A third (34\%) have taken action to address variations in rates of exclusion by socio-economic group.

As was the case for primary schools, out of the issues examined, lack of equity in academic performance is most widely found to be in need of action in secondary schools. 
Table CC8: Secondary schools' cohesion group equity and excellence - knowledge, monitoring and action

On the whole, how much, if anything, would you say you and your school know about whether its pupils from some different <groups> achieve/are <outcome> compared with other pupils ...?

In the last two or three years, has your school reviewed and found it necessary to take action to address $<$ group $><$ outcome $>$ ?

Base: All secondary respondents (348)

Ethnic origins and cultures

... worse academic results

.... more likely to be excluded

... more likely to be bullied

... less likely to apply for places

Socio-economic groups

... worse academic results

... more likely to be excluded

... more likely to be bullied

... are less likely to apply for places

Faiths and religions

... worse academic results

... more likely to be excluded

... more likely to be bullied

... less likely to apply for places

\begin{tabular}{c|c|c|c|c|c}
\multicolumn{3}{|c|}{ Knowledge } & \multicolumn{3}{c}{ Monitoring and action } \\
$\begin{array}{c}\text { Great } \\
\text { deal }\end{array}$ & $\begin{array}{c}\text { Fair } \\
\text { amount } \\
\text { or more }\end{array}$ & $\begin{array}{c}\text { Not } \\
\text { applic- } \\
\text { able }\end{array}$ & $\begin{array}{c}\text { Review- } \\
\text { ed }\end{array}$ & $\begin{array}{c}\text { Action } \\
\text { needed }\end{array}$ & $\begin{array}{c}\text { Not } \\
\text { applic- } \\
\text { able }\end{array}$ \\
$\%$ & $\%$ & $\%$ & $\%$ & $\%$ & $\%$ \\
69 & 93 & 3 & 84 & 41 & 2 \\
64 & 87 & 4 & 74 & 16 & 7 \\
48 & 84 & 3 & 71 & 16 & 6 \\
31 & 55 & 11 & 40 & 7 & 14 \\
\hline & & & & & \\
67 & 91 & 1 & 84 & 59 & 2 \\
59 & 85 & 3 & 75 & 34 & 4 \\
46 & 78 & 2 & 67 & 13 & 4 \\
33 & 56 & 11 & 38 & 11 & 13 \\
\hline 35 & 62 & 5 & 46 & 12 & 8 \\
31 & 57 & 7 & 45 & 6 & 10 \\
30 & 60 & 6 & 45 & 8 & 8 \\
19 & 44 & 12 & 28 & 6 & 15 \\
\hline
\end{tabular}

\section{Sub-groups within the secondary phase}

In line with findings for primary schools, there is a general tendency for secondary schools in the most deprived areas (and also in area with medium levels of deprivation) to say they have reviewed, and found it necessary to take action, in regard to pupils' academic underperformance across each cohesion group. Meanwhile, schools in the least deprived areas tend to be more likely to say they reviewed this and did not need to take any action ${ }^{57,58}$.

London secondary schools are more likely than average to say they reviewed and acted upon academic under-performance by pupils from some different ethnic origins and cultures (56\% versus $41 \%)^{59}$, as are 'highest BME population' quartile Q4 and the most ethnically diverse schools compared with 'highest white population' quartiles Q1/2 and the least ethnically diverse schools respectively ${ }^{60}$.

\footnotetext{
${ }^{57}$ Indicative finding: small base size for high $(n=88)$ and low $(n=88)$ IMD secondary schools.

${ }^{58}$ Likewise, secondary schools in high and medium IMD areas are more likely than those in low IMD areas to say they have reviewed and taken action to address the lower likelihood that pupils from different ethnic origins and cultures will apply for places at their schools compared with other pupils. [Indicative finding: small base size for high $(n=88)$ and low $(n=88)$ IMD secondary schools.] They have also more frequently examined and addressed the more frequent exclusion of pupils from some different faiths and religions.

59 Indicative finding: small base size for London secondary schools $(n=48)$.

${ }^{60}$ Indicative finding: small base sizes for pupil ethnicity Quartile $4(n=90)$ and fractionalisation Quartile 4 (n=88) secondary schools.
} 
The same London secondary schools are also twice as likely as average to say they have reviewed and taken action to address the more frequent exclusion of these pupils compared with other pupils (37\% versus $16 \%)^{61}$, as again are those in the "highest BME population' quartile Q4 and the most ethnically diverse schools ${ }^{62}$.

The more frequent exclusion of pupils from some different socio-economic groups compared with other pupils has more often than average been tackled by urban (including London) secondary schools (36\% versus 34\%).

\section{Special schools}

\section{Knowledge}

Unlike primary or secondary schools, special schools claim broadly similar levels of knowledge about variations in academic results, rates of exclusion and bullying. As Table CC9 shows, most say they know at least a fair amount. However, their perceived knowledge about these is mostly below the levels claimed by primary or secondary schools.

Special schools claim fairly similar levels of knowledge about variations by each of the three cohesion groups: ethnic origin/culture, socio-economic and faith/religion. Knowledge of variation by faith and religion is broadly similar to that expressed by primary or secondary schools, but special schools' perceived knowledge of variation by the other two strands is rather lower than that claimed by primary or secondary schools.

Most special schools do not give a rating of their knowledge of differences in likelihood of applying: they see this as not applicable.

\section{Monitoring and action}

Special schools face different challenges to their mainstream counterparts. As Table CC9 shows, cohesion-related reviews are less widespread than in primary and secondary schools. In addition, across all of the cohesion groups only small proportions have taken action to address any one of the issues. In particular, most special schools have not looked at variations in rates of application for places: for each of the three strands around three quarters say it is not applicable to their school.

\footnotetext{
${ }^{61}$ Indicative finding: small base size for London secondary schools $(n=48)$.

${ }^{62}$ Indicative finding: small base sizes for pupil ethnicity Quartile $4(n=90)$ and fractionalisation Quartile $4(n=88)$ secondary schools.
} 
Table Cc9: Special schools' cohesion group equity and excellence - knowledge, monitoring and action

On the whole, how much, if anything, would you say you and your school know about whether its pupils from some different <groups> achieve/are <outcome> compared with other pupils ...?

In the last two or three years, has your school reviewed and found it necessary to take action to address $<$ group $><$ outcome $>$ ?

Base: All special respondents (135)

Ethnic origins and cultures

... worse academic results

.... more likely to be excluded

... more likely to be bullied

... less likely to apply for places

Socio-economic groups

... worse academic results

... more likely to be excluded

... more likely to be bullied

... are less likely to apply for places

Faiths and religions

... worse academic results

... more likely to be excluded

... more likely to be bullied

... less likely to apply for places

\begin{tabular}{c|c|c|c|c|c}
\multicolumn{3}{c|}{ Knowledge } & \multicolumn{2}{c}{ Monitoring and action } \\
$\begin{array}{c}\text { Great } \\
\text { deal }\end{array}$ & $\begin{array}{c}\text { Fair } \\
\text { amount } \\
\text { or more }\end{array}$ & $\begin{array}{c}\text { Not } \\
\text { applic- } \\
\text { able }\end{array}$ & $\begin{array}{c}\text { Review- } \\
\text { ed }\end{array}$ & $\begin{array}{c}\text { Action } \\
\text { needed }\end{array}$ & $\begin{array}{c}\text { Not } \\
\text { applic- } \\
\text { able }\end{array}$ \\
$\%$ & $\%$ & $\%$ & $\%$ & $\%$ & $\%$ \\
46 & 27 & 22 & 64 & 7 & 17 \\
46 & 20 & 25 & 49 & 1 & 31 \\
50 & 20 & 22 & 56 & 4 & 25 \\
25 & 11 & 50 & 18 & 1 & 54 \\
\hline 42 & 32 & 18 & 59 & 13 & 16 \\
43 & 24 & 24 & 43 & 5 & 28 \\
42 & 30 & 22 & 53 & 5 & 22 \\
24 & 11 & 54 & 18 & 1 & 53 \\
\hline 34 & 27 & 24 & 50 & 1 & 19 \\
34 & 23 & 28 & 39 & 1 & 31 \\
36 & 27 & 23 & 45 & 2 & 26 \\
21 & 9 & 51 & 18 & 2 & 49 \\
\hline
\end{tabular}

\section{Sub-groups within the special phase}

In line with findings discussed earlier, special schools in the 'highest BME population' quartile Q4 and 'most ethnically diverse' quartile Q4 sub-groups more frequently say they have reviewed and found action to be necessary to address academic under-performance by pupils from different ethnic origins and cultures, compared with the average ${ }^{63}$.

Special schools differ from mainstream schools in the way in which deprivation appears linked to different experiences of variations in academic under-performance for some pupils from different ethnic origins and cultures or socio-economic groups. Special schools in the most deprived areas are as likely as those in the least deprived areas to have reviewed these kind of variations in outcome (just as was the case for mainstream primary and secondary schools). The difference lies in the proportion that have reviewed variations and did not find it necessary to take action: for primary and secondary schools, this is highest in schools in the least deprived areas. By contrast (and perhaps counter-intuitively), the special schools most likely to say that they have reviewed the variations but decided no action was required are in the most deprived areas $^{64}$.

\footnotetext{
${ }^{63}$ Indicative finding: small base sizes for pupil ethnicity Quartile $4(n=31)$ and fractionalisation Quartile $4(n=32)$ special schools.

${ }^{64}$ Indicative finding: small base size for high IMD special schools $(n=40)$.
} 


\section{What are schools doing to promote community cohesion?}

This section examines what it is that schools are doing to promote community cohesion and how they are doing it.

\section{Summary}

Use of the curriculum to promote community cohesion is widespread: half or more of all types of school say they are using the curriculum and enrichment activities in equal measure ( $51 \%$ of primary, $52 \%$ of secondary and $57 \%$ of special schools). A third or more say they are using the curriculum more than enrichment activities (39\% of primary, $37 \%$ of secondary and $33 \%$ of special). Only one in twenty (6\% among primary, secondary and special) say they are mainly using one-off enrichment activities.

Almost all schools promote cohesion through the school's ethos and values (97\%), the pastoral curriculum (94\%), curriculum subjects (94\%) and assemblies (93\%). In addition, most use one-off enrichment activities (85\%) and extended school activities (84\%). Use of English as an additional language (EAL) support is more widespread in more deprived areas.

Curriculum subjects most widely used to promote cohesion are: religious education, citizenship, geography, English, art, music, history, drama and modern foreign languages. The number of subjects mentioned suggests most schools have cohesion activities embedded across their curriculum.

The opportunities schools most widely offer pupils to promote cohesion are school councils (94\%) and after-school activities (89\%). Mentoring, volunteering and exchange visits are used more widely by secondary schools than by primary or special schools. Mentoring is also used more widely by secondary schools in more deprived areas and urban areas.

When conducting the literature review, we were unable to find detailed case studies of "whole school" approaches taken to promoting community cohesion. Much of the guidance from local authorities, and many of the publically available examples of schools' work, referred to individual, seemingly standalone, activities (albeit that some were long-term); there was little or no information on whether and how these activities were integrated with anything else that schools might be doing to meet their obligations under the legislation. In short, the available evidence did not make it possible to say whether schools are adopting coherent and multi-faceted, whole-school approaches to community cohesion-related work; taken purely at face value, the available evidence suggested that they were not. Therefore, one of the key questions for the quantitative research was: does the literature "do justice" to what is actually happening in schools?

To this extent, the survey findings indicate that the answer to this question is a qualified 'no': overall, schools are promoting community cohesion in a much more broad and "whole school" way than the picture derived from the review of the literature. Around half of all schools (51\%) say that they are promoting community cohesion through curriculum subjects and one-off enrichment activities in roughly equal measure, and a further four in ten (38\%) that they are doing so more through curriculum subjects than through one-off enrichment activities. Only one in twenty schools (6\%) say that they are promoting community cohesion more through one-off enrichment activities than through curriculum subjects. These patterns of response are consistent across phases. 


\section{Schools' promotion of community cohesion}

\section{Q16. On balance, would you say your school promotes community cohesion ...?

\footnotetext{
\% More through curriculum subjects than one-off enrichment activities

- \% Through curriculum subjects and one-off enrichment activities in roughly equal measure

\% More through one-off enrichment activities than through curriculum subjects
}

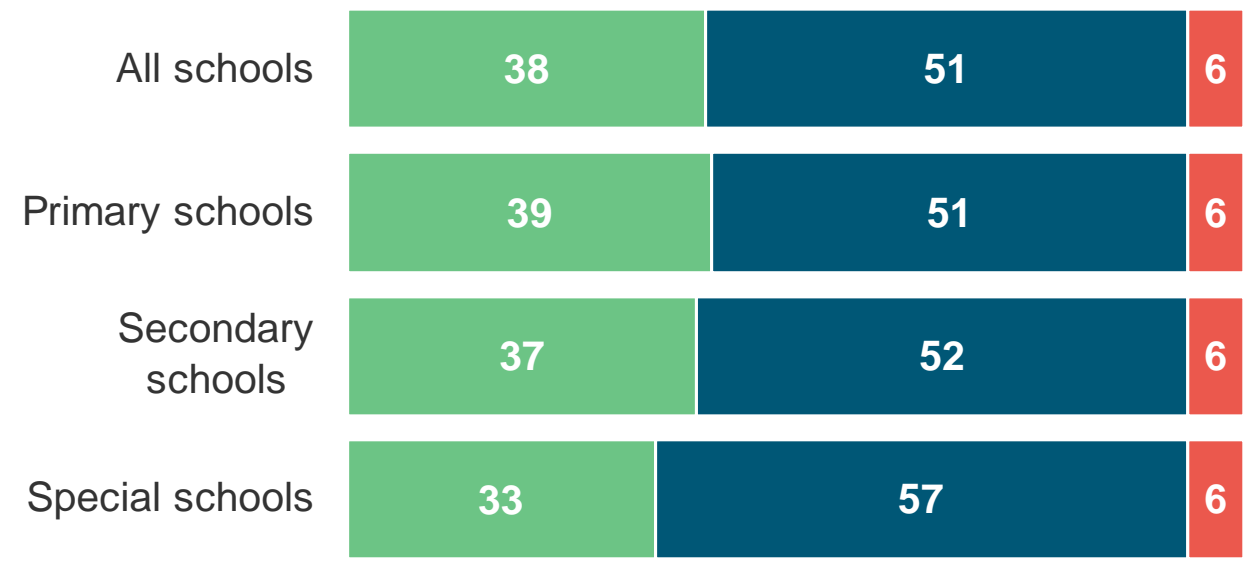

Base: 804 schools in England (321 primary, 348 secondary, 135 special); 10 February-14 May 2010 for DfE

Variations in approach for particular types of local area and school roll profiles are different within each phase:

- Primary schools: Non-faith primary schools are more likely than faith status primary schools to make up the minority overall which say the balance of their promotion activity is through one-off enrichment activities rather than through curriculum subjects (8\% versus $3 \%)$.

- Secondary schools: Secondary schools in the least deprived areas are more likely than average ( $47 \%$ versus $37 \%$ ) to say the balance of their community cohesion promotion is through the curriculum rather than through one-off enrichment activities. In contrast, amongst the minority of secondary schools which say the balance of their activity is the reverse of this - i.e. through one-off enrichment activities rather than through curriculum subjects - schools in areas of high (7\%) and medium (8\%) deprivation are more likely than those in areas of low deprivation (0\%) to say this ${ }^{65}$. Secondary schools in the 'highest BME population' quartile Q4 are significantly more likely than average to report a roughly equal measure of curriculum-based and one-off enrichment activities (63\% versus $52 \%)^{66}$.

- Special schools: Special schools in the most deprived areas are more likely than those in the least deprived areas to say they are promoting community cohesion through a roughly equal measure of curriculum-based and one-off enrichment activities $(69 \% \text { versus } 42 \%)^{67}$.

Regardless of phase (see Table CC10), almost all schools are promoting community cohesion through the school's ethos and values, the pastoral curriculum, curriculum subjects,

\footnotetext{
${ }^{65}$ Indicative finding: small base sizes for high $(n=83)$ and low $(n=72)$ IMD secondary schools.

${ }^{66}$ Indicative finding: small base size for pupil ethnicity Quartile $4(n=90)$ secondary schools.

${ }^{67}$ Indicative finding: small base size for high $(n=40)$ and low $(n=33)$ IMD special schools.
} 
and assemblies. Most, too, are doing so through one-off enrichment activities and Extended School activities.

\begin{tabular}{|c|c|c|c|c|}
\hline $\begin{array}{l}\text { In which of the following ways, if any, is } \\
\text { your school promoting community } \\
\text { cohesion? }\end{array}$ & $\begin{array}{c}\text { All } \\
\text { schools }\end{array}$ & $\begin{array}{l}\text { Primary } \\
\text { schools }\end{array}$ & $\begin{array}{l}\text { Secondary } \\
\text { schools }\end{array}$ & $\begin{array}{l}\text { Special } \\
\text { schools }\end{array}$ \\
\hline Base: All respondents & $\begin{array}{c}(804) \\
\%\end{array}$ & $\begin{array}{c}(321) \\
\%\end{array}$ & $\begin{array}{c}(348) \\
\%\end{array}$ & $\begin{array}{c}(135) \\
\%\end{array}$ \\
\hline Through the school's ethos and values & 97 & 97 & 97 & 96 \\
\hline $\begin{array}{l}\text { Through the pastoral curriculum or } \\
\text { PSHE }\end{array}$ & 97 & 97 & 97 & 94 \\
\hline Through curriculum subjects & 94 & 94 & 94 & 93 \\
\hline Assemblies & 93 & 93 & 93 & 87 \\
\hline $\begin{array}{l}\text { Through one-off enrichment activities } \\
\text { (e.g. a diversity day) }\end{array}$ & 85 & 85 & 84 & 86 \\
\hline 'Extended School' activities & 84 & 82 & 89 & 84 \\
\hline $\begin{array}{l}\mathrm{EAL}^{68} \text { support (for pupils, parents and } \\
\text { carers, and/or staff) }\end{array}$ & 59 & 58 & 67 & 43 \\
\hline
\end{tabular}

Variations in response within each phase mostly concern the use of EAL (English as an Additional Language) support:

- Primary schools: Primary schools in the most deprived areas $(77 \%)^{69}$, and urban (including London) primary schools (70\%) - rising to $90 \%$ of London primary schools ${ }^{70}$ - are much more likely than average to be using EAL support as a means of promoting community cohesion ${ }^{71}$. Perhaps this reflects a greater need for EAL support generally in deprived urban areas, though there is an extent to which this overlaps with variations according to the interconnected factors of the ethnic diversity of the school roll and proportion of BME pupils.

Specifically, three quarters of primary schools in the quartile with the highest (78\%) and second highest $(75 \%)$ proportions of BME pupils say they use EAL as a means of promoting community cohesion. In the two quartiles with the highest proportions of white pupils, less than half (44\%) say they do this. Similarly, a large majority of primary schools in the most diverse quartile (83\%) and second most diverse quartile (71\%) say they use EAL as a means of promoting community cohesion. In the two least diverse quartiles, less than half (44\%) say they do this.

Those that say they are doing more (a lot + a little) to promote community cohesion since the introduction of the statutory duty are more likely than average to be using most of these methods.

\footnotetext{
${ }^{68}$ English as an additional language

69 Indicative finding: small base size for high IMD primary schools $(n=88)$

${ }^{70}$ Indicative finding: small base size for London primary schools $(n=35)$.

${ }^{71}$ Likewise, schools in the 'highest BME population' Quartile 4 (78\%) and 'highest ethnic fractionalisation' Quartile 4 (83\%). [Indicative finding: small base size for fractionalisation Quartile $4(n=93)$ primary schools.]
} 
- Secondary schools: London secondary schools ${ }^{72}$ are much more likely than average to be using one-off enrichment activities (91\%) or EAL support (83\%) as a means of promoting community cohesion. Moreover, like primary schools, those that say they are doing more (a lot + a little) to promote community cohesion since the introduction of the statutory duty are more likely than average to be using most of these methods, as are those that say the introduction of the statutory duty improved their understanding of community cohesion.

- $\quad$ Special schools: Reflecting the findings for primary schools, special schools in the 'highest BME population' quartile Q4 (62\%) and 'most ethnically diverse' quartile Q4 (61\%) are more likely to be using EAL support as a means of promoting community cohesion than the 'lowest BME population' (35\%) or 'least ethnically diverse' (36\%) special schools ${ }^{73}$.

The most common curriculum subjects used to promote community cohesion are - as might be expected - RE, citizenship, geography, English, art, music, history, drama and modern foreign languages (see Table CC11). Dark shading indicates a subject more likely to be used in a particular phase and light shading shows that the subject is less likely to be used in a particular phase.

The most notable differences are in the subjects special schools use. Special schools tend to be less likely than other schools to promote community cohesion through RE, geography, history or modern foreign languages, and more likely to promote it through PSHE. Science is not especially widely used to promote community cohesion, but it is noticeable that secondary schools are more likely than other schools to say they promote community cohesion through science.

\footnotetext{
${ }^{72}$ Indicative finding: small base size for London secondary schools $(n=48)$.

${ }^{73}$ Indicative finding: small base sizes for pupil ethnicity Quartile $4(n=31)$ and fractionalisation Quartile $4(n=32)$ special schools.
} 
Table CC11: Curriculum subjects used to promote community cohesion (all responses $2 \%+$ )

Which curriculum subjects does your school use to promote community cohesion?

Base: All respondents whose schools use curriculum subjects to promote community cohesion

Religious Education (RE)

Citizenship

Geography

English

Art

Music

History

Drama

Modern Foreign Languages

PE/sports with other schools

Personal Social Health \& Economic education (PSHE)

All/cross-curricular

Information and Communication

Technology (ICT)

Maths

Science

\begin{tabular}{|c|c|c|c|}
\hline $\begin{array}{c}\text { All } \\
\text { schools }\end{array}$ & $\begin{array}{l}\text { Primary } \\
\text { schools }\end{array}$ & $\begin{array}{l}\text { Secondary } \\
\text { schools }\end{array}$ & $\begin{array}{l}\text { Special } \\
\text { schools }\end{array}$ \\
\hline $\begin{array}{c}(756) \\
\%\end{array}$ & $\begin{array}{c}(301) \\
\%\end{array}$ & $\begin{array}{c}(328) \\
\%\end{array}$ & $\begin{array}{c}(126) \\
\%\end{array}$ \\
\hline 89 & 90 & 89 & 82 \\
\hline 87 & 86 & 91 & 89 \\
\hline 81 & 82 & 79 & 67 \\
\hline 81 & 81 & 82 & 74 \\
\hline 78 & 78 & 78 & 79 \\
\hline 78 & 80 & 70 & 73 \\
\hline 74 & 73 & 82 & 64 \\
\hline 73 & 73 & 76 & 65 \\
\hline 73 & 74 & 75 & 47 \\
\hline 7 & 7 & 11 & 5 \\
\hline 6 & 6 & 5 & 11 \\
\hline 6 & 6 & 7 & 4 \\
\hline 5 & 6 & 3 & 2 \\
\hline 5 & 5 & 6 & 1 \\
\hline 3 & 2 & 10 & 4 \\
\hline
\end{tabular}

As a means of promoting community cohesion, high proportions of schools say they offer pupils the opportunity to participate in a range of extra-curricular activities. No doubt reflecting the age and physical/cognitive abilities of their pupils, secondary schools are much more likely than other schools to offer volunteering, mentoring (pupil-to-pupils and adult-topupil) and exchange visits. A slight caveat should be noted when interpreting the results of this question. The very high proportion of schools mentioning most of the items may suggest that they have responded with any activities that they do, regardless of whether they are actually used as a means of promoting community cohesion. 
Table CC12: Activities used to promote community cohesion

As a means of promoting community cohesion, are pupils in your school offered an opportunity to participate in any of the following types of activity?

Base: All respondents

School council

After-school activities

Peer mentoring (pupil-to-pupil)

Volunteering

Mentoring (adult-to-pupil, where adult mentors come from the local community)

Exchange visits

\begin{tabular}{c|c|c|c}
$\begin{array}{c}\text { All } \\
\text { schools }\end{array}$ & $\begin{array}{c}\text { Primary } \\
\text { schools }\end{array}$ & $\begin{array}{c}\text { Secondary } \\
\text { schools }\end{array}$ & $\begin{array}{c}\text { Special } \\
\text { schools }\end{array}$ \\
$\begin{array}{c}\text { (804) } \\
\%\end{array}$ & $\begin{array}{c}(321) \\
\%\end{array}$ & $\begin{array}{c}(348) \\
\%\end{array}$ & $\begin{array}{c}(135) \\
\%\end{array}$ \\
94 & 94 & 94 & 94 \\
89 & 88 & 93 & 90 \\
67 & 65 & 82 & 42 \\
59 & 56 & 79 & 51 \\
37 & 32 & 64 & 39 \\
& & & \\
26 & 19 & 64 & 22 \\
\hline
\end{tabular}

Looking at differences within phases:

- Primary schools: Urban (including London) primary schools are more likely than average to be offering after-school activities (90\%) and adult-to-pupil mentoring $(38 \%)^{74}$ as a means of promoting community cohesion. Those which say their understanding of community cohesion improved (a lot + a little) with the introduction of the statutory duty are more likely than average to be offering volunteering (58\%) and adult-to-pupil mentoring (34\%), while those which are now doing more (a lot + a little) to promote community cohesion are more likely than average to be operating a school council (95\%) and offering after-school activities (90\%) and peer mentoring (68\%).

- Secondary schools: Mentoring appears more widespread in secondary schools located in urban centres and in schools with high BME populations. London secondary schools are significantly more likely than average to say they are offering adult-to-pupil mentoring $(80 \% \text { versus } 64 \%)^{75}$. In line with this, those in the 'highest BME population' quartile Q4 (75\%) and the most ethnically diverse schools (75\%) are also more likely than average to be offering adult-to-pupil mentoring, and - in the case of secondary schools with the highest BME pupil population - to be offering peer mentoring $(88 \%)^{76}$.

\footnotetext{
${ }^{74}$ Rising to $49 \%$ of London primary schools. [Indicative finding: small base size for London primary schools ( $\left.\mathrm{n}=35\right)$.]

${ }^{75}$ Indicative finding: small base size for London secondary schools $(n=48)$.

${ }^{76}$ Indicative finding: small base sizes for pupil ethnicity Quartile $4(n=90)$ and fractionalisation Quartile 4 ( $\left.n=88\right)$ secondary schools.
} 


\section{Who are schools' partners in promoting community cohesion?}

\section{Summary}

Most schools have links with local charities or community groups (86\%), the police (83\%), national charities or organisations (72\%) or another school (or schools) with a different demographic profile (70\%). Slightly fewer have links with training partners $(60 \%)$ or their locality partnerships (52\%).

Most links have been developed since the duty became statutory: for any given partnership organisation, no more than one in five schools say they already had a link established before the duty became statutory

Schools in more deprived areas appear more likely to have developed links with other schools or partnership organisations since the duty became statutory.

Since the introduction of the statutory duty, schools have developed links with a variety of different organisations to enable them to promote community cohesion within their schools (see Table CC13). Seven in ten (70\%) have established links with local community groups/local charities, while six in ten have established links with the police or another school/other schools with a different demographic profile. By phase, secondary schools (71\%) are more likely than primary (61\%) and special (58\%) schools to say they've developed links with the police since the introduction of the statutory duty. Similarly, secondary schools (78\%) are more likely than primary (69\%) to have developed links with local community groups.

\section{Table CC13: Schools' partners in promoting community cohesion (all responses} $5 \%+)$ - developed links since statutory duty

\begin{tabular}{|c|c|c|c|c|}
\hline $\begin{array}{l}\text { Since the introduction of the statutory duty } \\
\text { to promote community cohesion, has your } \\
\text { school developed links with any of the } \\
\text { following organisations? }\end{array}$ & $\begin{array}{c}\text { All } \\
\text { schools }\end{array}$ & $\begin{array}{l}\text { Primary } \\
\text { schools }\end{array}$ & $\begin{array}{l}\text { Secondary } \\
\text { schools }\end{array}$ & $\begin{array}{l}\text { Special } \\
\text { schools }\end{array}$ \\
\hline Base: All respondents & $\begin{array}{c}(804) \\
\%\end{array}$ & $\begin{array}{c}(321) \\
\%\end{array}$ & $\begin{array}{c}(348) \\
\%\end{array}$ & $\begin{array}{c}(135) \\
\%\end{array}$ \\
\hline $\begin{array}{l}\text { Local community groups and/or local } \\
\text { charities or voluntary organisations }\end{array}$ & 70 & 69 & 78 & 74 \\
\hline The police & 62 & 61 & 71 & 58 \\
\hline $\begin{array}{l}\text { Another school (or schools) with a } \\
\text { different demographic profile to your } \\
\text { own school roll }\end{array}$ & 62 & 62 & 62 & 63 \\
\hline $\begin{array}{l}\text { National charities or voluntary } \\
\text { organisations }\end{array}$ & 54 & 53 & 58 & 60 \\
\hline Training providers & 47 & 46 & 47 & 53 \\
\hline The Locality Partnership & 41 & 40 & 46 & 40 \\
\hline Other: faith organisations & 14 & 16 & 5 & 8 \\
\hline Other: local businesses/employers & 5 & 5 & 8 & 4 \\
\hline
\end{tabular}


Within phases there are some differences in types of links that schools have established since the duty became statutory, many of which suggest linking may be developing more in more deprived areas:

- Primary schools: Primary schools in the most deprived areas are more likely than average to have developed post-statutory duty links with training providers (60\%), another school (or schools) with a different demographic profile (71\%) and the police $(72 \%)^{77}$. Urban (including London) primary schools tend to be more likely than average to have established links with each of the potential partners, but London primary schools are particularly likely (71\%) to now have links with national charities or voluntary organisations ${ }^{78}$.

- Secondary schools: Secondary schools in areas of high (85\%) and medium (79\%) deprivation are more likely than those in less deprived areas (64\%) to have established links with local community groups and/or local charities or voluntary organisations, with national charities or voluntary organisations ( $70 \%$ and $58 \%$ versus $44 \%$ respectively) and with training providers ( $55 \%$ and $51 \%$ versus $29 \%$ respectively) since the introduction of the statutory duty ${ }^{79}$. Having an improved understanding of community cohesion, and doing more (a lot + a little) to promote community cohesion, since the introduction of the statutory duty also increases the likelihood that schools say they've forged links with most of these potential partners.

- Special schools: Special schools in areas of low deprivation (89\%) are much more likely than average to have started working with local community groups and/or local charities or voluntary organisations since the introduction of the statutory duty ${ }^{80}$.

Table CC14 shows what proportion of schools currently have links in place. This includes both those which have established links since the duty became statutory and those which already had a link in place. Existing links with the police appear more widespread than average in secondary schools and slightly less widespread than average in special schools.

The proportions shown in Tables CC13 and CC14 are similar, which would suggest that most links have been developed since the duty became statutory. Indeed, for any given partnership organisation, no more than one in five schools say they already had a link established before the duty became statutory.

\footnotetext{
${ }^{77}$ Indicative finding: small base size for high IMD primary schools $(n=88)$.

${ }^{78}$ Indicative finding: small base size for London primary schools $(n=35)$.

${ }^{79}$ Indicative finding: small base size for high $(n=83)$ and low $(n=72)$ IMD secondary schools.

${ }^{80}$ Indicative finding: small base size for low IMD special schools $(n=38)$.
} 
Table CC14: Schools' partners in promoting community cohesion - currently have links

Since the introduction of the statutory duty to promote community cohesion, has your school developed links with any of the following organisations?

All saying "yes" or "Not applicable already had a link"

Base: All respondents

Local community groups and/or local charities or voluntary organisations

The police

National charities or voluntary organisations

Another school (or schools) with a different demographic profile to your own school roll

Training providers

The Locality Partnership

\begin{tabular}{c|c|c|c}
$\begin{array}{c}\text { All } \\
\text { schools }\end{array}$ & $\begin{array}{c}\text { Primary } \\
\text { schools }\end{array}$ & $\begin{array}{c}\text { Secondary } \\
\text { schools }\end{array}$ & $\begin{array}{c}\text { Special } \\
\text { schools }\end{array}$ \\
$\begin{array}{c}(804) \\
\%\end{array}$ & $\begin{array}{c}(321) \\
\%\end{array}$ & $\begin{array}{c}(348) \\
\%\end{array}$ & $\begin{array}{c}(135) \\
\%\end{array}$ \\
86 & 86 & 88 & 88 \\
83 & 82 & 90 & 74 \\
72 & 72 & 71 & 71 \\
70 & 70 & 70 & 74 \\
60 & 59 & 61 & 66 \\
52 & 52 & 57 & 52 \\
\hline
\end{tabular}

\section{How structured is what schools are doing?}

This section discusses the extent to which schools' community cohesion-related work is formalised through its inclusion in policies and planning, and the ways in which that work is monitored by schools.

\section{Summary}

Community cohesion is very frequently part of the school improvement plan: this is the case for $82 \%$ of primary, $84 \%$ of secondary and $84 \%$ of special schools. Written policies for promoting community cohesion are widespread in primary (75\%) and secondary schools $(68 \%)$, but less so in special schools $(61 \%)$.

Links to their local authority's children and young people's plan are more common (and found in $64 \%$ of all schools) than the inclusion of promoting community cohesion in the school's safeguarding policy (found in $53 \%$ of schools).

At a national level (see Table CC15), the majority of schools (73\%) say that promoting community cohesion is part of their school improvement plan, and there is little variation in this between phases. Most schools have a written policy or plan for promoting community cohesion, but there is considerable variation by phase with, for example, well over seven in ten primary schools $(75 \%)$ saying this is the case, compared with six in ten special schools (61\%). 
In line with guidance that the promotion of community cohesion in schools should be placed within the broader context of community planning ${ }^{81}$, over three in five schools (64\%) say it is part of their local authority's Children and Young People Plan. However, around a quarter of schools did not answer this question, suggesting that the true proportion that 'don't know' is nearer three in ten than one in ten.

Perhaps reflecting the fact that guidance for schools ${ }^{82}$ does not stipulate that community cohesion and safeguarding should intersect, around only half of schools say that promoting community cohesion is part of their school's safeguarding policy.

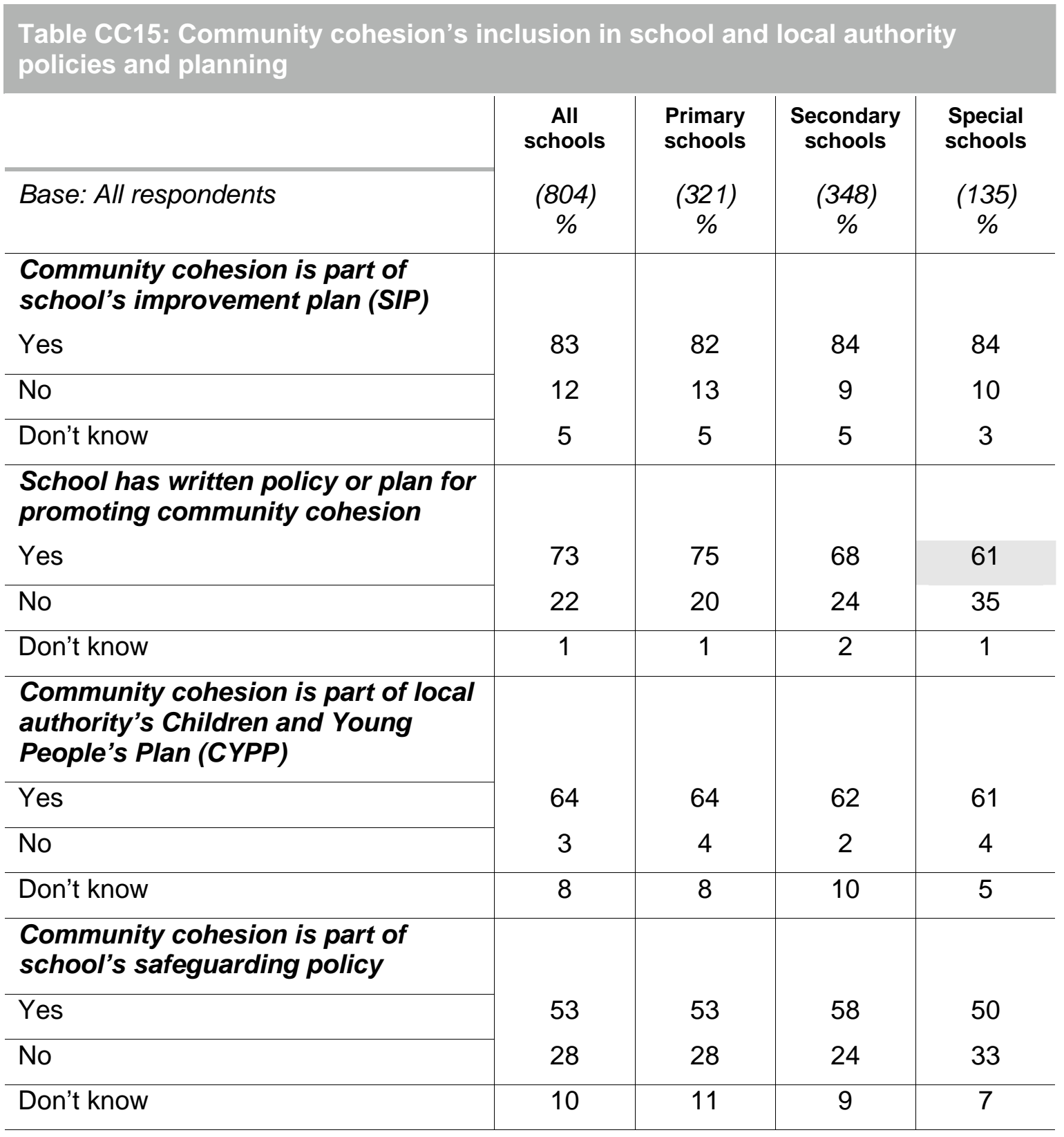

As was the case for within-phase variations in partnership working, much of the variation in the linking of community cohesion to broader strategies relates to how deprived the local area is. However, there is also a link to whether, since the duty became statutory, the school

\footnotetext{
${ }^{81}$ See page 11 of the Department's guidance on the duty to promote community cohesion http://publications.teachernet.gov.uk/eOrderingDownload/DCSF-00598-2007.pdf ${ }^{82}$ http://publications.teachernet.gov.uk/eOrderingDownload/DfES-0027-2004.pdf
} 
feels its understanding has improved or the amount it is doing has increased - a relationship examined in earlier discussion of the key drivers of changes since the duty became statutory.

Within phases:

- Primary schools: Primary schools in the most deprived areas are significantly less likely than those in the least deprived areas to say that promoting community cohesion is part of their school improvement plan ( $77 \%$ versus $94 \%)$ or the local CYPP (52\% versus $71 \%$ ), but significantly more likely to say it is part of their safeguarding policy $(65 \% \text { versus } 46 \%)^{83,84}$. Having a better (a lot + a little) understanding of community cohesion, and doing more (a lot + a little) to promote it, since the introduction of the statutory duty tends to increase the likelihood that primary schools say that community cohesion is a feature of all these policies/plans.

- Secondary schools: Secondary schools in the most deprived areas (77\%) are more likely than those in the least deprived areas (61\%) to have a written policy or plan for promoting community cohesion ${ }^{85}$. Meanwhile, secondary schools in the least deprived areas are twice as likely to say that community cohesion is not part of their safeguarding policy, compared with their counterparts in the most deprived areas (33\% versus $17 \%)^{86}$. Again, having a better (a lot + a little) understanding of community cohesion since the introduction of the statutory duty increases the likelihood that secondary schools will say that community cohesion is a feature of all these policies/plans.

\section{Measuring impact}

\section{Summary}

Almost all schools (91\%) measure the impact of their cohesion-related work through selfevaluation.

Contextual and demographic data is widely used in primary (74\%) and secondary schools (87\%), but rather less so in special schools (50\%).

Ofsted inspections and feedback are widely cited as monitoring tools for secondary (71\%) and special schools (70\%) though less so for primary schools (56\%).

Parent and carer consultations are also used, particularly in secondary schools (67\%).

Ofsted guidance for inspectors ${ }^{87}$ presents its requirements of schools, relating to measuring the impact of their cohesion-related work, in the following terms:

\footnotetext{
${ }^{83}$ Indicative finding: small base sizes for high $(\mathrm{n}=88)$ and low $(\mathrm{n}=68)$ IMD primary schools.

${ }^{84}$ However, it is worth noting that schools in the 'most ethnically diverse' quartile Q4 are markedly more likely than average to say that community cohesion is not part of their safeguarding policy (38\% versus 28\%). [Indicative finding: small base size for pupil fractionalisation Quartile 4 primary schools $(n=93)$.]

${ }^{85}$ Indicative finding: small base sizes for high $(n=83)$ and low $(n=61)$ IMD secondary schools.

${ }^{86}$ Indicative finding: small base sizes for high $(\mathrm{n}=83)$ and low $(\mathrm{n}=61)$ IMD secondary schools.

${ }^{87}$ Inspecting maintained schools' duty to promote community cohesion: guidance for inspectors

http://www.ofsted.gov.uk/Media/Ofsted/Forms-and-guidance2/Education-schools/s5/Community-Cohesion-Guidance-oninspecting.doc
} 


\begin{tabular}{|l|l|}
\hline Key question to ask the school & Minimum expectations \\
\hline What impact are you having? & $\begin{array}{l}\text { The school should be able to demonstrate } \\
\text { the impact of its actions covering faith, } \\
\text { ethnicity and culture, and socio-economic } \\
\text { cohesion. }\end{array}$ \\
& $\begin{array}{l}\text { There should be evidence that the school is } \\
\text { having an impact on its own community. }\end{array}$ \\
\hline
\end{tabular}

In monitoring/reviewing how effective they are in promoting community cohesion, a similar proportion of schools per phase (and the large majority each time) say they're using selfevaluation and improvement planning (see Table CC16).

The use of other sources of information is less frequent and - between phases - more variable. For example, as the darker shading in the table indicates, secondary schools are more likely to be using contextual/demographic data for pupils on the school roll (87\%), consultation with pupils (75\%), and consultation with other members of the local community $(41 \%)$ than primary and special schools. Perhaps this is the case because secondary schools have more resources with which to undertake such time-intensive and organisationally complex activities. Meanwhile, primary schools are markedly less likely than secondary and special schools to be reliant on evidence derived from Ofsted inspection findings and feedback: only $56 \%$ of primary schools do this.

Table CC16: Monitoring school effectiveness in promoting community cohesion (all responses 10\%+)

Which of the following sources of information, if any, have you and your colleagues used to monitor/review how effective your school is in promoting community cohesion?

Base: All respondents

School self-evaluation and improvement planning

Contextual/demographic data for pupils on the school roll (e.g. RAISEonline, PLASC)

Consultation with/surveys of parents and carers

Consultation with/surveys of pupils

Ofsted inspection findings and feedback

Consultation with/surveys of other members of the local community

\begin{tabular}{c|c|c|c}
$\begin{array}{c}\text { All } \\
\text { schools }\end{array}$ & $\begin{array}{c}\text { Primary } \\
\text { schools }\end{array}$ & $\begin{array}{c}\text { Secondary } \\
\text { schools }\end{array}$ & $\begin{array}{c}\text { Special } \\
\text { schools }\end{array}$ \\
$\begin{array}{c}(804) \\
\%\end{array}$ & $\begin{array}{c}(321) \\
\%\end{array}$ & $\begin{array}{c}(348) \\
\%\end{array}$ & $\begin{array}{c}(135) \\
\%\end{array}$ \\
91 & 91 & 92 & 87 \\
75 & 74 & 87 & 50 \\
64 & 63 & 67 & 61 \\
64 & 63 & 75 & 50 \\
59 & 56 & 71 & 70 \\
32 & 30 & 41 & 32 \\
\hline
\end{tabular}


Turning to look at schools by phase:

- Primary schools: Primary schools in the most deprived areas are more likely than average to say they use Ofsted inspection findings and feedback $(68 \%)^{88}$ and consultation with/surveys of local community members (39\%) as sources of monitoring information ${ }^{89}$.

- Secondary schools: Secondary schools in the most deprived areas (97\%) are more likely than those in the least deprived areas (86\%) to be using school self-evaluation and improvement planning as a means of reviewing their effectiveness in promoting community cohesion ${ }^{90}$. Urban (including London) secondary schools are also more frequently using consultation - with pupils, parents and carers, and members of the local community - as a monitoring tool than secondary schools generally ${ }^{91}$.

If we compare the sources of information which schools use to measure impact with those they use to acquire knowledge about different ethnic origins and cultures, different socioeconomic groups and different faiths and religions in their school and the local area it serves, we find that there are some differences. Over nine in ten primary and secondary schools use contextual/demographic data to find out more about different ethnic and cultural groups and different socio-economic groups, as compared with three quarters of primary schools and just under nine in ten secondary schools that use it to measure how effective they are at promoting community cohesion. This indicates greater scope for schools to use information sources with which they are already familiar to measure the impact/effectiveness of their community cohesion-related activity.

\section{Do schools want more training?}

\section{Summary}

Respondents themselves (usually headteachers and deputy headteachers) are the most likely to have received training or continuing professional development on the statutory duty: $74 \%$ have received training.

In three fifths of all schools, senior leadership teams (59\%) have received cohesion training. School governor and teaching staff training has been less widespread: training for these groups has taken place in $50 \%$ and $46 \%$ of schools respectively.

Support staff appear least likely to have received training: this has happened in only $27 \%$ of schools.

Most schools would welcome more training, especially for teaching staff.

Few schools overall (one in eight, or 12\%), but rising to one in six (18\%) special schools ${ }^{92}$, say that no-one has received continuing professional development/training on the statutory duty to promote community cohesion in the last two or three years (see Table CC17).

\footnotetext{
${ }^{88}$ Likewise, primary schools in the ‘highest BME population' quartile Q4 sub-group (66\% versus 56\%).

89 Indicative finding: small base size for high IMD primary schools $(n=88)$.

${ }^{90}$ Indicative finding: small vase sizes for high $(n=83)$ and low $(n=72)$ IMD secondary schools.

${ }^{91}$ Secondary schools in the 'highest BME population' quartile Q4 sub-group (77\%) and in the 'most ethnically diverse' quartile Q4 sub-group (76\%) are also more likely than average to use consultation with/surveys of parents and carers to monitor community cohesion-related effectiveness. [Indicative finding: small base sizes for pupil ethnicity Quartile 4 ( $n=90)$ and fractionalisation Quartile $4(n=88)$ secondary schools.]

${ }_{92}$ This may explain (in part at least) why the research has shown a consistently lower level of activity to promote community cohesion amongst special schools. It is difficult to say, though, whether special schools would evidence a higher level of activity if offered more training opportunities because they may not be seeking out opportunities for training because of their lower level of activity.
} 
However, the broad-brush picture is one where teaching staff, support staff and governors are less likely to have received training compared with respondents themselves ${ }^{93}$ and the wider senior leadership team. The governors in primary schools are more likely than their colleagues working in secondary and special schools to have received training; in special schools, the support staff are much more likely than average to have done so.

Table CC17: Recipients of community cohesion statutory duty continuing professional development - significant differences by phase

\begin{tabular}{l|c|c|c|c}
$\begin{array}{l}\text { In the last two or three years, which of the } \\
\text { following, if any, have received continuing } \\
\text { professional development/training on the } \\
\text { statutory duty on schools to promote } \\
\text { community cohesion? }\end{array}$ & $\begin{array}{c}\text { All } \\
\text { schools }\end{array}$ & $\begin{array}{c}\text { Primary } \\
\text { schools }\end{array}$ & $\begin{array}{c}\text { Secondary } \\
\text { schools }\end{array}$ & $\begin{array}{c}\text { Special } \\
\text { schools }\end{array}$ \\
\cline { 1 - 1 } Base: All respondents & $\begin{array}{c}(804) \\
\%\end{array}$ & $\begin{array}{c}(321) \\
\%\end{array}$ & $\begin{array}{c}(348) \\
\%\end{array}$ & $\begin{array}{c}(135) \\
\%\end{array}$ \\
\cline { 1 - 1 } Respondent personally & 74 & 76 & 64 & 59 \\
\cline { 1 - 1 } Respondent's senior leadership team & 59 & 58 & 65 & 59 \\
\cline { 1 - 1 } Respondent's school's governors & 50 & 52 & 43 & 42 \\
\cline { 1 - 1 } Respondent's school's teaching staff & 46 & 46 & 46 & 44 \\
\cline { 1 - 1 } Respondent's school's support staff & 27 & 26 & 27 & 37 \\
\cline { 1 - 1 } None of these & 12 & 12 & 12 & 18 \\
\hline
\end{tabular}

Turning to look at schools by phase:

- $\quad$ Primary schools: In urban (including London) primary schools, the senior leadership team (64\%), governors (54\%), teaching staff (50\%) and support staff (28\%) are all more likely than average to have received continuing professional development/training on the community cohesion statutory duty. The senior leadership team and governors are also more likely than average to have had training in schools with a better (a lot $+a$ little) understanding of community cohesion, and which are doing more (a lot + a little) to promote community cohesion, since the introduction of the statutory duty.

- Secondary schools: Echoing the latter finding for primary schools, the senior leadership team, teaching staff and governors are all significantly more likely than average to have received duty-related training in secondary schools which say their understanding of community cohesion has improved (a lot + a little), and they are doing more (a lot + a little) to promote community cohesion, since the introduction of the statutory duty.

- Special schools: Again, the senior leadership team, teaching staff and governors are all significantly more likely than average to have received duty-related training in special schools which say their understanding of community cohesion has improved (a lot + a little) since the introduction of the statutory duty. This is true, too, of the senior leadership team and governors in special schools which are now doing more to promote community cohesion in response to the duty's introduction.

\footnotetext{
${ }^{93}$ A breakdown of "you personally" shows that this group of respondents predominantly consists of headteachers and deputy headteachers.
} 
The majority of schools, across all phases, would welcome more (a lot + a little) training, particularly for the teaching staff. Secondary school respondents are more likely than those in special schools to say that colleagues on the teaching staff require more training $(83 \%$ versus $73 \%$ ); otherwise, findings are in line with each other across phases.

Demand for training across primary and secondary schools appears similarly strong, despite the differing levels of knowledge and confidence about the duty between phase that we noted earlier.

The perception that teaching staff are more in need of extra training than senior leadership teams mirrors the tendency noted earlier for senior leadership teams to be seen as more knowledgeable than teaching staff about the various cohesion groups in their school and its local area.

\section{Volume of training received}

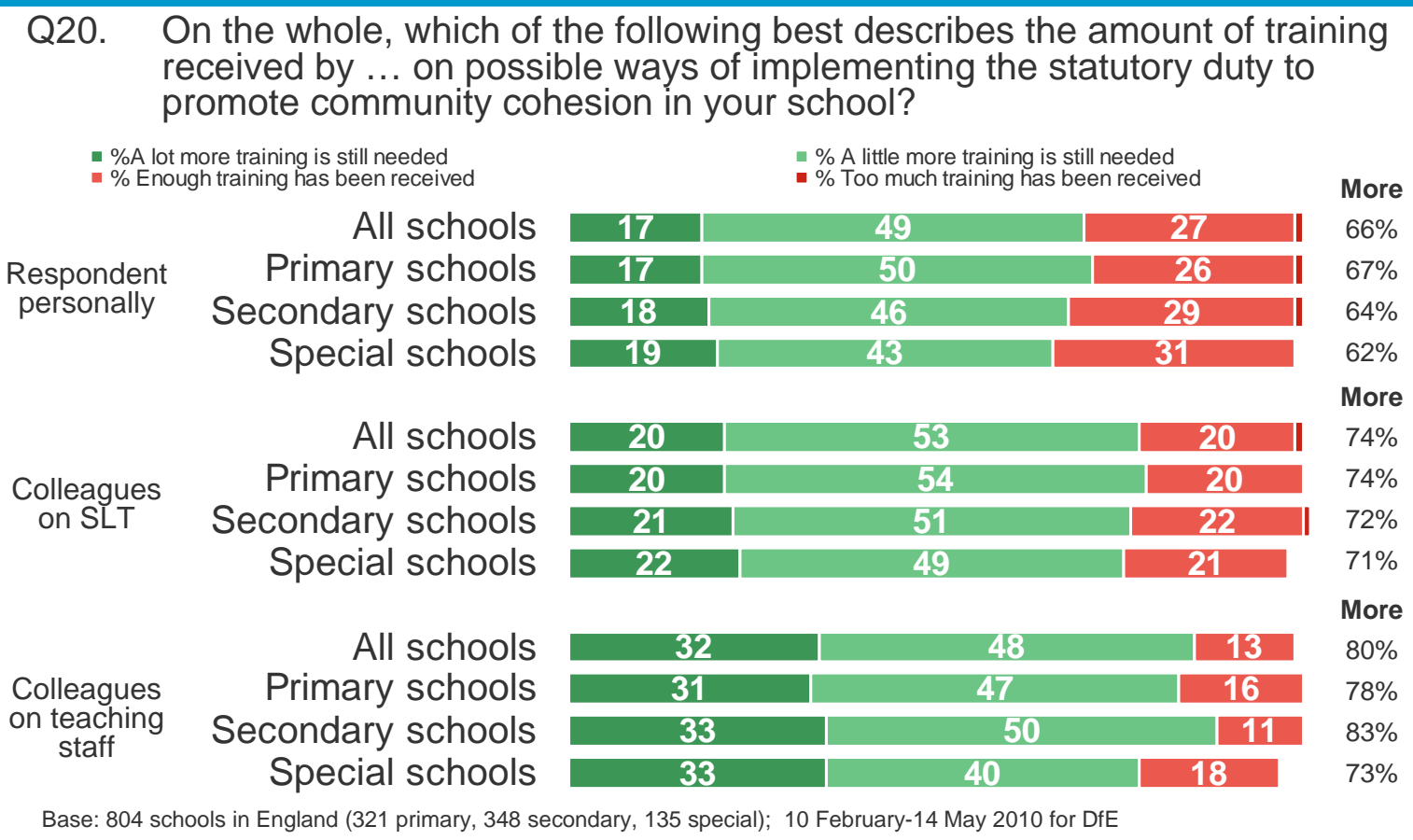

\section{Respondent personally needs more training}

Within the primary school phase, respondents in urban (including London) primary schools are more likely than average to think they personally need more training on ways of implementing the statutory duty to promote community cohesion in their school $69 \%$ versus $67 \%)^{94}$. However, these respondents tend to think they need a little rather than a lot of training. Working in schools with a better (a lot + a little) understanding of community cohesion, and which are doing more (a lot + a little) to promote community cohesion, since the introduction of the statutory duty also increases demand by these respondents for more training (70\% and $71 \%$ respectively, versus $67 \%)$.

Amongst secondary schools, respondents who, since the introduction of the statutory duty, work in schools with a better (a lot + a little) understanding of community cohesion, and

\footnotetext{
${ }^{94}$ As noted above, a breakdown of "you personally" shows that this group of respondents predominantly consists of headteachers and deputy headteachers.
} 
which are doing more (a lot + a little) to promote community cohesion, are again more likely than average to say they personally need more training (66\% and $67 \%$ respectively, versus $64 \%$ ). Respondents in the same schools also say this about senior leadership team colleagues (75\% and $76 \%$ respectively, versus $72 \%$ ), and about colleagues on the teaching staff ( $86 \%$ and $86 \%$ respectively, versus $83 \%)$.

Special school respondents in areas of low deprivation are more likely than average to say they personally need a lot more training on ways of implementing the duty (34\% versus $19 \%)^{95}$. They say the same, too, about colleagues on the senior leadership team (36\% versus $22 \%)^{96}$.

\section{Colleagues on respondent's senior leadership team need more training}

Again, within the primary school phase, respondents in schools with a better (a lot + a little) understanding of community cohesion, and which are doing more (a lot + a little) to promote community cohesion, since the introduction of the statutory duty are more likely than average to say that more training for senior leadership team colleagues is required.

\section{Colleagues on respondent's teaching staff need more training}

Once again, more primary school respondents who work in schools with a better (a lot $+a$ little) understanding of community cohesion, and which are doing more (a lot + a little) to promote community cohesion, since the introduction of the statutory duty feel that more training for colleagues on the teaching staff is required, compared with the average for all primary schools.

\footnotetext{
${ }^{95}$ Indicative finding: small base size for low IMD special schools $(n=33)$.

${ }^{96}$ Indicative finding: small base size for low IMD special schools $(n=33)$.
} 
Main findings: preventing
violent extremism Main findings: preventing
violent extremism (n)

.

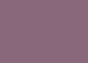
violent extremism (1)

(1) 


\section{Main findings: preventing violent extremism}

\section{Introduction}

Individuals who do not strongly identify with, or feel a sense of belonging to, 'mainstream' society, and feel marginalised by a (perceived) lack of legal, political, religious and/or socioeconomic equality and efficacy, may be vulnerable to radicalisation. This could make them more likely to support or perpetrate violent extremism.

The UK counter-terrorism strategy, CONTEST, was developed in the context of the al Qaeda-influenced but otherwise 'home-grown' terrorism witnessed in London on July 72005. However it also reflects a longer history of radical Irish republican and unionist terrorism, violent animal rights activism, and fascist/far-right/white-supremacist extremism. The PREVENT strategy forms one part of CONTEST. PREVENT's objective is to stop people from becoming radicalised and from turning to violent extremism in order to pursue their social and political ideals.

In June 2008, government guidance for local partners emphasised the importance of working with children and young people, through schools, to build their resilience to violent extremism. In support of this work, Learning together to be safe: A toolkit to help schools contribute to the prevention of violent extremism ${ }^{97}$ sets out advice and guidance for schools in extending and enhancing their existing work (including that related to the duty to promote community cohesion) to encompass and realise the five PREVENT strategy objectives ${ }^{98}$. In a school context, the toolkit states that these are to:

1. understand how an extremist narrative which can lead to harm can be challenged by staff in schools; and model to pupils how diverse views can be heard, analysed and challenged in a way which values freedom of speech and freedom from harm

2. understand how to prevent harm to pupils by individuals, groups or others who promote violent extremism, and manage risks within the school

3. understand how to support individuals who are vulnerable through strategies to support, challenge and protect

4. increase the resilience of pupils and of school communities through helping pupils acquire skills and knowledge to challenge extremist views, and promoting an ethos and values that promotes respect for others

5. use teaching styles and curriculum opportunities which allow grievances to be aired, explored and demonstrate the role of conflict resolution and active citizenship

At the time this research project was commissioned (October 2009), there was little robust evidence of the extent to which schools were aware of and had engaged with the PREVENT strategy, and the nature of any related activity they may be undertaking. The survey therefore provided an opportunity to establish baseline measures on:

\footnotetext{
${ }^{97}$ DEPARTMENT FOR CHILDREN, SCHOOLS AND FAMILIES (2008). Learning together to be safe: A toolkit to help schools contribute to the prevention of violent extremism. DCSF-00804-2008BKT-EN. London: DCSF.

${ }_{98}$ http://www.idea.gov.uk/idk/core/page.do?pageld $=7946870$
} 
- Schools' awareness of their role in preventing violent extremism, and their understanding of that role;

- Ways in which schools are working to build their pupils' resilience to violent extremism;

- Sources of information and support about preventing violent extremism (both actual and sought), and the adequacy of information received; and

- $\quad$ Professional development/training received, and the adequacy of that training.

An over-arching objective was to see whether schools regard PREVENT-related work as a universal responsibility, and not just for those serving particular types of community.

\section{Awareness and understanding of policy on schools' role in preventing violent extremism}

\section{Summary}

Schools' awareness of PREVENT is lower than their awareness of the statutory duty to promote community cohesion, perhaps reflecting the fact there is no statutory duty to engage in PREVENT-related work and the relatively recent publication of Department guidance. Half (50\%) say they know a fair amount or more about the policy compared with $95 \%$ claiming at least a fair amount of knowledge about the statutory duty.

Awareness is considerably higher in secondary schools ( $67 \%$ know a fair amount or more) than in primary or special schools ( $47 \%$ and $54 \%)$.

Faith-status primary schools are more aware of PREVENT than non-faith primary schools (54\% versus $43 \%$ ); no such difference exists amongst secondary or special schools.

Schools appear less confident in their understanding of the PREVENT strategy than they are about the statutory duty to promote community cohesion ( $48 \%$ are fairly confident or better about their understanding of PREVENT, compared with $93 \%$ saying they are fairly confident or better about their understanding of the community cohesion duty). Confidence appears to be linked to the amount of training received.

Secondary school knowledge of and confidence about PREVENT is higher in more deprived areas and urban centres, particularly London. Schools with an ethnically diverse school roll or a large proportion of BME pupils are likely to know more and feel more confident.

Almost all schools that know a great deal about PREVENT also say they know a great deal about the statutory duty to promote community cohesion. However, only a small proportion of the schools that say they know a great deal about the statutory duty also say they know a great deal about PREVENT.

Unlike the promotion of community cohesion, schools do not have a statutory duty to engage in PREVENT-related work. Moreover, at the time this research was conducted (spring 2010), the Learning together to be safe guidance for schools, encouraging this engagement, was a relatively recent publication.

Perhaps unsurprisingly, schools' reported awareness of the policy relating to their role in preventing violent extremism is markedly lower than that noted earlier for the statutory duty to promote community cohesion. At a national level, $50 \%$ of all schools say they know a fair amount or more about the policy, but with the emphasis on a fair amount (34\%) rather than a great deal (16\%). However, this headline figure masks considerable disparity by phase in 
reported levels of awareness: the majority of secondary schools (67\%) say they know at least a fair amount or more compared with around half each of primary schools (47\%) and special schools (54\%). It is worth noting, though, that no differences emerge by phase (at around 1 in 6 each) in the proportion saying they know a great deal about the policy.

Nine in ten schools (89\%) that know a great deal about PREVENT also say they know a great deal about the statutory duty to promote community cohesion. However, schools that say they know a great deal about the statutory duty are split roughly equally between those that know a great deal about PREVENT (30\%), those that know a fair amount (36\%) and those that know not very much or nothing at all (33\%).

\section{Knowledge of policy: schools' role in preventing violent extremism}

Q1. Before today, how much, if anything, would you say you knew about each of the following education policies?

Schools' role in preventing violent extremism

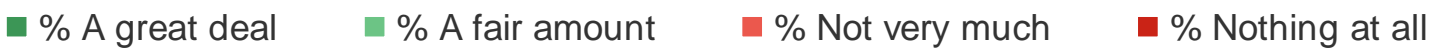

\begin{tabular}{|c|c|c|c|c|}
\hline All schools & 16 & 34 & 41 & $6 *$ \\
\hline Primary school & 16 & 31 & 44 & 6 \\
\hline Secondary schools & 17 & 50 & 29 & 3 \\
\hline Special schools & 15 & 39 & 34 & 9 \\
\hline
\end{tabular}

\% Fair amount or more

$\%$ Not very much or less

\begin{tabular}{r|c|c|} 
All schools & 50 & \multicolumn{2}{|c}{47} \\
Primary school & 47 & 50 \\
\hline Secondary schools & 67 & 31 \\
Special schools & 54 & 43
\end{tabular}

Base: 804 schools in England (321 primary, 348 secondary, 135 special); 10 February-14 May 2010 for DfE

Within phases, some key differences in patterns of response emerge:

- Primary schools: Faith-status primary schools are much more likely than their nonfaith counterparts to say they know a fair amount or more about the PREVENT-related schools policy (54\% versus $43 \%$ ). (No similar difference emerges amongst secondary or special schools.) In addition, primary schools which regard their role in preventing violent extremism as important (very + fairly) are twice as likely as those saying it is not important (not very important + not at all important) to know a fair amount or more about the policy (55\% versus $27 \%)^{99,100}$.

- Secondary schools: Secondary schools in the most deprived areas are three times more likely than those in the least deprived areas to say they know a great deal about

\footnotetext{
99 Indicative finding: small base size for primary schools describing role in preventing violent extremism as not important $(n=59)$.

${ }^{100}$ Similarly, secondary schools which describe this role as important are markedly more likely than those describing it as not important to say they know a fair amount or more about the policy ( $72 \%$ versus $40 \%)$. [Indicative finding: small base size for secondary schools describing role in preventing violent extremism as not important $(n=46)$.] The same pattern also emerges for special schools ( $64 \%$ of those which say the role is important versus $38 \%$ of those which say it is not important). [Indicative finding: small base size for special schools describing role in preventing violent extremism as important $(n=80)$ and not important $(n=46)$.]
} 
the policy relating to their role in preventing violent extremism (25\% versus $8 \%)^{101}$. Schools in London (32\%) are also significantly more likely than non-London urban $(16 \%)$ and rural, town and fringe (12\%) schools to say this ${ }^{102}$. In addition, secondary schools in the 'highest BME population' quartile Q4 (83\%), and those in the 'most ethnically diverse' quartile Q4 (82\%), are more likely than average (67\%) to say they know a fair amount or more about the policy ${ }^{103,104}$.

- Special schools: Echoing the finding for secondary schools, special schools in the 'highest BME population' quartile Q4 (24\%) are more likely than average (15\%) to say they know a great deal about the policy relating to their role in preventing violent extremism ${ }^{105}$.

In line with findings about awareness of the policy relating to their role in preventing violent extremism, schools' confidence in their understanding of the policy is lower than that expressed for community cohesion policy. Just under half of all schools (48\%) say they are fairly confident or better in their understanding; again, though, the tendency is to be fairly $(34 \%)$ rather than very (14\%) confident. As with awareness, by phase, secondary schools $(60 \%)$ more frequently express confidence in their understanding of the policy than primary $(46 \%)$ and special (50\%) schools. Primary and (in particular) special schools are significantly more likely than secondary schools to say they are not at all confident about their understanding of the policy ( $9 \%$ and $12 \%$ versus $5 \%$ respectively). As is discussed below, these patterns in response appear to be closely related to the adequacy of information and training which different types of school say they have received in support of the PREVENT strategy.

\section{Understanding of policy: schools' role in preventing violent extremism}

Q2. And how confident, if at all, would you say you feel about your understanding of each of the following education policies?

Schools' role in preventing violent extremism

घ \%ery confident $\quad \%$ Fairly confident $\quad \%$ Not very confident $\quad \%$ Not at all confident

\begin{tabular}{|c|c|c|c|c|}
\hline All schools & 14 & 34 & 39 & 9 \\
\hline Primary school & 13 & 33 & 41 & 9 \\
\hline Secondary schools & 17 & \multicolumn{2}{|c|}{44} & \\
\hline Special schools & 17 & 33 & 33 & 12 \\
\hline — Fairly confident or better & \multicolumn{4}{|c|}{ - \% Not very confident or wors } \\
\hline All schools & \multicolumn{2}{|r|}{48} & 48 & \\
\hline Primary school & \multicolumn{2}{|c|}{46} & 50 & \\
\hline Secondary schools & \multirow{2}{*}{\multicolumn{2}{|c|}{60}} & \multicolumn{2}{|c|}{37} \\
\hline Special schools & & & 45 & \\
\hline
\end{tabular}

Base: 804 schools in England (321 primary, 348 secondary, 135 special); 10 February-14 May 2010 for DfE

\footnotetext{
101 Indicative finding: small base size for high IMD $(n=83)$ and low IMD $(n=72)$ secondary schools.

102 Indicative finding: small base sizes for London $(n=48)$ and rural, town and fringe $(n=53)$ secondary schools.

${ }^{103}$ Indicative finding: small base sizes for pupil ethnicity Quartile $4(n=90)$ and fractionalisation Quartile 4 ( $\left.n=88\right)$ secondary schools.

${ }^{104}$ Please note that the high degree of overlap between several of the sub-groups described here (and elsewhere in this report) should be borne in mind when interpreting these findings.

${ }^{105}$ Indicative finding: small base size for pupil ethnicity Quartile $4(n=31)$ special schools.
} 
Again, some key differences in patterns of response emerge by phase:

- $\quad$ Primary schools: Those which regard schools' role in preventing violent extremism as important are nearly three times more likely than those regarding it as not important to say they are fairly confident or better about their understanding of the policy (56\% versus $20 \%)^{106,107}$.

- Secondary schools: Secondary schools in the most deprived areas $(27 \%)^{108}$, and those in London (32\%) ${ }^{109}$ are more likely than average (17\%) to say they are very confident about their understanding of the policy relating to schools' role in preventing violent extremism. Again, moreover, secondary schools in the 'highest BME population' quartile Q4 (73\%), and those in the 'most ethnically diverse' quartile Q4 (71\%), are more likely than average (60\%) to say they are fairly confident or better about their understanding ${ }^{110}$.

\section{Awareness and understanding of schools' role in preventing violent extremism}

\section{Summary}

Encouragingly, most schools (84\%) say they know at least something about their role in preventing violent extremism, and only a minority (20\%) regard this role as unimportant.

Secondary schools associate "community cohesion" with several other issues much more widely than they associate it with violent extremism or radicalisation. But a sizeable minority of secondary schools do associate the issue of "community cohesion" with violent extremism $(39 \%)$ or radicalisation (34\%) (more than is the case for primary or special schools).

A sizeable minority of schools have no-one with formal, named or lead responsibility for their work in preventing violent extremism (35\% of primary, $35 \%$ of secondary and $44 \%$ of special schools). By contrast, hardly any schools (less than $5 \%$ ) do not have a specific person responsible for their work relating to community cohesion.

At the start of the questionnaire, respondents were asked how much they knew about the policies of PREVENT and the statutory duty to promote community cohesion. Later in the questionnaire, we provided an explanation of PREVENT and asked respondents about schools' knowledge of their role in relation to PREVENT. Schools tended to profess slightly less knowledge in response to the second school-role focused question than to the first policy-based question.

Overall, few schools (14\%) say that - prior to being surveyed - they knew nothing at all about their role in preventing violent extremism, although, by phase, primary (15\%) and special $(13 \%)$ schools are twice as likely as secondary schools (7\%) to say this. At the same time, few schools (11\%) say they know a great deal about the role envisaged for them. While

\footnotetext{
106 Indicative finding: small base size for primary schools describing role in preventing violent extremism as not important $(\mathrm{n}=59)$.

107 Two-thirds of secondary schools (66\%) which describe this role as important say they know a fair amount or more about the policy, compared with $30 \%$ of those which say the role is not important. [Indicative finding: small base size for secondary schools describing role in preventing violent extremism as not important $(n=46)$.] Likewise, special schools which say the role is important are more likely than those which say it is not important to be fairly confident or better about their understanding of the policy (57\% versus $40 \%)$. [Indicative finding: small base size for special schools describing role in preventing violent extremism as important $(n=80)$ and not important $(n=46)$.]

108 Indicative finding: small base size for high IMD ( $n=83)$ and low IMD $(n=72)$ secondary schools.

109 Indicative finding: small base size for London $(n=48)$ secondary schools.

${ }^{110}$ Indicative finding: small base sizes for pupil ethnicity Quartile $4(n=90)$ and fractionalisation Quartile 4 ( $\left.n=88\right)$ secondary schools.
} 
the majority of secondary schools say they know a fair amount about their role in preventing violent extremism (42\%), the majority of primary schools (43\%) and special schools (39\%) know not very much.

\section{Understanding of role in preventing violent extremism}

Q21. Before today, how much, if anything, would you say you knew about schools' role in preventing violent extremism?

- \% A great deal $\quad \because \%$ A fair amount $\quad \because \%$ Not very much $\quad \%$ Nothing at all

\begin{tabular}{|c|c|c|c|c|}
\hline All schools & 11 & 31 & 42 & 14 \\
\hline Primary school & 11 & 28 & 43 & 15 \\
\hline Secondary schools & 15 & 42 & 35 & 7 \\
\hline Special schools & 8 & 33 & 39 & 13 \\
\hline
\end{tabular}

- \% Fair amount or more

\% Not very much or less

\begin{tabular}{|c|c|c|}
\hline All schools & 42 & 55 \\
\hline Primary school & 39 & 58 \\
\hline Secondary schools & 57 & 42 \\
\hline Special schools & 41 & 53 \\
\hline
\end{tabular}

Base: 804 schools in England (321 primary, 348 secondary, 135 special); 10 February-14 May 2010 for DfE

Within phases, the following differences in response emerge:

- Primary schools: Primary schools in areas of high deprivation (52\%) are markedly more likely than those in medium (37\%) and low (30\%) deprivation areas to say they know a fair amount or more about their role in preventing violent extremism ${ }^{111}$. Likewise, primary schools which say the role is an important one are four times more likely than those saying it is not important to know a fair amount or more about their role $(48 \% \text { versus } 12 \%)^{112,113}$.

- Secondary schools: Secondary schools in London $(72 \%)^{114}$ are more likely than average (57\%) to say they know a fair amount or more about their role in preventing violent extremism. This is true, too, of secondary schools in the 'highest BME population' quartile Q4 (80\%), and those in the 'most ethnically diverse' quartile Q4 $(79 \%)^{115}$. Conversely, secondary schools in the 'highest white population' quartiles Q1/2 (50\%), and those in the 'least ethnically diverse' quartiles Q1/2 (50\%), are more

\footnotetext{
${ }^{111}$ Indicative finding: small base sizes for high IMD $(n=88)$ and low IMD $(n=68)$ primary schools.

${ }^{112}$ Indicative finding: small base size for primary schools describing role in preventing violent extremism as not important $(n=59)$.

${ }^{113}$ A similar finding also emerges in the other two phases. Nearly two-thirds of secondary schools (64\%) which describe this role as important say they know a fair amount or more about their role, compared with $22 \%$ of those which say the role is not important. [Indicative finding: small base size for secondary schools describing role in preventing violent extremism as not important $(n=46)$.] Likewise, special schools which say the role is important are more likely than those saying it is not important to know a fair amount or more about their role (58\% versus $22 \%)$. [Indicative finding: small base size for special schools describing role in preventing violent extremism as important $(n=80)$ and not important $(n=46)$.]

${ }^{114}$ Indicative finding: small base size for London $(n=48)$ secondary schools.

${ }^{115}$ Indicative finding: small base sizes for pupil ethnicity Quartile $4(n=90)$ and fractionalisation Quartile $4(n=88)$ secondary schools.
} 
likely than average (42\%) to say they know not very much or nothing at all about their role.

Learning together to be safe notes that, in contributing to the goal of preventing violent extremism, ' ... schools can build on work they already do in ... promoting pupil wellbeing, equalities and community cohesion'. A generally higher level of understanding of their role reported by secondary schools may be reflected, therefore, in their higher than average tendency to associate violent extremism and radicalisation with the term "community cohesion" (see Table VE1). (It remains the case, though, that these are (respectively) the phrase and word least commonly associated with the term "community cohesion" across all phases.)

\begin{tabular}{l|c|c|c|c}
\hline Table VE1: Words or phrases associated with the term "community cohesion" \\
& $\begin{array}{c}\text { All } \\
\text { schools }\end{array}$ & $\begin{array}{c}\text { Primary } \\
\text { schools }\end{array}$ & $\begin{array}{c}\text { Secondary } \\
\text { schools }\end{array}$ & $\begin{array}{c}\text { Special } \\
\text { schools }\end{array}$ \\
\cline { 1 - 1 } Base: All respondents & $(804)$ & $(321)$ & $(348)$ & $(135)$ \\
& $\%$ & $\%$ & $\%$ & $\%$ \\
\cline { 1 - 1 } Violent extremism & 31 & 30 & 39 & 27 \\
\cline { 1 - 1 } Radicalisation & 27 & 26 & 34 & 21 \\
\hline
\end{tabular}

Within phases:

- Primary schools in low deprivation areas $(18 \%)^{116}$ are less likely than average $(30 \%)$ to associate violent extremism with the term "community cohesion". However, those with a fair amount or more knowledge about their role in preventing violent extremism (39\%), which see their role in preventing violent extremism as important (34\%), and are in the 'highest BME population' quartile Q4 (38\%), are all more likely than average to associate violent extremism with "community cohesion" 117 .

- Amongst secondary schools, there is a higher than average (39\%) association of violent extremism with the term "community cohesion" for those located in London $(55 \%)^{118}$, which know a fair amount or more about their role in preventing violent extremism (54\%), which see this role as important (43\%) and are in both the 'highest BME population' quartile Q4 and the 'most ethnically diverse' quartile Q4 (52\% and $53 \%$ respectively $)^{119}$.

- $\quad$ As with violent extremism, primary schools in the 'highest BME population' quartile Q4 (35\%) are more likely than average (26\%) to associate radicalisation with the term "community cohesion". This is true, too, of non-faith primary schools (29\%).

- $\quad$ Also in line with findings for violent extremism, secondary schools in London $(48 \%)^{120}$, which know a fair amount or more about their role in preventing violent

\footnotetext{
${ }^{116}$ Indicative finding: small base size for low IMD $(n=68)$ primary schools.

${ }^{117}$ Likewise, special schools with a fair amount or more knowledge about their role in preventing violent extremism (43\%) and which see their role in preventing violent extremism as important (35\%) are more likely than average to associate violent extremism with "community cohesion". [Indicative finding: small base sizes for special schools which know a fair amount or more about their role $(n=57)$ and describe their role in preventing violent extremism as important $(n=80)$.]

118 Indicative finding: small base size for London $(n=48)$ secondary schools.

119 Indicative finding: small base sizes for pupil ethnicity Quartile $4(n=90)$ and fractionalisation Quartile 4 (n=88) secondary schools.

${ }^{120}$ Indicative finding: small base size for London $(n=48)$ secondary schools.
} 
extremism (48\%), which see this role as important $(37 \%)^{121}$ and are in both the 'highest BME population' quartile Q4 and the 'most ethnically diverse' quartile Q4 (53\% and $55 \%$ respectively) ${ }^{122}$ more frequently associate radicalisation with the term "community cohesion" than average (34\%). Secondary schools in areas of high deprivation (45\%) are also more likely than average to do so.

The majority of schools, at both a national level, and by phase, say that their role in preventing violent extremism is important (very + fairly), with the tendency towards saying it is very important. However, primary $(74 \%)$ and secondary schools (83\%) are significantly more likely than special schools (58\%) to describe the role as an important one; indeed, special schools (12\%) are four times more likely than average (3\%) to say it is not at all important, while around one in four (23\%) describe it as not very important compared with one in six primary $(17 \%)$ and one in ten secondary (11\%) schools.

\section{Importance of role in preventing violent extremism}

Q22. How important, if at all, do you think your school's role is in preventing violent extremism?

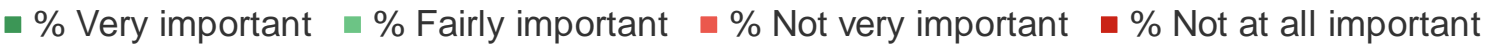

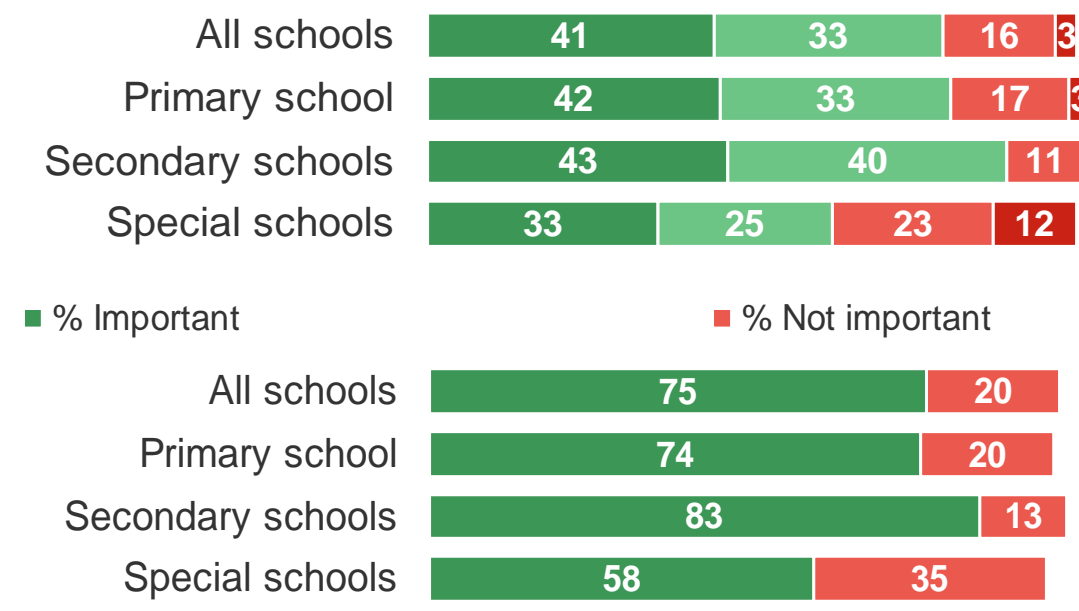

Base: 804 schools in England (321 primary, 348 secondary, 135 special); 10 February-14 May 2010 for DfE

Within phases, several differences emerge in how different types of school respond to this question:

- $\quad$ Primary schools: There is a greater than average (20\%) tendency for primary schools in low deprivation areas (33\%), and rural, town and fringe primary schools (30\%) to describe their role in preventing violent extremism as not important ${ }^{123}$. Those which say this are also more likely than average to know not very much or nothing at all about their role (30\%).

\footnotetext{
${ }^{121}$ Likewise special schools, where $35 \%$ which regard their role in preventing violent extremism as important associate radicalisation with community cohesion, compared with $21 \%$ on average. [Indicative finding: small base size for special schools which describe their role in preventing violent extremism as important $(n=80)$.]

${ }^{122}$ Indicative finding: small base sizes for pupil ethnicity Quartile $4(n=90)$ and fractionalisation Quartile $4(n=88)$ secondary schools.

${ }^{123}$ Indicative finding: small bases sizes for low IMD primary schools $(n=68)$ and rural, town and fringe primary schools $(n=53)$.
} 
- Secondary schools: Likewise, secondary schools in low deprivation areas are twice as likely as average $(13 \%)$ to describe their role in preventing violent extremism as not important $(25 \%)^{124}$, as are those which know not very much or nothing at all about the role (25\%). Being in the 'highest BME population' quartile Q4 and the 'most ethnically diverse' quartile Q4 (93\% and 95\% respectively) increases the likelihood that secondary schools will describe their role as important ${ }^{125}$, compared with the average (83\%).

- Special schools: Those which know a fair amount or more about their role in preventing violent extremism are considerably more likely than average (81\% versus $58 \%)$ to say the role is important ${ }^{126}$.

Another possible measure of the importance which schools attach to their role in preventing violent extremism involves examining whether the school has anyone who has formal, named or lead responsibility for the school's PREVENT work. As Table VE2 shows, only 1 in 20 or fewer say that no-one has this specific responsibility for community cohesion. When it comes to preventing violent extremism, this rises to more than 1 in 3 respondents per phase.

Table VE2: Formal/named/lead responsibility for work related to promoting community cohesion and preventing violent extremism

\begin{tabular}{|c|c|c|c|}
\hline & $\begin{array}{l}\text { Primary } \\
\text { schools }\end{array}$ & $\begin{array}{l}\text { Secondary } \\
\text { schools }\end{array}$ & $\begin{array}{l}\text { Special } \\
\text { schools }\end{array}$ \\
\hline Base: All respondents & $\begin{array}{c}(321) \\
\%\end{array}$ & $\begin{array}{c}(348) \\
\%\end{array}$ & $\begin{array}{c}(135) \\
\%\end{array}$ \\
\hline \multicolumn{4}{|l|}{ Community cohesion } \\
\hline Headteacher has this responsibility & 68 & 17 & 48 \\
\hline Deputy headteacher has this responsibility & 12 & 54 & 23 \\
\hline Other member of staff has this responsibility & 15 & 22 & 21 \\
\hline No-one has this responsibility & 3 & 3 & 5 \\
\hline \multicolumn{4}{|l|}{ Violent extremism } \\
\hline Headteacher has this responsibility & 49 & 21 & 29 \\
\hline Deputy headteacher has this responsibility & 3 & 23 & 10 \\
\hline Other member of staff has this responsibility & 5 & 6 & 9 \\
\hline No-one has this responsibility & 35 & 35 & 44 \\
\hline
\end{tabular}

\footnotetext{
${ }^{124}$ Indicative finding: small base size for low IMD secondary schools $(n=72)$.

${ }^{125}$ Indicative finding: small base sizes for pupil ethnicity Quartile $4(n=90)$ and fractionalisation Quartile 4 ( $\left.n=88\right)$ secondary schools.

${ }^{126}$ Indicative finding: small base size for special schools which describe their role in preventing violent extremism as important $(n=80)$.
} 


\title{
How are schools building their pupils' resilience to violent extremism?
}

\author{
Summary \\ Schools most widely say that they build pupils' resilience to violent extremism through their \\ ethos and values (75\%), internet safety policies or processes $(67 \%)$ and through the pastoral \\ curriculum or PSHE (67\%). \\ Only half (49\%) of schools use the curriculum to build resistance to violent extremism. By \\ contrast, almost all (94\%) use the curriculum to promote community cohesion.
}

As Table VE3 shows, a feature common to all three types of school is a greater emphasis on building pupils' resilience via the pastoral and safeguarding side of schools' work than on work through the taught curriculum. Earlier we noted that almost all schools said they used the curriculum to promote community cohesion. By contrast, rather fewer use it to build resilience to violent extremism and it appears further down the ranked list of activities.

Given the generally lower importance placed by special schools on their role in preventing violent extremism, it is not surprising to find that twice as many as schools on average say we are not building the resilience of our pupils towards violent extremism (20\% versus $11 \%)$. Where schools say that they are trying to do this, the broad-brush picture is one where secondary schools much more frequently say they're undertaking a range of activities than special schools, and - in several cases - primary schools as well. To this extent, primary and secondary schools are significantly more likely than special schools to say they are building pupils' resilience to violent extremism via the school's ethos and values, assemblies and safeguarding policies and processes. Meanwhile, compared with both primary and special schools, secondary schools more often say they are using internet safety policies and processes, the pastoral curriculum/PSHE and curriculum subjects to build resilience. 
Table VE3: Resilience-building activities for pupils - significant differences by phase

\begin{tabular}{|c|c|c|c|c|}
\hline $\begin{array}{l}\text { In which of the following ways, if any, is } \\
\text { your school building the resilience of your } \\
\text { pupils to violent extremism? }\end{array}$ & $\begin{array}{c}\text { All } \\
\text { schools }\end{array}$ & $\begin{array}{l}\text { Primary } \\
\text { schools }\end{array}$ & $\begin{array}{l}\text { Secondary } \\
\text { schools }\end{array}$ & $\begin{array}{l}\text { Special } \\
\text { schools }\end{array}$ \\
\hline Base: All respondents & $\begin{array}{c}(804) \\
\%\end{array}$ & $\begin{array}{c}(321) \\
\%\end{array}$ & $\begin{array}{c}(348) \\
\%\end{array}$ & $\begin{array}{c}(135) \\
\%\end{array}$ \\
\hline Through the school's ethos and values & 75 & 76 & 76 & 60 \\
\hline Internet safety policy and/or processes & 67 & 66 & 75 & 62 \\
\hline $\begin{array}{l}\text { Through the pastoral curriculum or } \\
\text { PSHE }\end{array}$ & 67 & 66 & 74 & 55 \\
\hline Assemblies & 64 & 65 & 64 & 48 \\
\hline Safeguarding policy and/or processes & 62 & 62 & 64 & 55 \\
\hline Through curriculum subjects & 49 & 47 & 60 & 43 \\
\hline $\begin{array}{l}\text { Risk management policy and/or } \\
\text { processes }\end{array}$ & 46 & 46 & 44 & 44 \\
\hline $\begin{array}{l}\text { Through one-off enrichment activities } \\
\text { (e.g. a theatre-in-education } \\
\text { performance) }\end{array}$ & 38 & 37 & 44 & 35 \\
\hline $\begin{array}{l}\text { We are not building the resilience of } \\
\text { our pupils towards violent extremism }\end{array}$ & 11 & 11 & 9 & 20 \\
\hline
\end{tabular}

Turning to look at individual phases:

- $\quad$ Primary schools: As might be expected, primary schools with little or no knowledge of schools' role in preventing violent extremism (17\%), and that say the role is not important $(23 \%)^{127}$ are more likely than average $(11 \%)$ to say they are not building the resilience of pupils towards violent extremism. Conversely, those which say they know a fair amount or more about the role, and regard it as important, are markedly more likely than average to say they are undertaking each of the resilience-building activities suggested.

In almost all cases, this is also the case for urban (including London) primary schools. For example, urban primary schools are more likely than average to be using the school's ethos and values (79\% versus $76 \%)$ and the pastoral curriculum/PSHE $(72 \%$ versus 66\%) to help build their pupils' resilience.

- Secondary schools: Again, secondary schools with little or no knowledge of schools' role in preventing violent extremism (14\%), and that say the role is not important $(19 \%)^{128}$ are more likely than average $(9 \%)$ to say they are not building the resilience of pupils towards violent extremism. This finding applies, too, to schools in the 'highest white population' quartiles Q1/2 (13\%).

\footnotetext{
${ }^{127}$ Indicative finding: small base size for primary schools describing role in preventing violent extremism as not important $(\mathrm{n}=59)$.

${ }^{128}$ Indicative finding: small base size for secondary schools describing role in preventing violent extremism as not important $(n=46)$.
} 
London secondary schools (in particular) and (more generally) urban (including London) secondary schools are, compared with rural, town and fringe schools, much more likely to say they are undertaking most of the resilience-building activities suggested. For example, $91 \%$ of London secondary schools, and $77 \%$ of urban (including London) schools, say they are using the school's ethos and values in their PREVENT-related research, compared with $69 \%$ of rural, town and fringe secondary schools. It is also worth noting that secondary schools in areas with high (69\%) and medium (67\%) levels of deprivation are more likely than those in (51\%) the least deprived areas to be making a link between building pupils' resilience and safeguarding policy and/or processes ${ }^{129}$.

In building pupils' resilience, there is also a higher than average use by secondary schools in the 'highest BME population' quartile Q4 and the 'most ethnically diverse' quartile Q $4{ }^{130}$ of safeguarding policy and/or processes (81\% and $80 \%$ respectively, versus $64 \%$ ), school ethos and values (85\% and $86 \%$ respectively, versus $76 \%$ ) and the pastoral curriculum/PSHE (84\% and $84 \%$ respectively, versus $74 \%)$.

- Special schools: Consistent with findings for other phases, special schools with little or no knowledge of schools' role in preventing violent extremism (27\%), and that say the role is not important $(41 \%)^{131}$, are more likely than average $(20 \%)$ to say they are not building the resilience of pupils towards violent extremism. In keeping with this, those that say they know a fair amount or more about the role, and regard it as important, are markedly more likely than average to say they are undertaking each of the resilience-building activities suggested.

In special schools in the most deprived areas, there is markedly higher than average use of the pastoral curriculum/PSHE (75\% versus 55\%), curriculum subjects (57\% versus $43 \%$ ) and one-off enrichment activities (55\% versus $35 \%$ ) to help to build pupils' resilience.

\footnotetext{
${ }^{129}$ Indicative finding: small base size for high IMD ( $\left.n=83\right)$ and low IMD $(n=72)$ secondary schools.

130 Indicative finding: small base sizes for pupil ethnicity Quartile $4(n=90)$ and fractionalisation Quartile 4 ( $n=88)$ secondary schools.

${ }^{131}$ Indicative finding: small base sizes for special schools which know not very much/nothing at all about role in preventing violent extremism $(n=57)$ and describe role in preventing violent extremism as not important $(n=46)$.
} 


\section{Information and support: how much and what have schools received?}

\section{Summary}

Three quarters of schools (74\%) have obtained information about preventing violent extremism. Secondary schools are slightly more likely to have obtained information than primary or special schools.

The three most widely used information sources are: DfE guidance, local authority guidance and the media (used by $48 \%, 32 \%$ and $30 \%$ respectively). The police are another important source of information for secondary schools - almost half (48\%) have used them.

Secondary schools appear to be accessing more information than primary or special schools: a larger proportion of secondary schools has used almost every given source.

Primary schools in areas of low deprivation are particularly likely not to have accessed any information.

Secondary schools in urban areas (especially London) and those with the highest BME populations or the most ethnically diverse school rolls are particularly likely to have used each of the information sources.

Most schools (70\%) would like a little or a lot more information about preventing violent extremism (though the proportion of special schools that want more information $(60 \%)$ is smaller). Preferred sources of information are the local authority, DfE and the police.

Nationally, around one in four schools (26\%) say they have obtained no information about preventing violent extremism, but with primary (28\%) and special (26\%) schools significantly more likely to say this than secondary schools (17\%). Looking again at the national picture, the top 3 reported sources are published DfE guidance, published LA guidance and the media.

By phase, however, there are variations in this picture, with the police moving into the top 3 sources of information and support for secondary schools. As Table VE4 shows, a sizeable proportion of schools (i.e. more than half of primary and special schools, and around two in five secondary schools) appears to be unaware of the Learning together to be safe toolkit. More generally, the broad-brush picture is again one in which secondary schools are, in many cases, more likely than primary or special schools to say they've obtained information or support from a particular source. Here, it may be that a more detailed understanding of their role in preventing violent extremism is driving secondary schools to seek information and support for their work. They may also have a more developed sense of the types of support they should be seeking and, in turn, where they might source it from. 
Table VE4: Sources of information and or/support

Where have you obtained information and/or support about preventing violent extremism?

\begin{tabular}{|c|c|c|c|c|}
\hline Base: All respondents & $\begin{array}{c}(804) \\
\%\end{array}$ & $\begin{array}{c}(321) \\
\%\end{array}$ & $\begin{array}{c}(348) \\
\%\end{array}$ & $\begin{array}{c}(135) \\
\%\end{array}$ \\
\hline Published DfE guidance & 48 & 46 & 58 & 43 \\
\hline Published local authority guidance & 32 & 30 & 40 & 35 \\
\hline $\begin{array}{l}\text { The media (including Teachers' TV, } \\
\text { TES) }\end{array}$ & 30 & 29 & 33 & 40 \\
\hline The police & 26 & 22 & 48 & 21 \\
\hline $\begin{array}{l}\text { Teaching unions, professional bodies, } \\
\text { subject associations and/or national } \\
\text { organisations in the education sector }\end{array}$ & 24 & 25 & 22 & 24 \\
\hline Local authority advisory staff & 22 & 21 & 26 & 15 \\
\hline Senior leadership team & 21 & 19 & 36 & 20 \\
\hline Colleagues in other schools & 18 & 18 & 16 & 16 \\
\hline Training providers & 15 & 15 & 17 & 9 \\
\hline Other colleagues in my school & 14 & 13 & 22 & 10 \\
\hline Governors & 11 & 11 & 8 & 5 \\
\hline $\begin{array}{l}\text { Local community groups and/or local } \\
\text { charities or voluntary organisations }\end{array}$ & 8 & 7 & 16 & 9 \\
\hline Local religious leaders & 7 & 6 & 14 & 7 \\
\hline $\begin{array}{l}\text { National charities or voluntary } \\
\text { organisations }\end{array}$ & 7 & 6 & 12 & 7 \\
\hline Other local partners & * & * & 1 & - \\
\hline $\begin{array}{l}\text { We have not obtained information } \\
\text { about preventing violent extremism }\end{array}$ & 26 & 28 & 17 & 26 \\
\hline
\end{tabular}

Looking at schools by phase:

- $\quad$ Primary schools: Primary schools in low deprivation areas (36\%) are twice as likely as those in high deprivation areas (18\%) to say they have not obtained information about preventing violent extremism. Knowing not very much/nothing at all about schools' role in preventing violent extremism (40\% versus an average of $28 \%$ ), and regarding the role as not important (48\%), also increase the likelihood with which primary schools say they have not obtained information ${ }^{132}$.

Urban (including London) primary schools tend to be more likely than average to have

\footnotetext{
${ }^{132}$ On the other hand, and reflecting a consistent pattern in the dataset, primary schools (and likewise secondary and special schools) which say they know a fair amount or more about schools' role in preventing violent extremism, and regard it as important, are markedly more likely than average to say they have obtained information/support from each of the potential sources listed in the questionnaire. Respondents were free to mention additional sources of information/support if they wished: fewer than one in twenty did so.
} 
sought information from most of the potential sources suggested. For example, over one in four $(26 \%)$ mention the police (rising to over one in three (34\%) London primary schools ${ }^{133}$ ), compared with one in five primary schools on average.

Meanwhile, primary schools in the 'highest white population' quartiles Q1/2 are less likely than average to say they have obtained information/support from published DfE guidance (38\% versus $46 \%$ ) or the police (15\% versus $22 \%)$.

- Secondary schools: The findings here indicate that the PREVENT strategy is receiving more of an urban focus, with $28 \%$ of rural, town and fringe schools saying they have not obtained any information/support about preventing violent extremism, compared with an average for all secondary schools of $17 \%{ }^{134}$. Urban (including London) schools, and London schools in particular ${ }^{135}$, are all more likely than average to have received information/support from most of the potential sources listed. For example, London secondary schools are three times more likely than secondary schools generally to have obtained information/support from local religious leaders (45\% versus $14 \%$ ), and twice as likely than average (40\% versus $16 \%)$ to have used local community groups and/or local charities or voluntary organisations as a source of information/support.

As might be expected, therefore, secondary schools in the 'highest BME population' quartile Q4 and the 'most ethnically diverse' quartile Q4 ${ }^{136}$ are also more likely than average to have obtained information/support from most of the potential sources suggested (see Table VE5).

\begin{tabular}{|c|c|c|c|c|c|}
\hline $\begin{array}{l}\text { Where have you obtained } \\
\text { information and/or support about } \\
\text { preventing violent extremism? }\end{array}$ & $\begin{array}{l}\text { All } \\
\text { secondary } \\
\text { schools }\end{array}$ & $\begin{array}{l}\text { Highest } \\
\text { white } \\
\text { population } \\
\text { quartile } \\
\text { (Q1/2) }\end{array}$ & $\begin{array}{l}\text { Highest } \\
\text { BME } \\
\text { population } \\
\text { quartile } \\
\text { (Q4) }\end{array}$ & $\begin{array}{l}\text { Least } \\
\text { ethnically } \\
\text { fractional- } \\
\text { ised } \\
\text { quartile } \\
\text { (Q1/2) }\end{array}$ & $\begin{array}{l}\text { Most } \\
\text { ethnically } \\
\text { fractional- } \\
\text { ised } \\
\text { quartile } \\
\text { (Q4) }\end{array}$ \\
\hline Base: All respondents & $\begin{array}{c}(348) \\
\%\end{array}$ & $\begin{array}{c}(162) \\
\%\end{array}$ & $\begin{array}{l}(90) \\
\%\end{array}$ & $\begin{array}{c}(168) \\
\%\end{array}$ & $\begin{array}{l}(88) \\
\%\end{array}$ \\
\hline Published DfE guidance & 58 & 50 & 75 & 51 & 75 \\
\hline The police & 48 & 35 & 73 & 35 & 71 \\
\hline $\begin{array}{l}\text { Published local authority } \\
\text { guidance }\end{array}$ & 40 & 31 & 55 & 32 & 54 \\
\hline Training providers & 17 & 15 & 24 & 15 & 25 \\
\hline $\begin{array}{l}\text { Local community groups and/or } \\
\text { local charities or voluntary } \\
\text { organisations }\end{array}$ & 16 & 11 & 31 & 11 & 29 \\
\hline Local religious leaders & 14 & 4 & 38 & 5 & 36 \\
\hline
\end{tabular}

\footnotetext{
133 Indicative finding: small base size for London $(n=35)$ primary schools.

134 Indicative finding: small base size for rural, town and fringe $(n=53)$ secondary schools.

135 Indicative finding: small base size for London $(n=48)$ secondary schools.

${ }^{136}$ Indicative finding: small base sizes for pupil ethnicity Quartile $4(n=90)$ and fractionalisation Quartile 4 ( $\left.n=88\right)$ secondary schools.
} 
In keeping with the relatively low reported levels of understanding about their role in preventing violent extremism, the majority of schools (at both a national level and by phase) say they would like more (a lot + a little) information about the contribution they can make to the PREVENT strategy. Secondary schools are the most likely to say they want more information (77\%), special schools the least likely (60\%). Arguably, the fact that so many schools want more information implies that they consider themselves to have a role to play in preventing violent extremism.

This said, around one in five schools overall (18\%) say they have received enough information, rising to one in four special schools (24\%). Special schools are also significantly more likely than average (13\% versus $8 \%)$ to say they don't know how much information they have received. Taken together, these findings suggest that some special schools are rather uncertain about their role in preventing violent extremism.

\section{Volume of information received}

Q25. Which of the following best describes the amount of information your school has received about its contribution to preventing violent extremism?

- \% We would like a lot more information - \% We have received enough information

$\%$ We would like a little more information $\%$ We have received too much information

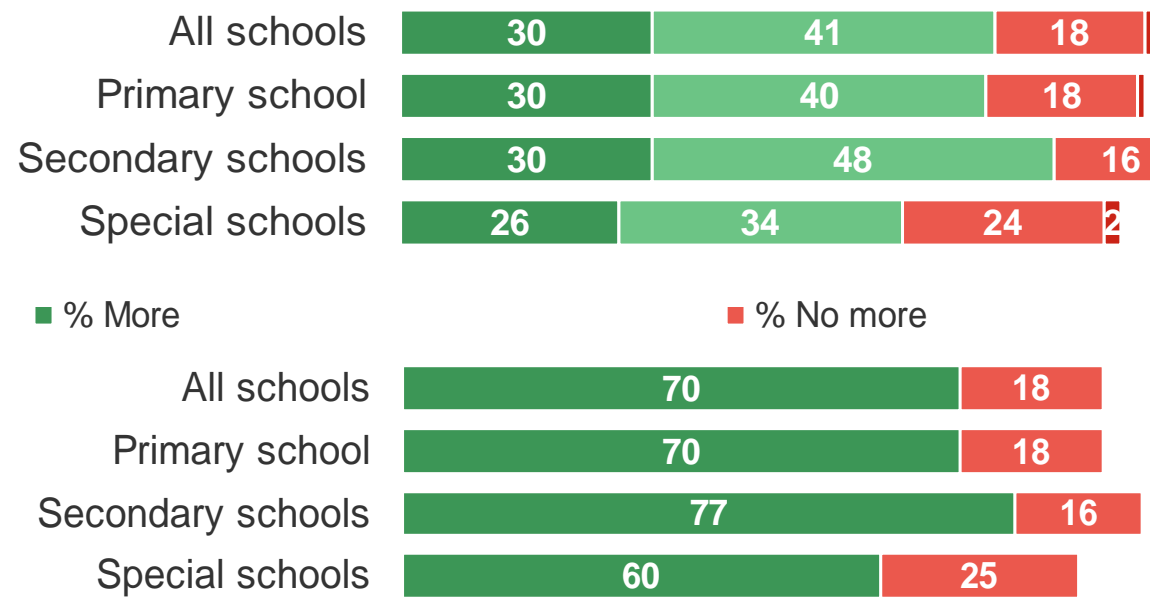

Base: 804 schools in England (321 primary, 348 secondary, 135 special); 10 February-14 May 2010 for DfE

Across all phases, schools which regard their role in preventing violent extremism to be important are more likely than the average for their phase to say they want more (a lot $+a$ little) information (primary schools: $75 \%$ versus $70 \%$; secondary schools: $81 \%$ versus $77 \%$; special schools: $73 \%$ versus $60 \%$ ). Other differences within phases also emerge:

- Primary schools: There is a greater than average (70\%) tendency for urban (including London) primary schools (74\%), and urban (excluding London) primary schools (76\%) in particular, to say they would like more (a lot + a little) information about their role in preventing violent extremism. Perhaps reflecting the greater than average tendency of rural, town and fringe primary schools to describe their role in preventing violent extremism as not important ${ }^{137}$, the same schools are more likely than average to say they have received enough information (28\% versus $18 \%)$. More generally, though, primary schools which know not very much/nothing at all about schools' role in

\footnotetext{
${ }^{137}$ Indicative finding: small bases size for rural, town and fringe primary schools $(n=53)$.
} 
preventing violent extremism are more likely than average to say they would like a lot more information (38\% versus $30 \%$ ). Those that describe the role as important are also more likely than average to say this (34\% versus $30 \%)^{138}$.

- Special schools: In a departure from the general trend in responses as described in this report, special schools in the 'highest white population' quartiles Q1/2 (35\%) and the 'least ethnically diverse' quartiles Q1/2 (36\%) are more likely than the average for their phase (26\%) to say they would like a lot more information ${ }^{139}$.

In developing their approaches to building pupils' resilience to violent extremism, schools at both a national level (68\%) and by phase most frequently say they would like local authorities to provide more help (see Table VE6). In a pattern of response seen elsewhere in the survey findings, primary and - especially - secondary schools are often more likely than special schools to want additional support from each of the sources suggested.

Table VE6: Additional help in developing approaches - significant differences by phase

And which of the following organisations, if any would you like to provide more help in developing your school's approaches to building pupils' resilience to violent extremism?

Base: All respondents

Your local authority

The DfE

The police

Local community groups and/or local charities or voluntary organisation

Local religious leaders

Teaching unions, professional bodies, subject associations and/or national organisations in the education sector

National charities or voluntary organisations

\begin{tabular}{|c|c|c|c|}
$\begin{array}{c}\text { All } \\
\text { schools }\end{array}$ & $\begin{array}{c}\text { Primary } \\
\text { schools }\end{array}$ & $\begin{array}{c}\text { Secondary } \\
\text { schools }\end{array}$ & $\begin{array}{c}\text { Special } \\
\text { schools }\end{array}$ \\
$\begin{array}{c}(804) \\
\%\end{array}$ & $\begin{array}{c}(321) \\
\%\end{array}$ & $\begin{array}{c}(348) \\
\%\end{array}$ & $\begin{array}{c}(135) \\
\%\end{array}$ \\
68 & 70 & 63 & 52 \\
53 & 53 & 58 & 46 \\
45 & 45 & 49 & 35 \\
38 & 38 & 41 & 31 \\
37 & 36 & 43 & 34 \\
35 & 36 & 35 & 27 \\
& & & \\
\hline 29 & 30 & 31 & 21 \\
\hline
\end{tabular}

Turning to look at schools by individual phase:

- $\quad$ Primary schools: As Table VE7 below shows, urban (including London) primary schools, and urban (excluding London) primary schools in particular, are more likely than average to want more help in developing their schools' approaches to building pupils' resilience to violent extremism from several of the sources suggested ${ }^{140}$.

\footnotetext{
${ }^{138}$ The same finding emerges for secondary schools which say they know not very much/nothing at all about schools' role in preventing violent extremism: $40 \%$, compared with an average of $30 \%$, would like a lot more information.

${ }_{139}$ Indicative finding: small base sizes for 'highest white population' quartiles Q1/2 $(n=60)$ and 'least ethnically diverse' quartiles Q1/2 ( $n=59)$ special schools.

${ }^{140}$ Primary schools which describe their role in preventing violent extremism as important are also more likely than average to say they want more help from each of these sources, as well as from local community groups and/or local charities or voluntary organisations.
} 
And which of the following organisations, if any would you like to provide more help in developing your school's approaches to building pupils' resilience to violent extremism?

\begin{tabular}{l} 
Base: All respondents \\
\hline Your local authority \\
\hline The DfE \\
\hline The police \\
\hline Local religious leaders \\
\hline
\end{tabular}

\begin{tabular}{c|c|c}
$\begin{array}{c}\text { All primary } \\
\text { schools }\end{array}$ & $\begin{array}{c}\text { Urban } \\
\text { (including } \\
\text { London) } \\
\text { primary } \\
\text { schools }\end{array}$ & $\begin{array}{c}\text { Urban } \\
\text { (excluding } \\
\text { London) } \\
\text { primary } \\
\text { schools }\end{array}$ \\
$(321)$ & $\begin{array}{c}268) \\
\%\end{array}$ & $\begin{array}{c}(233) \\
\%\end{array}$ \\
70 & 70 & 73 \\
53 & 57 & 59 \\
45 & 50 & 50 \\
36 & 40 & 41 \\
\hline
\end{tabular}

Likewise, primary schools in high and medium deprivation areas are more likely than their counterparts in low deprivation areas to be seeking more help from the police (51\% and $48 \%$ respectively, versus 34\%), local religious leaders (49\% and $38 \%$ respectively, versus $18 \%$ ), local community groups and/or local charities or voluntary organisations (41\% and $45 \%$ respectively, versus $21 \%$ ), teaching unions, professional bodies, subject associations and/or national organisations in the education sector (40\% and $39 \%$ respectively, versus $24 \%$ ) and national charities or voluntary organisations (35\% and $32 \%$ respectively, versus $19 \%)^{141}$.

- Secondary schools: Urban secondary schools are more likely than average to say they want more help from local religious leaders (48\% versus 43\%). Amongst London secondary schools, the proportion saying they want more help from local religious leaders rises to $58 \%^{142,143}$.

Moreover, in a similar pattern to that seen amongst primary schools, secondary schools in high and medium deprivation areas are more likely than their counterparts in low deprivation areas to be seeking more help from local religious leaders (51\% and $48 \%$ respectively, versus $22 \%)^{144}$.

- $\quad$ Special schools: The likelihood that special schools say they want more help from a particular source is influenced by whether they consider their role in preventing violent extremism to be important ${ }^{145}$ (see Table VE8). Those that say the role is important are at least twice as likely as those saying it is unimportant to want more help from each of the sources suggested.

\footnotetext{
141 Indicative finding: small bases sizes for high $(n=88)$ and low $(n=68)$ IMD primary schools.

142 Indicative finding: small base size for London secondary schools $(n=48)$.

143 Likewise, to $54 \%$ of secondary schools in the 'highest BME population' quartile Q4 and to 52\% in the 'most ethnically diverse' quartile Q4. [Indicative finding: small base sizes for pupil ethnicity Quartile $4(n=90)$ and fractionalisation Quartile 4 ( $n=88)$ secondary schools.]

${ }^{144}$ Indicative finding: small bases sizes for high $(n=83)$ and low $(n=72)$ IMD secondary schools.

145 Indicative finding: small base sizes for special schools describing role in preventing violent extremism as important ( $\mathrm{n}=80$ ) or not important $(n=46)$.
} 
And which of the following organisations, if any would you like to provide more help in developing your school's approaches to building pupils' resilience to violent extremism?

Base: All respondents

The DfE

The police

Local religious leaders

Local community groups and/or local charities or voluntary organisation

Teaching unions, professional bodies, subject associations and/or national organisations in the education sector

National charities or voluntary organisations

\begin{tabular}{c|c|c}
$\begin{array}{c}\text { All special } \\
\text { schools }\end{array}$ & $\begin{array}{c}\text { Schools' role in } \\
\text { preventing } \\
\text { violent } \\
\text { extremism: } \\
\text { important }\end{array}$ & $\begin{array}{c}\text { Schools' role in } \\
\text { preventing } \\
\text { violent } \\
\text { extremism: not } \\
\text { important }\end{array}$ \\
$\begin{array}{c}(135) \\
\%\end{array}$ & $\begin{array}{c}(80) \\
\%\end{array}$ & $\begin{array}{c}(46) \\
\%\end{array}$ \\
46 & 60 & 26 \\
35 & 47 & 16 \\
34 & 45 & 16 \\
31 & 40 & 17 \\
27 & 33 & 16 \\
& & \\
21 & 28 &
\end{tabular}

\section{Training: who has received it and how much have they received?}

\section{Summary}

In two thirds of schools (65\%), no-one has received continuing professional development or training related to preventing violent extremism in the past year. In secondary schools, this figure is a little lower (58\%) than in primary $(66 \%)$ or special schools $(74 \%)$

Three quarters of schools (74\%) think both they personally, colleagues on their school's senior leadership team and colleagues on the teaching staff need more training related to preventing violent extremism.

For teaching staff, this is less than the proportion of schools saying they need more training about promoting community cohesion (80\%). But there are significantly more schools that want a lot more training for their teaching staff about preventing violent extremism than say the same about community cohesion: $39 \%$ would like a lot more training about preventing violent extremism, compared with $32 \%$ for community cohesion.

Secondary schools in more deprived areas are more likely to want more a lot more training for their staff.

At a national level, two in three schools (65\%) say that no-one from their school (that is, neither the survey respondent, the senior leadership team, governing body, teaching staff nor support staff combined) has received continuing professional development/training on their school's contribution to preventing violent extremism in the last year (see Table VE9). This headline figure masks some differences by phase: albeit still a majority, secondary schools are significantly less likely (58\%) than primary (66\%) and (in particular) special (74\%) schools to say that no-one has received continuing professional development of this nature. 
They are also more likely than other schools to say that the senior leadership team has received PREVENT-related continuing professional development.

\begin{tabular}{|c|c|c|c|c|}
\hline $\begin{array}{l}\text { In the last year, which of the following, if } \\
\text { any, have received continuing professional } \\
\text { development/training on your school's } \\
\text { contribution to preventing violent } \\
\text { extremism? }\end{array}$ & $\begin{array}{c}\text { All } \\
\text { schools }\end{array}$ & $\begin{array}{l}\text { Primary } \\
\text { schools }\end{array}$ & $\begin{array}{l}\text { Secondary } \\
\text { schools }\end{array}$ & $\begin{array}{l}\text { Special } \\
\text { schools }\end{array}$ \\
\hline Base: All respondents & $\begin{array}{c}(804) \\
\%\end{array}$ & $\begin{array}{c}(321) \\
\%\end{array}$ & $\begin{array}{c}(348) \\
\%\end{array}$ & $\begin{array}{c}(135) \\
\%\end{array}$ \\
\hline Respondent personally & 23 & 23 & 25 & 12 \\
\hline Respondent's senior leadership team & 15 & 14 & 22 & 13 \\
\hline Respondent's school's governors & 7 & 7 & 6 & 5 \\
\hline Respondent's school's teaching staff & 6 & 6 & 10 & 6 \\
\hline Respondent's school's support staff & 6 & 6 & 6 & 3 \\
\hline None of these & 65 & 66 & 58 & 74 \\
\hline
\end{tabular}

By phase:

- $\quad$ Primary schools: Primary schools are more likely than average to say no-one has received continuing professional development /training on their school's contribution to preventing violent extremism in the last year if they know not very much/nothing at all about schools' role in preventing violent extremism (80\%) and describe the role as not important $(89 \%)^{146}$.

- Secondary schools: Seven in ten (71\%) rural, town and fringe secondary schools say that no-one has received continuing professional development/training on their school's contribution to preventing violent extremism in the last year, compared with an average of less than six in ten (58\%) for secondary schools as a whole ${ }^{147}$. Likewise, secondary schools which know not very much/nothing at all about schools' role in preventing violent extremism $(81 \%)$ and that describe the role as not important $(88 \%)^{148}$ more frequently say this. Conversely, secondary schools in the 'highest BME population' quartile Q4 (33\%) and the 'most ethnically diverse' quartile Q4 (35\%) ${ }^{149}$ are around half as likely to say that no-one has received any training as the average for all secondary schools.

- Special schools: Again, special schools which know not very much/nothing at all about schools' role in preventing violent extremism (83\%) are more likely than average $(74 \%)$ to say that no-one has received continuing professional development / training on their school's contribution to preventing violent extremism in the last year ${ }^{150}$.

\footnotetext{
${ }^{146}$ Indicative finding: small base size for primary schools describing role as not important $(n=59)$.

147 Indicative finding: small base size for rural, town and fringe $(n=53)$ secondary schools.

${ }^{148}$ Indicative finding: small base size for secondary schools describing role as not important $(n=46)$.

${ }^{149}$ Indicative finding: small base sizes for pupil ethnicity Quartile $4(n=90)$ and fractionalisation Quartile $4(n=88)$ secondary schools.

${ }^{150}$ Indicative finding: small base size for special schools which know not very much/nothing at all about schools' role in preventing violent extremism $(n=70)$.
} 
In this context, it is not surprising that, at a national level, three in four respondents (74\%) say that they personally, colleagues on their school's senior leadership team and colleagues on the teaching staff need to receive more (a lot + a little) training on the contribution their school can make to the PREVENT strategy. By phase, secondary schools are more likely than other types of school to say that colleagues on the teaching staff need more training ( $80 \%$ versus $73 \%$ primary and $64 \%$ special). Meanwhile, special school respondents are less likely than colleagues in other phases to say that they personally (65\% versus $74 \%$ primary and $78 \%$ secondary) or colleagues on the senior leadership team (66\% versus $74 \%$ primary and $78 \%$ secondary) need more training, and are more likely to say that they and their colleagues have received enough training.

\section{Volume of training received}

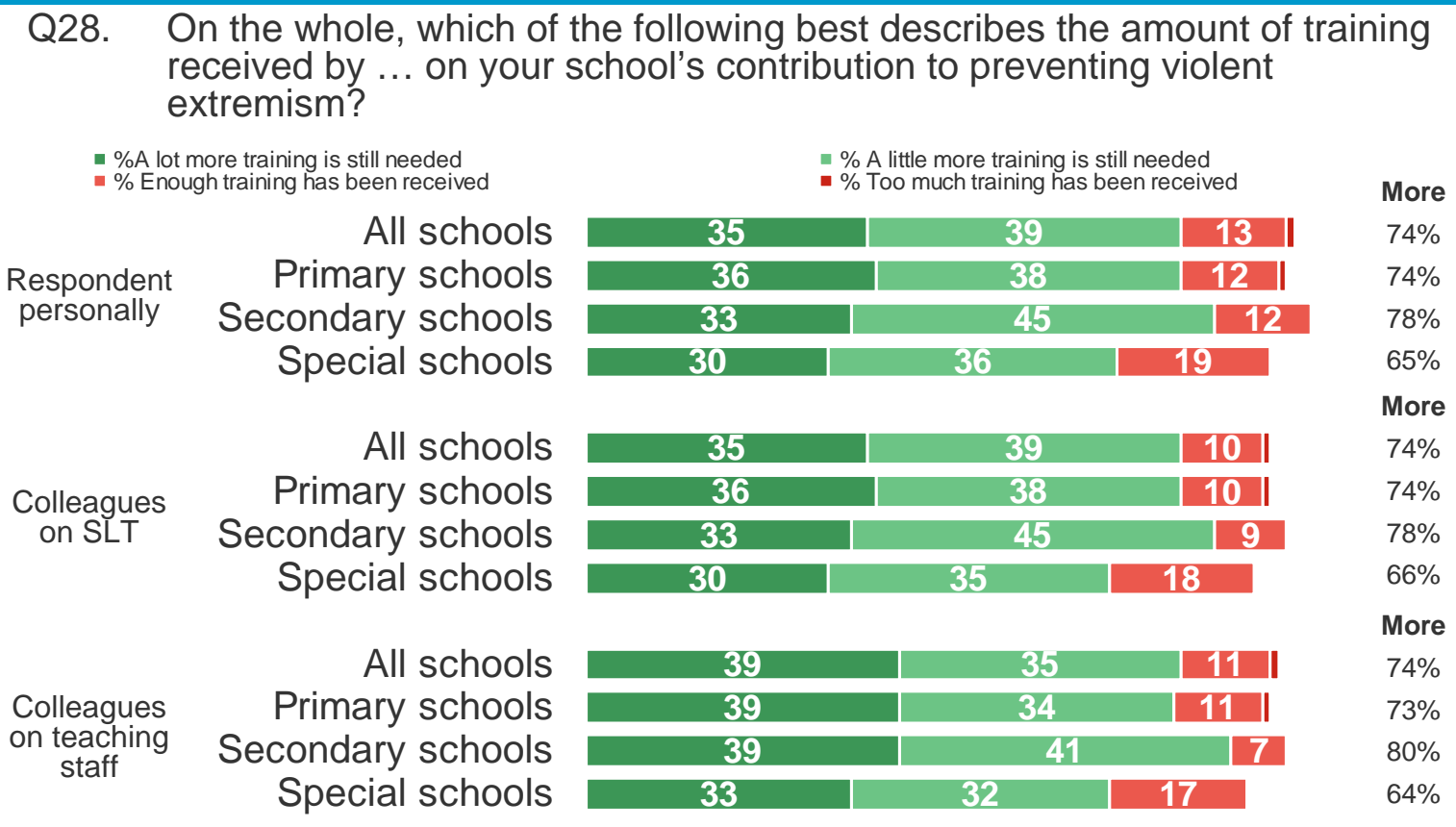

Base: 804 schools in England (321 primary, 348 secondary, 135 special); 10 February-14 May 2010 for DfE

Broadly speaking, schools are slightly less likely to say their staff need more training about preventing violent extremism than about community cohesion, perhaps reflecting the lower priority it is given within some schools. However, when schools do want training they want a lot more of it, rather than a little: they are more likely to say that their staff need a lot more training about preventing violent extremism than they are to say the same thing about community cohesion.

\section{Respondent personally needs more training}

Within the primary school phase, a significantly higher than average (74\%) proportion of respondents in urban (including London) primary schools (79\%), and in urban (excluding London) primary schools in particular (80\%), say that they personally need more (a lot $+a$ little) training. This is also the case for those who say they know not very much/nothing at all 
about schools' role in preventing violent extremism (80\% versus $74 \%$ ), as well as those who say that role is important $(79 \% \text { versus } 74 \%)^{151}$.

Amongst secondary schools, those in areas with high (38\%) and medium (36\%) levels of deprivation are more likely than those in areas of low deprivation (17\%) to say that they personally need a lot more training. Those who say they know not very much/nothing at all about schools' role in preventing violent extremism are also more likely than average to identify this need $(47 \% \text { versus } 33 \%)^{152}$. Describing this role as important also increases the likelihood that respondents say they need more training (81\% versus $78 \%)$.

Similarly, special school respondents who say they know not very much/nothing at all about schools' role in preventing violent extremism are more likely than average to say they personally need a lot more training (40\% versus $30 \%)$, as are those who describe schools' role in preventing violent extremism as important (41\% versus $30 \%)^{153}$. Those who describe it as not important say more frequently than average that they have received enough training $(29 \% \text { versus } 19 \%)^{154}$.

\section{Colleagues on respondent's senior leadership team need more training}

Again, within the primary school phase, more respondents than average (74\%) who work in urban (including London) primary schools (77\%), and in urban (excluding London) primary schools in particular (79\%), say that senior leadership team colleagues need more training on their contribution to the PREVENT strategy. This is true, too, of those who say schools' role in preventing violent extremism is important $(80 \% \text { versus } 74 \%)^{155}$.

For secondary schools again, those who say they know not very much/nothing at all about schools' role in preventing violent extremism are more likely than average to identify their senior leadership team's need ${ }^{156}$ for a lot more training (46\% versus $33 \%$ ), as are those who say the role is important ( $81 \%$ versus $78 \%)$.

Echoing the finding for secondary schools, special school respondents who say they know not very much/nothing at all about schools' role in preventing violent extremism are more likely than average to identify a need for a lot more training for senior leadership team colleagues (38\% versus $30 \%$ ), as do those who say the role is an important one ( $42 \%$ versus $30 \%)^{157}$.

\section{Colleagues on respondent's teaching staff need more training}

Once again, more primary school respondents than average (73\%) that work in urban (including London) primary schools (76\%), and in urban (excluding London) primary schools in particular (78\%), say that colleagues on their schools' teaching staff need more (a lot $+a$ little) training on their school's contribution to preventing violent extremism. This is true, too, of those who say schools' role in preventing violent extremism is important ( $80 \%$ versus $74 \%)$.

\footnotetext{
${ }^{151}$ In contrast, $61 \%$ of respondents who say schools' role in preventing violent extremism is not important think they personally need more training. [Indicative finding: small base size for primary schools describing role in preventing violent extremism as not important $(\mathrm{n}=59)$.]

${ }^{152}$ In contrast, $61 \%$ of respondents who say schools' role in preventing violent extremism is not important think they personally need more training. [Indicative finding: small base size for primary schools describing role in preventing violent extremism as not important ( $\mathrm{n}=59)$.]

153 [Indicative finding: small base size for special schools describing role in preventing violent extremism as important $(n=80)$.]

${ }^{154}$ [Indicative finding: small base size for special schools describing role in preventing violent extremism as not important $(\mathrm{n}=46)$.]

${ }^{155}$ The same respondents also tend more frequently to say that colleagues on their schools' teaching staff need more training (80\% versus $73 \%$ on average).

${ }^{156}$ And also colleagues on their schools' teaching staff (84\% versus an average of $\left.80 \%\right)$

${ }^{157}$ Likewise, colleagues on their schools' teaching staff (46\% versus $33 \%$ ).
} 
Respondents working in urban (including London) secondary schools are also more likely than those working in rural, town and fringe secondary schools to say this (82\% versus $68 \%)^{158}$.

As before, respondents working in high (45\%) and medium (42\%) IMD secondary schools are more likely than colleagues working in low (23\%) IMD schools to say that colleagues on their schools' teaching staff need a lot more training.

${ }^{158}$ Indicative finding: small base size for rural, town and fringe $(n=53)$ secondary schools. 
Conclusions

$$
\text { s }
$$

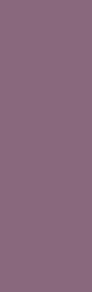
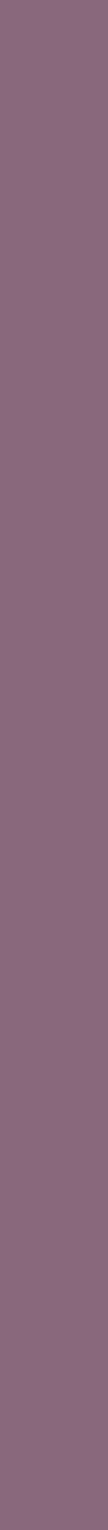


\section{Conclusions}

Before this study there was little quantitative information about how schools were implementing the statutory duty to promote community cohesion or approaching the PREVENT agenda. Key objectives for the research described here were to:

- $\quad$ investigate the implementation of the statutory duty;

- $\quad$ examine awareness and activity related to PREVENT;

- compare different types, settings and phases of schools; and

- $\quad$ identify promising practice.

Focusing on these four objectives (and especially the latter two), this section identifies some conclusions that policy-makers and practitioners can draw from the research findings. These are presented as answers to some questions frequently asked about community cohesion and the PREVENT strategy.

\section{Objective 1 - investigating implementation of the statutory duty}

\section{What impact is the statutory duty having, and how are schools measuring this?}

Schools generally say that they understand community cohesion better and are doing more since the duty became statutory. Almost all primary (89\%), secondary (93\%) and special schools (89\%) say their understanding of community cohesion is better since the statutory duty was introduced. Well over half say it is a lot better (56\% of primary, $64 \%$ of secondary and $54 \%$ of special schools).

Almost all schools say they are doing more ( $87 \%$ of primary, $91 \%$ of secondary and $82 \%$ of special schools), but around half of these are doing a little more - perhaps understanding has increased more than activity.

Almost all schools (91\%) measure the impact of their cohesion-related work through selfevaluation. Contextual and demographic data is widely used in primary (74\%) and secondary schools (87\%), but rather less so in special schools (50\%). Ofsted inspections and feedback are widely cited as monitoring tools for secondary (71\%) and special schools (70\%).Parent and carer consultations are also used, particularly in secondary schools (67\%).

\section{Objective 2 - awareness and activity related to PREVENT}

\section{How much do schools know about PREVENT?}

Schools' awareness of PREVENT is lower than their awareness of the statutory duty to promote community cohesion, perhaps reflecting the fact there is no statutory duty to engage in PREVENT-related work and the relatively recent publication of Department guidance. However, half $(50 \%)$ say they know a fair amount or more about the policy compared with $95 \%$ claiming at least a fair amount of knowledge about the statutory duty.

Schools also appear less confident in their understanding of the PREVENT strategy than of the statutory duty, and this seems to be linked to the amount of training received (or not received). In addition, three quarters of schools would like a little or a lot more information about preventing violent extremism. Most commonly, schools would like this to come from their local authority, the DfE or the police. 


\section{How far advanced is school implementation of PREVENT?}

Although many schools are active on PREVENT, the survey findings suggest it is seen as a lower priority than implementing the statutory duty to promote community cohesion (almost certainly because schools' engagement with PREVENT is not statutory). In particular, a sizeable minority of schools have no-one with formal, named or lead responsibility for their work in preventing violent extremism (35\% of both primary and secondary and $44 \%$ of special schools). By contrast, hardly any schools (3\% of both primary and special and $5 \%$ of special schools) do not have a specific person responsible for their work relating to community cohesion, and some schools point out that they have deliberately recruited someone to have this responsibility.

\section{Objective 3 - Comparing different types, settings and phases of schools}

\section{Are faith schools more active on community cohesion and PREVENT than non-faith schools?}

Differences in approach between faith and non-faith schools are perhaps more limited than might be imagined. As might be expected, issues of faith and religion appear more of a concern for faith schools than for their non-faith counterparts. In particular, faith-status primary and secondary schools tend to say their senior leadership teams, teaching staff, support staff and governors know more about different faiths and religious groups in the school and the local area. For example, $69 \%$ of faith primary senior leadership teams are thought to know a great deal about faiths and religions in the school and local area, compared with $51 \%$ of non-faith primary senior leadership teams.

However, the approaches used to promote cohesion, monitor effectiveness and involve the broader community do not differ dramatically between faith and non-faith schools.

Faith-status primary schools are more likely than their non-faith counterparts to say they know a fair amount or more about the PREVENT-related schools policy (though no similar difference emerges amongst secondary or special schools). Beyond this, attitudes to PREVENT and approaches used appear broadly similar between faith schools and non-faith schools.

\section{Are schools with more diverse populations most active on promoting community cohesion?}

Yes, to an extent, but the picture is complex. A good illustration of this is secondary schools' perceived knowledge of ethnic origins and cultures. This appears greatest in both the most ethnically diverse schools (where presumably it is seen as a particularly pressing issue) and in the least ethnically diverse schools (perhaps reflecting a view that in a homogenous school there is little complexity to understand). Schools with 'middling' levels of ethnic diversity tend to claim the least knowledge.

Local factors other than the make-up of the school roll are often associated with bigger variations in approach. Schools in deprived areas and those in urban centres appear most active in promoting community cohesion: there is more variation associated with these factors than with the degree of ethnic diversity in a school. In particular, schools in deprived areas appear to have been most active in developing links, producing written policies or linking cohesion to broader strategies.

On PREVENT, it does appear that schools with an ethnically diverse school roll or a large proportion of BME pupils are likely to know more about PREVENT and feel more confident about their knowledge of PREVENT. 


\section{Have schools with mono-cultural intakes seen the biggest increases in knowledge and activity?}

In primary schools, whatever the school's ethnic mix, understanding and activity appear to have increased: there are no statistically significant differences between schools with different degrees of ethnic diversity or those with different proportions of white and BME pupils.

Secondary schools from different types of areas and with different ethnic mixes report similar levels of improved understanding. Differences in the extent to which schools are doing more are more associated with whether the school is in an urban area than with whether it is mono-cultural.

\section{Objective 4. Identifying promising practice}

\section{Do schools tend to take a 'whole school' approach?}

During the literature review, we were unable to find detailed case studies of "whole school" approaches taken to promoting community cohesion. Much published guidance referred to individual, seemingly stand-alone, activities - some of them long-term and some one-off. Findings from the quantitative survey suggest that schools are promoting community cohesion in a much more broad and "whole school" way than the picture derived from the review of the literature. Half of schools say they mostly promote community cohesion through curriculum subjects and one-off enrichment activities in roughly equal measure; a further four in ten say that they are doing so more through curriculum subjects than through one-off enrichment activities. Only one in twenty schools say that they are promoting community cohesion more through one-off enrichment activities than through curriculum subjects. The picture is similar for primary, secondary and special schools.

\section{How, if at all, are schools using the curriculum?}

Almost all schools say they are using the curriculum to promote community cohesion. Typically this appears to be across a range of subjects. Use of the curriculum to build resistance to violent extremism is significantly less widespread: half of all schools say they use it (though this varies between phases from nearer two fifths of special schools to three fifths of secondary schools).

To an extent this reflects the fact that schools are less active on preventing violent extremism than on promoting community cohesion. But use of the curriculum also appears to be relatively less important: it is the third most-cited means of promoting community cohesion, but the sixth or seventh most-cited means for pursuing the PREVENT agenda. Instead, schools most widely say that they build pupils' resilience to violent extremism through their ethos and values (75\%), internet safety policies or processes (67\%) and through the pastoral curriculum or PSHE (67\%).

\section{What is the role of workforce training and support?}

Training is happening but schools would generally like more of it.

In most schools, the senior leadership team has received training or continuing professional development on the statutory duty. School governors and teaching staff training are less likely to have received training than senior leadership teams, and support staff are the least likely of all types of staff to have received training. 
In two thirds of schools (65\%), no-one has received continuing professional development or training related to preventing violent extremism in the past year. In secondary schools this figure is a little lower $(58 \%)$ than in primary $(66 \%)$ or special schools $(74 \%)$.

Most schools would welcome more training on community cohesion, especially for teaching staff. Only slightly fewer think they need more training related to preventing violent extremism, but schools are more likely to want a lot more training about preventing violent extremism than about community cohesion.

Secondary schools in more deprived areas are particularly likely to want more a lot more PREVENT training for their staff.

\section{What is the role of partnerships?}

Most schools have links with local charities or community groups, the police or another school. Rather fewer have links with training partners or their locality partnerships. Schools in more deprived areas appear more likely to have developed links. Secondary schools are more likely than primary and special schools to say they've developed links with the police since the introduction of the statutory duty. 
Appendices 


\section{Review of materials to support the implementation of the duty}

This appendix outlines the findings from a collation, synthesis and critical examination of material produced to support the implementation of the duty to promote community cohesion and the application of PREVENT strategy guidance, in order to identify the main themes and approaches (or models) being used by schools. This work was undertaken in Autumn 2009 to inform the development of the survey questionnaire.

Formal responsibilities with regard to promoting community cohesion and in support of the PREVENT strategy are relatively recent developments for schools. As such, we did not expect large amounts of material to be available. (In a similar context, the Macdonald review of PSHE (i.e. a long-standing area of school provision) found "not enough evidence available at a national level for the Review to make a definitive statement regarding actual prevalence or effectiveness of particular delivery models [of PSHE] in schools"159.)

In fact, two types of material were reasonably prevalent:

- National guidance, resource packs and toolkits ${ }^{160}$ which provide a generic/ideal model of approach for schools

- Case studies and exemplars of individual activities being undertaken by schools and local authorities

However, a case study relating to an individual activity undertaken by one school provides no clue as to whether this is all the school does or is just one strand within a particular, multidimensional delivery model, something which is in line with the model being promoted within the national guidance. Material which would provide this more rounded picture of delivery on the ground did not seem to be publicly available - this is discussed in more detail below, but it meant we were unable to draw any real conclusions about the types of approach being adopted by schools. The most we were able to conclude was that things were definitely happening, but the extent, coherence and effectiveness of this activity was an unknown quantity, at least as far as the material evidence would suggest.

\section{Materials in scope}

We reviewed materials produced by local authorities and supporting material from a range of other sources including Teachernet, iCoCo and the Schools Linking Network. Before the review commenced, our expectation was that materials would have been produced at several levels:

- $\quad$ national guidance or toolkits (such as DfE's cohesion guidance and PREVENT toolkit);

\footnotetext{
${ }^{159}$ Independent Review of the proposal to make Personal, Social, Health and Economic (PSHE) education statutory, paragraph 63, April 2009.

${ }^{160}$ For example

Guidance on the duty to promote community cohesion

http://www.teachernet.gov.uk/ doc/11635/Guidance\%20on\%20the\%20duty\%20to\%20promote\%20community\%20cohesion\%2 Opdf.pdf

Inspecting maintained schools' duty to promote community cohesion: guidance for inspectors

http://www.ofsted.gov.uk/Media/Ofsted/Forms-and-guidance2/Education-schools/s5/Community-Cohesion-Guidance-oninspecting.doc

Community Cohesion Resource Pack

http://www.teachernet.gov.uk/wholeschool/Communitycohesion/communitycohesionresourcepack/

Learning together to be safe: a toolkit to help schools contribute to the prevention of violent extremism

http://www.dcsf.gov.uk/violentextremism/toolkitforschools/index.shtml and

http://www.teachernet.gov.uk/wholeschool/violentextremism/
} 
- local authorities' own summaries of the generic national guidance;

- $\quad$ examples of how the duty could be implemented across a range of school activities (i.e. a "whole school" approach); and

- examples of individual activities undertaken.

The review found no shortage of materials at three of these four levels: the existence of guidance at national level is already known and the initial review found many local authority summaries and examples of individual activities. The situation was less clear regarding the prevalence of materials which provided examples of how to implement a "multi-dimensional" approach. It could be that these are merely more difficult to access than the other types of material. Alternatively, it may be that little of this nature has been produced, either because schools are being left to 'find their own way', are choosing to 'find their own way' or are not yet very far advanced in the implementation of their responsibilities. More information on this was a focus for the quantitative survey, but from the review of materials it was difficult to construct possible models of different delivery methods.

\section{Review of materials}

The material reviewed suggests that local authorities vary considerably in terms of their approach to supporting the implementation of the duty. This was reflected in differences in the amount and format of guidance they provide, the type of best practice examples it includes and the strength of the steer that the local authority provides to its schools.

The guidance provided to schools by local authorities could be divided into three groups, depending on the level of detail and extent to which local authorities adapt it to their local circumstances:

- Basic guidance - many local authorities have produced their own basic guidance, which draws heavily on DfE's community cohesion guidance, the PREVENT schools toolkit and the Ofsted inspection framework. In other cases, guidance produced by the authority is limited and mainly signposts these resources and those provided by Teachernet and iCoco. Some local authorities have designed an audit tool based on the Ofsted inspection framework to enable schools to ensure they can satisfy Ofsted that they are promoting community cohesion. Whichever format it is presented in, this "basic guidance" generally does not suggest specific delivery models or include reference to local circumstances: it is a wholly generic approach.

- Basic guidance with local modification - this guidance is similar to that just described, but makes explicit mention of specific local circumstances or areas of concern.

- Basic guidance which incorporates best practice examples - this guidance explicitly identifies local priorities or issues and suggests best practice examples that address them.

The local authorities examined consisted of a broad mixture of unitary, metropolitan, county and London boroughs, as well as authorities with contrasting perceived levels of community cohesion and differing proportions of white and BME populations. From the initial review there appeared to be little discernable connection between any of these factors and the type of guidance produced.

Although there may be an instinct to prefer local-focused guidance to a more generic form, arguments could be made in favour of the merits of all three approaches, especially since the provision of guidance is very much a means to an end, rather than an end in itself. The 
quantitative stage of the research has examined what approaches are perceived as most effective.

Schools can promote community cohesion across some or all of the curriculum. Alternatively, or in addition to this, they may make use of individual, one-off (drop-down) activities or shortterm projects. Best practice examples included in the guidance from local authorities cover a mixture of these approaches, but are mainly one-off activities, though some local authorities do give examples of implementing the duty on an ongoing basis through use of the curriculum or other longer-term, extra-curricular activities.

Local authorities differ in terms of how they interact with their schools and there is some variation in the strength of the steer provided by the local authority in its guidance. Many local authorities provide guidance on possible approaches but express little preference as to how the duty should be implemented (though they may go as far as providing training to staff or audit tools). Others are more actively providing activities, resources or support for schools. When the local authority does provide a stronger steer, the activities tend to be one-off, drop downs, rather than curriculum-based. Prescription from local authorities on how the duty should be integrated into the curriculum does not appear to be common. On the basis of the initial review, it would appear that local authorities are more likely to leave schools to work this out for themselves. 


\section{Topline findings}

Ipsos MORI/J09-030311

\section{Promoting community cohesion and preventing violent extremism Schools survey: topline results (4 June 2010)}

- The results in this document are based on a survey of schools in England conducted for the Department for Education.

- Results are based on questionnaires from 804 schools: 321 primary, 348 secondary, and 135 special schools. Fieldwork was conducted from $10^{\text {th }}$ February to $14^{\text {th }}$ May and consisted of 492 postal questionnaires and 312 telephone interviews.

- The figures shown for primary, secondary and special schools have been weighted to match the profile of each phase/type of school in terms of: IMD, faith or non-faith school, proportion of white/BME pupils, ethnic fractionalisation and settlement type. An additional weight based on the numbers of primary, secondary and special schools has been applied to the "all schools" data to make it representative of all schools within England.

- Where results do not sum to 100 , this is due to multiple responses, computer rounding or the exclusion of don't knows/not stated.

- An asterisk (*) represents a value of less than half of one per cent, but not zero.

- Results are based on all respondents unless otherwise stated.

\section{EDUCATION POLICIES}

Q1. Before today, how much, if anything, would you say you knew about each of the following education policies?

SINGLE CODE ONLY FOR EACH STATEMENT

A

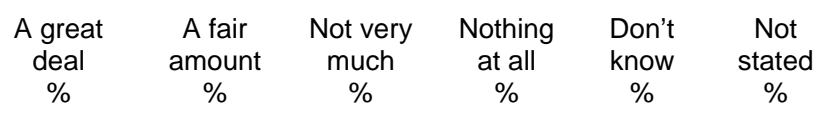

A Schools' duty to promote community cohesion

\begin{tabular}{r|cccccc} 
All Schools & 47 & 48 & 2 & $*$ & - & 2 \\
\hline Primary Schools & 46 & 50 & 2 & $*$ & - & 2 \\
\hline Secondary Schools & 54 & 41 & 4 & - & - & 1 \\
\hline $\begin{array}{r}\text { Special Schools } \\
\text { Schools' role in preventing } \\
\text { violent extremism }\end{array}$ & 44 & 50 & 4 & 1 & - & 2 \\
All Schools & 16 & 34 & 41 & 6 & $*$ & 2 \\
\hline Primary Schools & 16 & 31 & 44 & 6 & - & 3 \\
\hline Secondary Schools & 17 & 50 & 29 & 3 & $*$ & 1 \\
\hline Special Schools & 15 & 39 & 34 & 9 & 2 & 2 \\
\hline
\end{tabular}


Q2. And how confident, if at all, would you say you feel about your understanding of each of the following education policies?

SINGLE CODE ONLY FOR EACH STATEMENT

A

$\begin{array}{cccccc}\begin{array}{c}\text { Very } \\ \text { confident }\end{array} & \begin{array}{c}\text { Fairly } \\ \text { confident }\end{array} & \begin{array}{c}\text { Not very } \\ \text { confident }\end{array} & \begin{array}{c}\text { Not at all } \\ \text { confident }\end{array} & \begin{array}{c}\text { Don't } \\ \text { know }\end{array} & \begin{array}{c}\text { Not } \\ \text { stated }\end{array} \\ \% & \% & \% & \% & \% & \%\end{array}$

B

\begin{tabular}{|c|c|c|c|c|c|c|}
\hline $\begin{array}{r}\text { Schools' duty to promote } \\
\text { community cohesion } \\
\text { All Schools }\end{array}$ & 44 & 49 & 5 & * & - & 1 \\
\hline Primary Schools & 42 & 51 & 5 & - & - & 2 \\
\hline Secondary Schools & 51 & 43 & 5 & 1 & - & 1 \\
\hline Special Schools & 50 & 40 & 7 & 1 & - & 2 \\
\hline $\begin{array}{r}\text { Schools' role in preventing } \\
\text { violent extremism } \\
\text { All Schools }\end{array}$ & 14 & 34 & 39 & 9 & 1 & 3 \\
\hline Primary Schools & 13 & 33 & 41 & 9 & 1 & 3 \\
\hline Secondary Schools & 17 & 44 & 32 & 5 & 1 & 2 \\
\hline Special Schools & 17 & 33 & 33 & 12 & 3 & 2 \\
\hline
\end{tabular}

\section{COMMUNITY COHESION}

Q3. Thinking about your school and the local area it serves, which of the following words or phrases do you associate with the term "community cohesion", if any? MULTICODE OK

\begin{tabular}{|c|c|c|c|c|}
\hline & $\begin{array}{c}\text { All } \\
\text { Schools } \\
\%\end{array}$ & $\begin{array}{c}\text { Primary } \\
\text { Schools } \\
\%\end{array}$ & $\begin{array}{c}\text { Secondary } \\
\text { Schools } \\
\%\end{array}$ & $\begin{array}{c}\text { Special } \\
\text { Schools } \\
\%\end{array}$ \\
\hline Citizenship & 87 & 87 & 85 & 89 \\
\hline Multiculturalism & 85 & 85 & 84 & 84 \\
\hline Faith & 82 & 83 & 81 & 76 \\
\hline Race/ethnicity & 82 & 81 & 84 & 79 \\
\hline Disability & 74 & 74 & 73 & 90 \\
\hline Socio-economic status & 73 & 71 & 85 & 71 \\
\hline Gender & 68 & 68 & 70 & 72 \\
\hline Tradition & 64 & 66 & 60 & 51 \\
\hline Age & 64 & 63 & 66 & 59 \\
\hline Deprivation & 63 & 61 & 75 & 67 \\
\hline Anti-social behaviour & 62 & 59 & 76 & 59 \\
\hline Sexual identity & 46 & 43 & 60 & 49 \\
\hline Britishness & 41 & 41 & 43 & 28 \\
\hline Violent extremism & 31 & 30 & 39 & 27 \\
\hline Radicalisation & 27 & 26 & 34 & 21 \\
\hline Other & 4 & 4 & 5 & 6 \\
\hline None of these & 1 & 1 & * & - \\
\hline Don't know & * & 1 & - & - \\
\hline Not stated & 2 & 2 & 1 & 1 \\
\hline
\end{tabular}


Q4.a On the whole, how much, if anything, would you say the <statement> know about the different ethnic origins and cultures in your school and the local area it serves?

SINGLE CODE ONLY FOR EACH STATEMENT

A great A fair

deal amount

Not
very

Nothing

at all

Don't

know

Not Not

applic- stated

A

Your school's senior leadership team All Schools Primary Schools

$\% \quad \%$

$\% \quad \%$

B

\begin{tabular}{|c|c|c|c|c|c|c|c|}
\hline $\begin{array}{r}\text { leadership team } \\
\text { All Schools }\end{array}$ & 60 & 36 & 2 & * & * & * & 2 \\
\hline Primary Schools & 58 & 37 & 2 & - & - & * & 2 \\
\hline Secondary Schools & 64 & 32 & 1 & * & * & - & 1 \\
\hline Special Schools & 65 & 33 & 1 & - & - & - & 1 \\
\hline \multicolumn{8}{|l|}{$\begin{array}{r}\text { Your school's teaching } \\
\text { staff }\end{array}$} \\
\hline All Schools & 43 & 52 & 3 & * & * & * & 1 \\
\hline Primary Schools & 44 & 51 & 3 & - & - & 1 & 2 \\
\hline Secondary Schools & 34 & 58 & 6 & * & 1 & - & 1 \\
\hline Special Schools & 45 & 54 & 1 & - & - & - & 1 \\
\hline \multicolumn{8}{|l|}{ Your school's support staff } \\
\hline All Schools & 34 & 55 & 8 & * & * & * & 2 \\
\hline Primary Schools & 35 & 54 & 8 & * & - & * & 2 \\
\hline Secondary Schools & 28 & 58 & 12 & * & 1 & * & 1 \\
\hline Special Schools & 39 & 53 & 7 & - & - & - & 1 \\
\hline \multicolumn{8}{|l|}{ Your school's governors } \\
\hline All Schools & 35 & 53 & 9 & * & * & * & 2 \\
\hline Primary Schools & 36 & 52 & 9 & - & * & * & 2 \\
\hline Secondary Schools & 31 & 58 & 8 & 1 & 1 & - & 1 \\
\hline Special Schools & 32 & 50 & 15 & - & 1 & - & 2 \\
\hline
\end{tabular}


Q4b On the whole, how much, if anything, would you say <statement> know about the different socio-economic groups in your school and the local area it serves?

SINGLE CODE ONLY FOR EACH STATEMENT

A great A fai

deal amount

Not
very

Nothing

at all

Don't

know applic- stated

Not Not

A

\begin{tabular}{|c|c|c|c|c|c|c|c|}
\hline $\begin{array}{r}\text { Your school's senior } \\
\text { leadership team } \\
\text { All Schools }\end{array}$ & 63 & 34 & 1 & - & - & - & 2 \\
\hline Primary Schools & 62 & 35 & 1 & - & - & - & 2 \\
\hline Secondary Schools & 70 & 27 & 2 & - & - & - & 1 \\
\hline Special Schools & 67 & 30 & 3 & - & - & - & 1 \\
\hline $\begin{array}{r}\text { Your school's teaching } \\
\text { staff } \\
\text { All Schools }\end{array}$ & 41 & 52 & 4 & - & - & - & 2 \\
\hline Primary Schools & 43 & 51 & 3 & - & - & - & 2 \\
\hline Secondary Schools & 32 & 57 & 9 & - & - & - & 2 \\
\hline Special Schools & 44 & 50 & 6 & - & - & - & 1 \\
\hline $\begin{array}{r}\text { Your school's support staff } \\
\text { All Schools }\end{array}$ & 28 & 56 & 13 & * & * & * & 2 \\
\hline Primary Schools & 27 & 56 & 13 & - & * & - & 3 \\
\hline Secondary Schools & 26 & 58 & 14 & * & * & * & 1 \\
\hline Special Schools & 36 & 53 & 10 & - & - & - & 1 \\
\hline $\begin{array}{r}\text { Your school's governors } \\
\text { All Schools }\end{array}$ & 38 & 52 & 7 & - & * & - & 3 \\
\hline Primary Schools & 38 & 52 & 7 & - & * & - & 3 \\
\hline Secondary Schools & 35 & 55 & 8 & - & 1 & - & 2 \\
\hline Special Schools & 33 & 52 & 12 & - & 2 & - & 2 \\
\hline
\end{tabular}


Q4C On the whole, how much, if anything, would you say <statement> know about the different faiths and religions in your school and the local area it serves?

SINGLE CODE ONLY FOR EACH STATEMENT

$$
\begin{aligned}
& \text { A great A fair Not Nothing Don't Not Not } \\
& \text { deal amount very at all know applic- stated }
\end{aligned}
$$

A

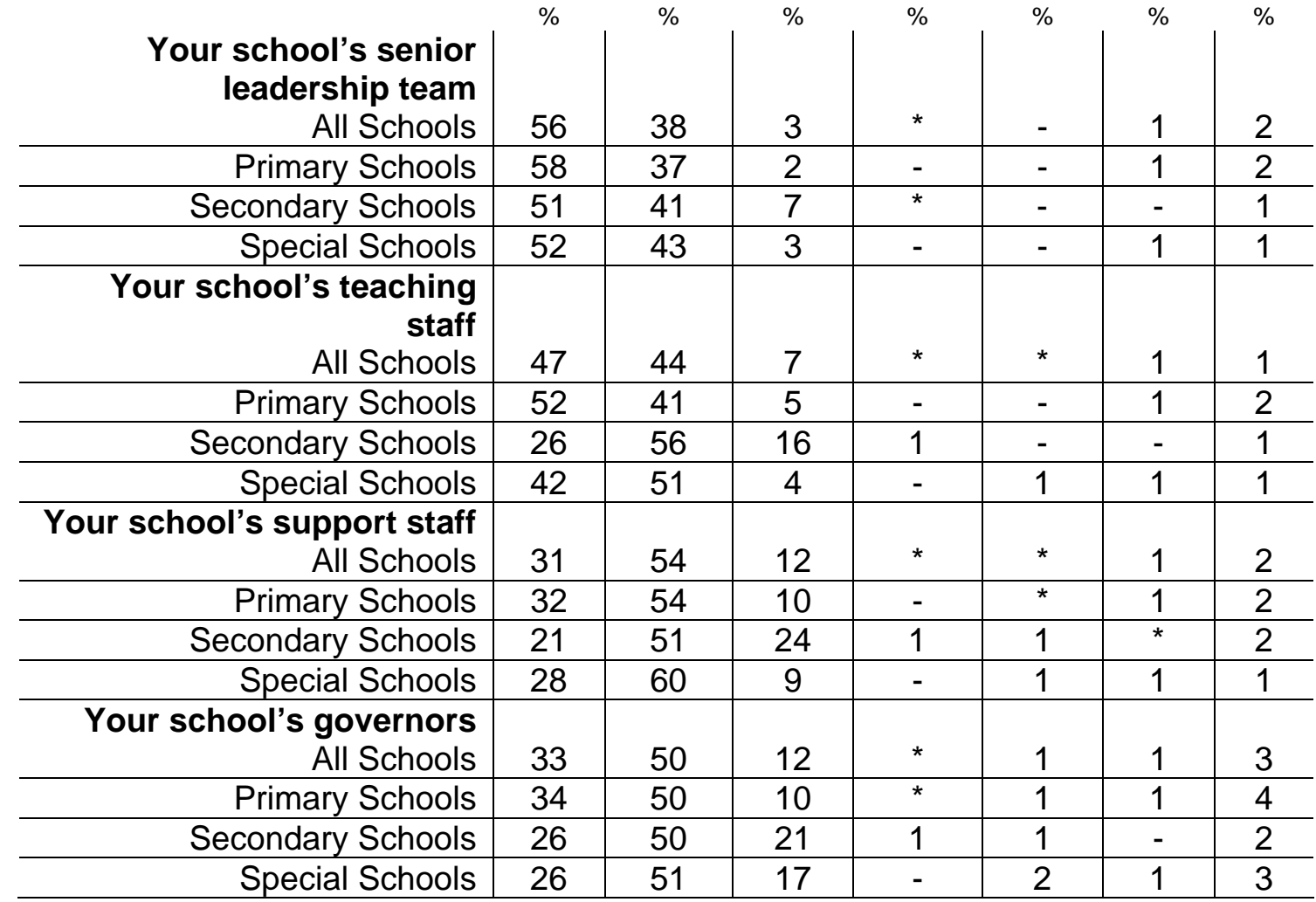


Q5. Which of the following sources of information, if any, have you and your colleagues used to learn more or understand better about ...

A. The different ethnic origins and cultures

B. The different socio-economic groups

C. The different faiths and religions

... in your school and the local area it serves?

MULTICODE OK FOR EACH STATEMENT

\begin{tabular}{|c|c|c|c|}
\hline & $\begin{array}{l}\text { A } \\
\text { Different ethnic } \\
\text { origins and } \\
\text { cultures } \\
\%\end{array}$ & $\begin{array}{l}\text { B } \\
\text { Different socio- } \\
\text { economic } \\
\text { groups } \\
\%\end{array}$ & $\begin{array}{l}\text { C } \\
\text { Different faiths } \\
\text { and religions } \\
\%\end{array}$ \\
\hline $\begin{array}{r}\text { Contextual/demographic data for pupils on the } \\
\text { school roll (e.g. RAISEonline, PLASC) } \\
\text { All Schools }\end{array}$ & 93 & 92 & 72 \\
\hline Primary Schools & 94 & 93 & 73 \\
\hline Secondary Schools & 94 & 95 & 69 \\
\hline Special Schools & 74 & 76 & 63 \\
\hline $\begin{array}{r}\text { Consultation with/surveys of pupils } \\
\text { All Schools }\end{array}$ & 59 & 46 & 50 \\
\hline Primary Schools & 58 & 46 & 48 \\
\hline Secondary Schools & 66 & 50 & 56 \\
\hline Special Schools & 55 & 37 & 47 \\
\hline $\begin{array}{r}\text { Consultation with/surveys of parents and carers } \\
\text { All Schools }\end{array}$ & 68 & 57 & 62 \\
\hline $\begin{array}{ll} & \text { Primary Schools } \\
\end{array}$ & 69 & 57 & 64 \\
\hline Secondary Schools & 65 & 52 & 52 \\
\hline Special Schools & 73 & 56 & 69 \\
\hline $\begin{array}{r}\text { Consultation with/surveys of other members of } \\
\text { the local community } \\
\text { All Schools }\end{array}$ & 27 & 28 & 33 \\
\hline Primary Schools & 24 & 27 & 31 \\
\hline Secondary Schools & 42 & 39 & 41 \\
\hline Special Schools & 23 & 21 & 26 \\
\hline $\begin{array}{r}\text { Guidance from/training by local community } \\
\text { groups or local charities or voluntary } \\
\text { organisations } \\
\text { All Schools }\end{array}$ & 42 & 31 & 35 \\
\hline Primary Schools & 42 & 29 & 33 \\
\hline Secondary Schools & 44 & 38 & 43 \\
\hline Special Schools & 41 & 29 & 37 \\
\hline $\begin{array}{r}\text { Guidance from/training by national charities or } \\
\text { voluntary organisations } \\
\text { All Schools }\end{array}$ & 29 & 24 & 21 \\
\hline Primary Schools & 29 & 24 & 21 \\
\hline Secondary Schools & 29 & 25 & 22 \\
\hline Special Schools & 25 & 21 & 20 \\
\hline $\begin{array}{r}\text { Guidance from the DCSFIon Teachernet } \\
\text { All Schools }\end{array}$ & 53 & 49 & 42 \\
\hline Primary Schools & 52 & 48 & 41 \\
\hline Secondary Schools & 57 & 53 & 43 \\
\hline Special Schools & 58 & 51 & 54 \\
\hline
\end{tabular}




\begin{tabular}{|c|c|c|c|}
\hline $\begin{array}{r}\text { Local Authority guidance/training } \\
\text { All Schools }\end{array}$ & $\begin{array}{c}\% \\
69 \\
\end{array}$ & $\begin{array}{c}\% \\
60 \\
\end{array}$ & $\%$ \\
\hline Primary Schools & 69 & 60 & 55 \\
\hline Secondary Schools & 65 & 62 & 52 \\
\hline Special Schools & 66 & 58 & 59 \\
\hline $\begin{array}{r}\text { Other } \\
\text { All Schools }\end{array}$ & 4 & 2 & 1 \\
\hline Primary Schools & 4 & 2 & 1 \\
\hline Secondary Schools & 5 & 2 & 1 \\
\hline Special Schools & 7 & 2 & 1 \\
\hline $\begin{array}{r}\text { None of these } \\
\text { All Schools } \\
\end{array}$ & 1 & 1 & 1 \\
\hline Primary Schools & 1 & 1 & * \\
\hline Secondary Schools & - & 1 & 1 \\
\hline Special Schools & 2 & 2 & 1 \\
\hline $\begin{array}{r}\text { Don't know } \\
\text { All Schools } \\
\end{array}$ & * & * & * \\
\hline Primary Schools & - & - & - \\
\hline Secondary Schools & - & - & - \\
\hline Special Schools & 1 & 1 & 2 \\
\hline $\begin{array}{l}\text { Not stated } \\
\text { All Schools }\end{array}$ & 1 & 2 & 4 \\
\hline Primary Schools & 1 & 2 & 4 \\
\hline Secondary Schools & 2 & 2 & 7 \\
\hline Special Schools & 1 & 4 & 2 \\
\hline
\end{tabular}


Q6.a On the whole, how much, if anything, would you say your school knows about whether its pupils from some different ethnic origins and cultures ...?

SINGLE CODE ONLY FOR EACH STATEMENT

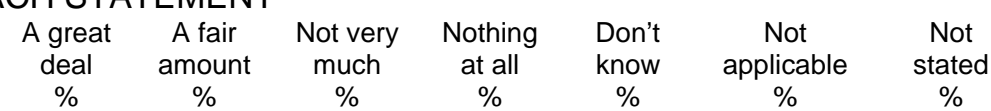

A

... achieve worse

academic results compared with other

pupils

All Schools

Primary Schools
Secondary School

B Special Schools

\begin{tabular}{|c|c|}
\hline 67 & 2 \\
\hline 69 & 2 \\
\hline 46 & 2 \\
\hline
\end{tabular}

... are more likely to be
excluded compared with
other pupils

All Schools

$\begin{array}{r}\text { Primary Schools } \\ \hline \text { Secondary Schools } \\ \hline \text { Special Schools }\end{array}$

C

... are more likely to be

bullied compared with

other pupils

All Schools

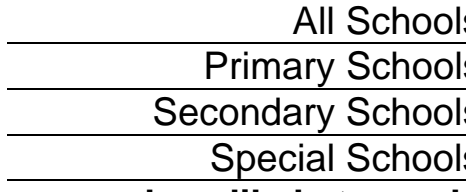

D

\begin{tabular}{|c|c|c|c|c|c|c|c|}
\hline $\begin{array}{r}\ldots \text { are less likely to apply } \\
\text { for places at the school } \\
\text { compared with other } \\
\text { pupils } \\
\text { All Schools }\end{array}$ & 29 & 20 & 17 & 5 & 6 & 20 & 2 \\
\hline Primary Schools & 29 & 19 & 17 & 5 & 7 & 20 & 2 \\
\hline Secondary Schools & 31 & 24 & 20 & 6 & 5 & 11 & 4 \\
\hline Special Schools & 25 & 11 & 4 & 2 & 3 & 50 & 4 \\
\hline
\end{tabular}


Q6b On the whole, how much, if anything, would you say your school knows about whether its pupils from some different socio-economic groups ... ?

SINGLE CODE ONLY FOR EACH STATEMENT

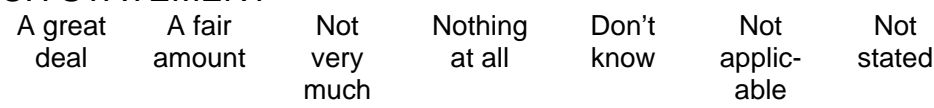

A

\begin{tabular}{|c|c|c|c|c|c|c|c|}
\hline $\begin{array}{r}\text {... achieve worse } \\
\text { academic results } \\
\text { compared with other } \\
\text { pupils } \\
\text { All Schools }\end{array}$ & 61 & 29 & $\%$ & 1 & 1 & 3 & 3 \\
\hline Primary Schools & 61 & 29 & 3 & 1 & 1 & 2 & 3 \\
\hline Secondary Schools & 67 & 24 & 6 & - & - & 1 & 2 \\
\hline Special Schools & 42 & 32 & 6 & 1 & - & 18 & - \\
\hline $\begin{array}{r}\ldots \text { are more likely to be } \\
\text { excluded compared with } \\
\text { other pupils } \\
\text { All Schools }\end{array}$ & 51 & 27 & 5 & 1 & 1 & 10 & 4 \\
\hline Primary Schools & 50 & 28 & 4 & 1 & 2 & 11 & 4 \\
\hline Secondary Schools & 59 & 26 & 8 & 1 & 1 & 3 & 3 \\
\hline Special Schools & 43 & 24 & 7 & 1 & - & 24 & 1 \\
\hline $\begin{array}{r}\ldots \text { are more likely to be } \\
\text { bullied compared with } \\
\text { other pupils } \\
\text { All Schools }\end{array}$ & 46 & 32 & 10 & 1 & 2 & 6 & 3 \\
\hline Primary Schools & 46 & 32 & 10 & 1 & 2 & 6 & 3 \\
\hline Secondary Schools & 46 & 32 & 14 & 1 & 2 & 2 & 3 \\
\hline Special Schools & 42 & 30 & 3 & 2 & 1 & 22 & - \\
\hline $\begin{array}{r}\text {... are less likely to apply } \\
\text { for places at the school } \\
\text { compared with other } \\
\text { pupils } \\
\text { All Schools }\end{array}$ & 29 & 22 & 17 & 5 & 6 & 18 & 3 \\
\hline Primary Schools & 29 & 22 & 18 & 5 & 6 & 18 & 3 \\
\hline Secondary Schools & 33 & 23 & 19 & 5 & 4 & 11 & 4 \\
\hline Special Schools & 24 & 11 & 5 & 2 & 1 & 54 & 4 \\
\hline
\end{tabular}


Q6c On the whole, how much, if anything, would you say your school knows about whether its pupils from some different faiths and religions ...?

SINGLE CODE ONLY FOR EACH STATEMENT

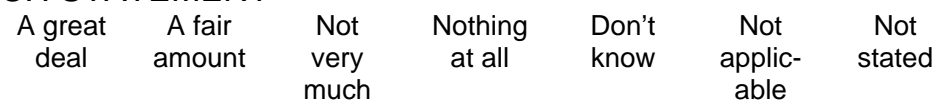

A

\begin{tabular}{|c|c|c|c|c|c|c|c|}
\hline $\begin{array}{r}\text {... achieve worse } \\
\text { academic results } \\
\text { compared with other } \\
\text { pupils } \\
\text { All Schools }\end{array}$ & 41 & 25 & $\%$ & $\%$ & $\%$ & 11 & $\%$ \\
\hline Primary Schools & 43 & 24 & 14 & 3 & 1 & 12 & 3 \\
\hline Secondary Schools & 35 & 27 & 22 & 6 & 2 & 5 & 4 \\
\hline Special Schools & 34 & 27 & 10 & 4 & 1 & 24 & - \\
\hline $\begin{array}{r}\ldots \text { are more likely to be } \\
\text { excluded compared with } \\
\text { other pupils } \\
\text { All Schools }\end{array}$ & 38 & 26 & 13 & 4 & 2 & 16 & 1 \\
\hline Primary Schools & 39 & 26 & 12 & 4 & 2 & 17 & 1 \\
\hline Secondary Schools & 31 & 26 & 24 & 6 & 2 & 7 & 4 \\
\hline Special Schools & 34 & 23 & 8 & 6 & - & 28 & 1 \\
\hline $\begin{array}{r}\ldots \text { are more likely to be } \\
\text { bullied compared with } \\
\text { other pupils } \\
\text { All Schools }\end{array}$ & 38 & 27 & 14 & 4 & 2 & 13 & 3 \\
\hline Primary Schools & 40 & 26 & 13 & 3 & 2 & 14 & 3 \\
\hline Secondary Schools & 30 & 30 & 22 & 5 & 3 & 6 & 3 \\
\hline Special Schools & 36 & 27 & 6 & 4 & - & 23 & 3 \\
\hline $\begin{array}{r}\text {... are less likely to apply } \\
\text { for places at the school } \\
\text { compared with other } \\
\text { pupils } \\
\text { All Schools }\end{array}$ & 23 & 19 & 21 & 6 & 6 & 21 & 4 \\
\hline Primary Schools & 24 & 19 & 21 & 5 & 7 & 20 & 4 \\
\hline Secondary Schools & 19 & 25 & 26 & 8 & 5 & 12 & 5 \\
\hline Special Schools & 21 & 9 & 8 & 5 & 2 & 51 & 4 \\
\hline
\end{tabular}


Q7.a Thinking again about pupils from some different ethnic origins and cultures....

In the last two or three years, has your school reviewed and found it necessary to take action to address ...?

SINGLE CODE ONLY FOR EACH STATEMENT

A

$\begin{array}{cc}\text { Yes, we } & \text { Yes, we } \\ \text { have } & \text { have } \\ \text { reviewed } & \text { reviewed } \\ \text { this and } & \text { this and } \\ \text { found we } & \text { found we did } \\ \text { needed to } & \text { not need to } \\ \text { take action } & \text { take action }\end{array}$
No, we
have not
reviewed
this so don't
know
whether
action is
necessary

No, we have

not reviewed

this because

it's not

applicable to

our school

Don't applic- Not

$\%$

$\%$

know

able

... their academic under-performance compared with other pupils All Schools Primary Schools Secondary Schools Special Schools

B ... their more frequent exclusion compared with other pupils All Schools Primary Schools

Secondary Schools
Special Schools

C ... their more frequent bullying compared with other pupils All Schools Primary Schools Secondary Schools Special Schools

D ... the lower likelihood that they will apply for places at the school compared with other pupils All Schools Primary Schools Secondary Schools Special Schools

\begin{tabular}{|c|c|c|c|c|}
\hline 1 & 13 & 1 & 5 & 2 \\
\hline 1 & 13 & 1 & 4 & 2 \\
\hline 2 & 9 & 1 & 2 & 1 \\
\hline 5 & 13 & 1 & 17 & - \\
\hline 2 & 22 & 1 & 19 & 2 \\
\hline 2 & 24 & 1 & 20 & 2 \\
\hline 2 & 13 & 2 & 7 & 1 \\
\hline 5 & 14 & 1 & 31 & - \\
\hline 4 & 19 & 1 & 9 & 2 \\
\hline 3 & 21 & 1 & 8 & 2 \\
\hline 9 & 11 & 2 & 6 & 1 \\
\hline 5 & 14 & 1 & 25 & - \\
\hline 13 & 22 & 9 & 22 & 2 \\
\hline 12 & 23 & 10 & 21 & 2 \\
\hline 17 & 17 & 10 & 14 & 2 \\
\hline 5 & 18 & 2 & 54 & 3 \\
\hline
\end{tabular}


Q7b Thinking again about pupils from some different socio-economic groups....

In the last two or three years, has your school reviewed and found it necessary to take action to address ... ?

SINGLE CODE ONLY FOR EACH STATEMENT

A

$\begin{array}{ccc}\text { Yes, we } & \text { Yes, we } & \text { No, we } \\ \text { have } & \text { reviewed } & \text { have not } \\ \text { reviewed } \\ \text { reviewed } & \text { this and } & \text { this so } \\ \text { this and } & \text { found we } & \text { don't know } \\ \text { found we } & \text { did not } & \text { whether } \\ \text { needed to } & \text { need to } & \text { action is } \\ \text { take action } & \text { take action } & \text { necessary } \\ \% & \% & \%\end{array}$

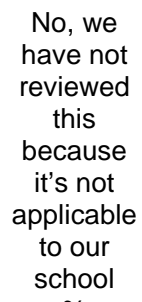

No, we

have not

reviewed

this

because

it's not

applicable

to our

school

Don't Not

know able

\begin{tabular}{c|c|c|c|}
\hline$\%$ & $\%$ & $\%$ & $\%$
\end{tabular}

... their academic under-performance compared with

other pupils

All Schools

Primary Schools

Secondary Schools

Special Schools

B

... their more

frequent exclusion

compared with

other pupils

All Schools

Primary Schools

Secondary Schools

Special Schools

C

... their more

frequent bullying

compared with

other pupils

All Schools

Primary Schools

Secondary Schools

Special Schools

D

... the lower

likelihood that they

will apply for

places at the

school compared

with other pupils

All Schools

Primary Schools

Secondary Schools

Special Schools

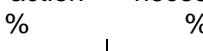

$\% \quad \%$

\begin{tabular}{|c|c|c|c|c|c|}
\hline 46 & 35 & 5 & 7 & 1 & 5 \\
\hline 45 & 36 & 4 & 6 & 1 & 4 \\
\hline 59 & 25 & 5 & 6 & 2 & 2 \\
\hline 13 & 46 & 10 & 13 & - & 16 \\
\hline
\end{tabular}

13

\begin{tabular}{|c|c|c|c|c|c|c|}
\hline 13 & 42 & 5 & 17 & 2 & 17 & 3 \\
\hline 10 & 43 & 5 & 19 & 2 & 19 & 3 \\
\hline 34 & 41 & 8 & 7 & 3 & 4 & 2 \\
\hline 5 & 38 & 8 & 16 & 1 & 28 & 3 \\
\hline
\end{tabular}


Q7c Thinking again about pupils from some different faiths and religions...

In the last two or three years, has your school reviewed and found it necessary to take action to address ... ?

SINGLE CODE ONLY FOR EACH STATEMENT

A

... their academic under-performance compared with other pupils All Schools Primary Schools Secondary Schools Special Schools

B ... their more frequent exclusion compared with other pupils

\begin{tabular}{|c|c|c|}
\hline & Yes, we & No, we \\
\hline Yes, we & have & have not \\
\hline have & reviewed & reviewed \\
\hline reviewed & this and & this so \\
\hline this and & found we & don't know \\
\hline $\begin{array}{l}\text { found we } \\
\text { needed to }\end{array}$ & $\begin{array}{l}\text { did not } \\
\text { need to }\end{array}$ & $\begin{array}{l}\text { whether } \\
\text { action is }\end{array}$ \\
\hline take action & take action & necessary \\
\hline \% & $\%$ & $\%$ \\
\hline
\end{tabular}

$$
\begin{aligned}
& \text { No, we } \\
& \text { have not } \\
& \text { reviewed } \\
& \text { this } \\
& \text { because } \\
& \text { it's not } \\
& \text { applicable } \\
& \text { to our } \\
& \text { school }
\end{aligned}
$$

\begin{tabular}{|c|c|c|c|c|c|c|}
\hline$\%$ & $\%$ & $\%$ & $\%$ & $\%$ & $\%$ & $\%$ \\
\hline 10 & 41 & 15 & 16 & 2 & 12 & 2 \\
\hline 11 & 42 & 14 & 16 & 2 & 12 & 2 \\
\hline 12 & 34 & 22 & 17 & 4 & 8 & 3 \\
\hline 1 & 49 & 11 & 18 & 2 & 19 & 1 \\
\hline
\end{tabular}

C

All Schools

Primary Schools

Secondary Schools

Special Schools ... their more

frequent bullying compared with other pupils All Schools Primary Schools

Secondary Schools Special Schools

D ... the lower

likelihood that they

\begin{tabular}{|c|c|c|c|c|c|c|}
\hline 3 & 36 & 11 & 23 & 3 & 22 & 3 \\
\hline 2 & 35 & 9 & 23 & 3 & 24 & 3 \\
\hline 6 & 39 & 19 & 19 & 4 & 10 & 3 \\
\hline 1 & 38 & 8 & 21 & 1 & 31 & 1 \\
\hline 4 & 44 & 14 & 17 & 3 & 16 & 3 \\
\hline 3 & 45 & 12 & 17 & 2 & 17 & 3 \\
\hline 8 & 37 & 23 & 16 & 4 & 8 & 3 \\
\hline 2 & 43 & 8 & 19 & 1 & 26 & 1 \\
\hline 4 & 24 & 16 & 19 & 8 & 24 & 5 \\
\hline 4 & 26 & 15 & 19 & 8 & 24 & 4 \\
\hline 6 & 22 & 22 & 21 & 9 & 15 & 5 \\
\hline 2 & 16 & 7 & 20 & 2 & 49 & 4 \\
\hline
\end{tabular}
will apply for places at the school compared with other pupils All Schools Primary Schools Secondary Schools Special Schools 
Since 2007 , schools have had a statutory duty to promote community cohesion.

Q8.a Since the introduction of the statutory duty, which of the following best describes your school's understanding of community cohesion in your school and the local area it serves?

SINGLE CODE

Our understanding is a lot better

Our understanding is a little better

There has been no change in our understanding

Our understanding is a little worse

Our understanding is a lot worse Don't know Not stated

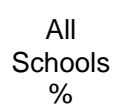

57

32

32

\section{Primary Schools}

56

33

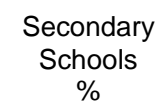

64

$\begin{array}{ll}29 & 35 \\ 5 & 9\end{array}$

\begin{tabular}{r|cccc}
\hline Our understanding is a little worse & $*$ & - & $*$ & - \\
\hline Our understanding is a lot worse & $*$ & - & - & 1 \\
\hline Don't know & $*$ & $*$ & $*$ & 2 \\
\hline Not stated & 2 & 2 & 1 & - \\
\hline
\end{tabular}

Q8b Why do you say that? PLEASE WRITE IN BELOW. See computer tabulations.

Q9. Since the introduction of the statutory duty, which of the following best describes how much your school is doing to promote community cohesion?

\begin{tabular}{r|cccc}
\multicolumn{1}{|c}{$\begin{array}{c}\text { All } \\
\text { SINGLE CODE } \\
\%\end{array}$} & $\begin{array}{c}\text { Primary } \\
\text { Schools } \\
\%\end{array}$ & $\begin{array}{c}\text { Secondary } \\
\text { Schools } \\
\%\end{array}$ & $\begin{array}{c}\text { Special } \\
\text { Schools } \\
\%\end{array}$ \\
We are doing a lot more & 42 & 41 & 45 & 43 \\
\hline We are doing a little more & 46 & 46 & 46 & 39 \\
\hline There has been no change in how & 11 & 11 & 7 & 17 \\
much we are doing & & - & - & - \\
\hline We are doing a little less & - & - & - & - \\
\hline We are doing a lot less & - & - & - & - \\
\hline Don't know & 3 & $*$ & 2 & 1 \\
\hline Not stated & 1 & 1 &
\end{tabular}

Q9b Why do you say that? PLEASE WRITE IN BELOW. See computer tabulations.

Q10. Which of the following sources of information, if any, have you and your colleagues used to monitor/review how effective your school is in promoting community cohesion?

MULTICODE OK

Answers 2\% and below are not shown

\begin{tabular}{r|cccc}
$\begin{array}{c}\text { School self-evaluation and } \\
\text { improvement planning }\end{array}$ & 91 & $\begin{array}{c}\text { Schools } \\
\%\end{array}$ & $\begin{array}{c}\text { Schools } \\
\%\end{array}$ & $\begin{array}{c}\text { Schools } \\
\% \\
87\end{array}$ \\
\hline $\begin{array}{r}\text { Contextual/demographic data for } \\
\text { pupils on the school roll (e.g. } \\
\text { RAISEonline, PLASC) }\end{array}$ & 75 & 74 & 87 & 50 \\
\hline $\begin{array}{r}\text { Consultation with/ surveys of } \\
\text { parents and carers }\end{array}$ & 64 & 63 & 67 & 61 \\
\hline $\begin{array}{r}\text { Consultation with/surveys of pupils } \\
\text { Ofsted inspection findings and } \\
\text { feedback }\end{array}$ & 64 & 63 & 75 & 50 \\
\hline $\begin{array}{r}\text { Consultation with/surveys of other } \\
\text { members of the local community }\end{array}$ & 32 & 36 & 71 & 70 \\
\hline None of these & 1 & 1 & $*$ & 32 \\
\hline Don't know & $*$ & $*$ & $*$ & - \\
\hline Not stated & 1 & 1 & 1 & 2 \\
\hline & & & & \\
\hline
\end{tabular}


Q11. Does your school have a written policy or plan for promoting community cohesion?

\begin{tabular}{|c|c|c|c|c|}
\hline SINGLE CODE & $\begin{array}{c}\text { All } \\
\text { Schools } \\
\%\end{array}$ & $\begin{array}{c}\text { Primary } \\
\text { Schools } \\
\quad \%\end{array}$ & $\begin{array}{c}\text { Secondary } \\
\text { Schools } \\
\%\end{array}$ & $\begin{array}{c}\text { Special } \\
\text { Schools } \\
\%\end{array}$ \\
\hline Yes & 73 & 75 & 68 & 61 \\
\hline No & 22 & 20 & 24 & 35 \\
\hline Don't know & 1 & 1 & 2 & 1 \\
\hline Not stated & 4 & 4 & 5 & 3 \\
\hline
\end{tabular}

PLEASE COMPLETE THE FOLLOWING QUESTION IF YOU ANSWERED YES AT Q11. IF YOU ANSWERED NO OR DON'T KNOW AT Q11, PLEASE SKIP TO Q13.

Q12. On the whole, how much, if anything, would you say the following colleagues know about your school's written policy or plan for promoting community cohesion?

SINGLE CODE ONLY FOR EACH STATEMENT

Base: All respondents whose school has a written policy or plan for promoting community cohesion (All schools 563, primary schools 240 , secondary schools 240, special schools 83)

A

\begin{tabular}{|c|c|c|c|c|c|c|}
\hline $\begin{array}{r}\text { Your school's } \\
\text { senior leadership } \\
\text { team } \\
\text { All Schools }\end{array}$ & $\begin{array}{l}\text { A great } \\
\text { deal } \\
\%\end{array}$ & $\begin{array}{l}\text { A fair } \\
\text { amount } \\
\%\end{array}$ & $\begin{array}{l}\text { Not very } \\
\text { much } \\
\%\end{array}$ & $\begin{array}{c}\text { Nothing at } \\
\text { all } \\
\%\end{array}$ & $\begin{array}{l}\text { Don't } \\
\text { know } \\
\%\end{array}$ & $\begin{array}{l}\text { Not } \\
\text { stated } \\
\%\end{array}$ \\
\hline Primary Schools & 69 & 29 & 1 & - & - & 1 \\
\hline Secondary Schools & 72 & 26 & 2 & - & - & - \\
\hline Special Schools & 78 & 21 & 1 & - & - & - \\
\hline $\begin{array}{r}\text { Your school's } \\
\text { teaching staff } \\
\text { All Schools }\end{array}$ & 35 & 55 & 7 & * & * & 3 \\
\hline Primary Schools & 38 & 54 & 5 & * & - & 3 \\
\hline Secondary Schools & 14 & 65 & 20 & 1 & * & * \\
\hline Special Schools & 43 & 42 & 13 & - & - & 1 \\
\hline $\begin{array}{r}\text { Your school's } \\
\text { support staff } \\
\text { All Schools }\end{array}$ & 19 & 55 & 22 & 1 & * & 3 \\
\hline Primary Schools & 20 & 57 & 20 & 1 & - & 3 \\
\hline Secondary Schools & 12 & 45 & 39 & 3 & 1 & 1 \\
\hline Special Schools & 31 & 42 & 24 & 1 & - & 2 \\
\hline $\begin{array}{r}\text { Your school's } \\
\text { governors } \\
\text { All Schools }\end{array}$ & 40 & 49 & 9 & * & * & 2 \\
\hline Primary Schools & 40 & 48 & 8 & * & * & 3 \\
\hline Secondary Schools & 35 & 52 & 11 & 1 & * & 1 \\
\hline Special Schools & 43 & 46 & 10 & - & - & 1 \\
\hline
\end{tabular}


Q13. Is promoting community cohesion part of ... ?

SINGLE CODE ONLY FOR EACH STATEMENT

A Your school's improvement plan

All Schools

Primary Schools

Secondary Schools Special Schools

B

\begin{tabular}{|c|c|c|c|c|c|}
\hline & & & & & \\
\hline Primary Schools & 82 & 13 & * & - & 5 \\
\hline Secondary Schools & 84 & 9 & 1 & - & 5 \\
\hline Special Schools & 84 & 10 & 3 & 1 & 2 \\
\hline $\begin{array}{r}\text { Your school's safeguarding } \\
\text { policy } \\
\text { All Schools }\end{array}$ & 53 & 28 & 6 & 2 & 10 \\
\hline Primary Schools & 53 & 28 & 6 & 2 & 11 \\
\hline Secondary Schools & 58 & 24 & 9 & 1 & 9 \\
\hline Special Schools & 50 & 33 & 7 & 3 & 7 \\
\hline $\begin{array}{l}\text { Your local authority's Children } \\
\text { and Young People's Plan (CYPP) }\end{array}$ & & & & & \\
\hline All Schools & 64 & 3 & 23 & 1 & 8 \\
\hline Primary Schools & 64 & 4 & 23 & 1 & 8 \\
\hline Secondary Schools & 62 & 2 & 26 & * & 10 \\
\hline Special Schools & 61 & 4 & 26 & 5 & 5 \\
\hline
\end{tabular}

Q14. In which of the following ways, if any, is your school promoting community cohesion?

MULTICODE OK. Answers 2\% and below not shown Through the school's ethos and
values All Primary Secondary Special Schools Schools Schools Schools

Through the pastoral curriculum or PSHE

\begin{tabular}{|c|c|c|c|c|}
\hline Through curriculum subjects & 94 & 94 & 94 & 93 \\
\hline $\begin{array}{l}\text { Assemblies (for example, involving } \\
\text { members of the local community) }\end{array}$ & 93 & 93 & 93 & 87 \\
\hline $\begin{array}{l}\text { Through one-off enrichment } \\
\text { activities (e.g. a diversity day) }\end{array}$ & 85 & 85 & 84 & 86 \\
\hline $\begin{array}{l}\text { 'Extended School' activities (e.g. } \\
\text { holiday play schemes, letting school } \\
\text { premises to community users etc.) }\end{array}$ & 84 & 82 & 89 & 84 \\
\hline $\begin{array}{r}\text { EAL support (for pupils, parents and } \\
\text { carers and/ or staff) }\end{array}$ & 59 & 58 & 67 & 43 \\
\hline Links with other schools/colleges & 7 & 7 & 3 & 4 \\
\hline $\begin{array}{r}\text { Community projects/local } \\
\text { community projects }\end{array}$ & 6 & 6 & 6 & 1 \\
\hline Overseas links with partner schools & 5 & 5 & 3 & 5 \\
\hline Links with faith groups/ churches & 3 & 3 & * & - \\
\hline Cultural visits/links & 3 & 3 & 2 & 1 \\
\hline Other & 5 & 4 & 7 & 10 \\
\hline Don't know & - & - & - & - \\
\hline Not stated & 1 & 1 & 1 & - \\
\hline
\end{tabular}


PLEASE COMPLETE THE FOLLOWING QUESTION IF YOU ANSWERED 'THROUGH CURRICULUM SUBJECTS' AT Q14.

EVERYONE ELSE, PLEASE SKIP TO Q16.

Q15. Which curriculum subjects does your school use to promote community cohesion?

MULTICODE OK.

Base: All respondents whose schools promote community cohesion through

curriculum subjects (All schools 756, primary schools 301, secondary schools 329 , special schools 126)

\begin{tabular}{|c|c|c|c|c|}
\hline & $\begin{array}{c}\text { All } \\
\text { Schools } \\
\%\end{array}$ & $\begin{array}{c}\text { Primary } \\
\text { Schools } \\
\%\end{array}$ & $\begin{array}{c}\text { Secondary } \\
\text { Schools } \\
\%\end{array}$ & $\begin{array}{c}\text { Special } \\
\text { Schools } \\
\%\end{array}$ \\
\hline RE & 89 & 90 & 89 & 82 \\
\hline Citizenship & 87 & 86 & 91 & 89 \\
\hline Geography & 81 & 82 & 79 & 67 \\
\hline English & 81 & 81 & 82 & 74 \\
\hline Art & 78 & 78 & 78 & 79 \\
\hline Music & 78 & 80 & 70 & 73 \\
\hline History & 74 & 73 & 82 & 64 \\
\hline Drama & 73 & 73 & 76 & 65 \\
\hline Modern Foreign Languages & 73 & 74 & 75 & 47 \\
\hline PE/Sports with other schools & 7 & 7 & 11 & 5 \\
\hline PSHE & 6 & 6 & 5 & 11 \\
\hline All/cross-curricular & 6 & 6 & 7 & 4 \\
\hline ICT & 5 & 6 & 3 & 2 \\
\hline Maths & 5 & 5 & 6 & 1 \\
\hline Science & 3 & 2 & 10 & 4 \\
\hline Other & 5 & 4 & 9 & 13 \\
\hline Don't know & * & * & 1 & - \\
\hline Not stated & * & * & * & - \\
\hline
\end{tabular}

Q16. On balance, would you say your school promotes community cohesion ...? ? SINGLE CODE

octs than through onesubjects than through oneoff enrichment activities Through curriculum subjects and one-off enrichment activities in roughly equal measure Less through curriculum subjects than through oneoff enrichment activities

\begin{tabular}{|c|c|c|c|}
\hline All & Primary & Secondary & Special \\
\hline $\begin{array}{c}\text { Schools } \\
\%\end{array}$ & $\begin{array}{c}\text { Schools } \\
\%\end{array}$ & $\begin{array}{c}\text { Schools } \\
\%\end{array}$ & $\begin{array}{c}\text { Schools } \\
\%\end{array}$ \\
\hline 38 & 39 & 37 & 33 \\
\hline
\end{tabular}

\begin{tabular}{r|llll} 
Don't know & 2 & 2 & 3 & 1 \\
\hline Not stated & 3 & 3 & 1 & 3
\end{tabular}


Q17. Since the introduction of the statutory duty to promote community cohesion, has your school developed links with any of the following organisations? SINGLE CODE ONLY FOR EACH STATEMENT

A

B

C

D

$\mathbf{E}$

Another school (or schools) with a different demographic profile to your own school roll All Schools Primary Schools Secondary Schools Special Schools Local community groups and/or local charities or voluntary organisations All Schools Primary Schools Secondary Schools Special Schools National charities or voluntary organisations All Schools Primary Schools Secondary Schools Special Schools

\begin{tabular}{|c|c|c|c|c|c|}
\hline \multicolumn{6}{|l|}{ The Locality Partnership } \\
\hline All Schools & 41 & 23 & 6 & 11 & 18 \\
\hline Primary Schools & 40 & 25 & 6 & 12 & 18 \\
\hline Secondary Schools & 46 & 19 & 9 & 11 & 16 \\
\hline Special Schools & 40 & 17 & 8 & 12 & 23 \\
\hline $\begin{array}{l}\text { The Police } \\
\text { All Schools }\end{array}$ & 62 & 9 & * & 21 & 7 \\
\hline Primary Schools & 61 & 10 & * & 21 & 8 \\
\hline Secondary Schools & 71 & 5 & * & 19 & 4 \\
\hline Special Schools & 58 & 14 & 2 & 16 & 11 \\
\hline $\begin{array}{r}\text { Training providers (local authority } \\
\text { or private) }\end{array}$ & & & & & \\
\hline All Schools & 47 & 20 & 2 & 13 & 18 \\
\hline Primary Schools & 46 & 21 & 1 & 13 & 18 \\
\hline Secondary Schools & 47 & 16 & 4 & 14 & 20 \\
\hline Special Schools & 53 & 13 & 1 & 13 & 19 \\
\hline
\end{tabular}

G

\begin{tabular}{r|c|c|c|c}
\hline $\begin{array}{r}\text { Other local partners } \\
\text { Answers of 4\% or below not shown }\end{array}$ & $\begin{array}{c}\text { All } \\
\text { Schools }\end{array}$ & $\begin{array}{c}\text { Primary } \\
\text { Schools }\end{array}$ & $\begin{array}{c}\text { Secondary } \\
\text { Schools }\end{array}$ & $\begin{array}{c}\text { Special } \\
\text { schools }\end{array}$ \\
\hline Churches/religious organisations & 14 & 16 & 5 & 8 \\
\hline Local businesses/employers & 5 & 5 & 8 & 4 \\
\hline Other & 6 & 5 & 8 & 7 \\
\hline Don't know & $\star$ & 1 & - & -
\end{tabular}


Q18. As a means of promoting community cohesion, are pupils in your school offered an opportunity to participate in any of the following types of activity?

MULTICODE OK

\begin{tabular}{r|cccc} 
& $\begin{array}{c}\text { All } \\
\text { Schools } \\
\%\end{array}$ & $\begin{array}{c}\text { Primary } \\
\text { Schools } \\
\%\end{array}$ & $\begin{array}{c}\text { Secondary } \\
\text { Schools } \\
\%\end{array}$ & $\begin{array}{c}\text { Special } \\
\text { Schools } \\
\%\end{array}$ \\
School council & 94 & 94 & 94 & 94 \\
\hline After-school activities & 89 & 88 & 93 & 90 \\
\hline $\begin{array}{r}\text { Peer mentoring (pupil to } \\
\text { pupil) }\end{array}$ & 67 & 65 & 82 & 42 \\
\hline $\begin{array}{r}\text { Volunteering } \\
\text { Mentoring (adult to pupil, }\end{array}$ & 59 & 56 & 79 & 51 \\
$\begin{array}{r}\text { where adult mentors come } \\
\text { from the local community) }\end{array}$ & & 32 & 64 & 39 \\
\hline Exchange visits & 26 & 19 & 64 & 22 \\
\hline None of these & 2 & 2 & 1 & 1 \\
\hline Don't know & - & - & - & - \\
\hline Not stated & 2 & 2 & 2 & - \\
\hline & & & &
\end{tabular}

Q19. In the last two or three years, which of the following, if any, have received continuing professional development/training on the statutory duty on schools to promote community cohesion? MULTICODE OK

\begin{tabular}{r|cccc} 
& $\begin{array}{c}\text { All } \\
\text { Schools } \\
\%\end{array}$ & $\begin{array}{c}\text { Primary } \\
\text { Schools } \\
\%\end{array}$ & $\begin{array}{c}\text { Secondary } \\
\text { Schools } \\
\%\end{array}$ & $\begin{array}{c}\text { Special } \\
\text { Schools } \\
\%\end{array}$ \\
You personally & 74 & 76 & 64 & 59 \\
\hline $\begin{array}{r}\text { Your school's senior } \\
\text { leadership team }\end{array}$ & 59 & 58 & 65 & 59 \\
\hline Your school's governors & 50 & 52 & 43 & 42 \\
\hline Your school's teaching & 46 & 46 & 46 & 44 \\
staff & & & & \\
\hline Your school's support staff & 27 & 26 & 27 & 37 \\
\hline None of these & 12 & 12 & 12 & 18 \\
\hline Don't know & 2 & 2 & 4 & 3 \\
\hline Not stated & 2 & 2 & 2 & - \\
\hline & & & &
\end{tabular}


Q20. On the whole, which of the following best describes the amount of training received by ...
A. You personally
B. Colleagues on your school's senior leadership team
C. Colleagues on your school's teaching staff

... on possible ways of implementing the statutory duty to promote community cohesion in your school?

SINGLE CODE PER STATEMENT

\begin{tabular}{|c|c|c|c|}
\hline & $\begin{array}{c}\text { You } \\
\text { personally } \\
\%\end{array}$ & $\begin{array}{c}\text { B } \\
\text { Colleagues } \\
\text { on the } \\
\text { senior } \\
\text { leadership } \\
\text { team } \\
\%\end{array}$ & $\begin{array}{c}\text { C } \\
\text { Colleagues } \\
\text { on the } \\
\text { teaching } \\
\text { staff } \\
\%\end{array}$ \\
\hline \multicolumn{4}{|c|}{ A lot more training is still needed } \\
\hline All Schools & 17 & 20 & 32 \\
\hline Primary Schools & 17 & 20 & 31 \\
\hline Secondary Schools & 18 & 21 & 33 \\
\hline Special Schools & 19 & 22 & 33 \\
\hline $\begin{array}{r}\text { A little more training is still needed } \\
\text { All Schools }\end{array}$ & 49 & 53 & 48 \\
\hline Primary Schools & 50 & 54 & 47 \\
\hline Secondary Schools & 46 & 51 & 50 \\
\hline Special Schools & 43 & 49 & 40 \\
\hline $\begin{array}{r}\begin{array}{r}\text { Enough training has been received } \\
\text { All Schools }\end{array} \\
\end{array}$ & 27 & 20 & 13 \\
\hline $\begin{array}{l}\text { Primary Schools } \\
\end{array}$ & 26 & 20 & 16 \\
\hline Secondary Schools & 29 & 22 & 11 \\
\hline Special Schools & 31 & 21 & 18 \\
\hline $\begin{array}{r}\text { Too much training has been received } \\
\text { All Schools }\end{array}$ & * & * & - \\
\hline Primary Schools & * & - & - \\
\hline Secondary Schools & * & * & - \\
\hline Special Schools & - & - & - \\
\hline $\begin{array}{r}\text { Don't know } \\
\text { All Schools }\end{array}$ & 1 & 2 & 2 \\
\hline Primary Schools & 1 & 1 & 1 \\
\hline Secondary Schools & 2 & 2 & 2 \\
\hline Special Schools & 4 & 4 & 4 \\
\hline $\begin{array}{l}\text { Not stated } \\
\text { All Schools }\end{array}$ & 5 & 4 & 5 \\
\hline Primary Schools & 6 & 4 & 5 \\
\hline Secondary Schools & 5 & 4 & 4 \\
\hline Special Schools & 3 & 3 & 4 \\
\hline
\end{tabular}


Now, thinking about violent extremism...

Violent extremism is taking actions to cause injury or death to people in order to make a political protest.

Q21. Before today, how much, if anything, would you say you knew about schools' role in preventing violent extremism? SINGLE CODE

\begin{tabular}{|c|c|c|c|c|}
\hline & $\begin{array}{c}\text { All } \\
\text { Schools } \\
\%\end{array}$ & $\begin{array}{c}\text { Primary } \\
\text { Schools } \\
\%\end{array}$ & $\begin{array}{c}\text { Secondary } \\
\text { Schools } \\
\%\end{array}$ & $\begin{array}{c}\text { Special } \\
\text { Schools } \\
\%\end{array}$ \\
\hline A great deal & 11 & 11 & 15 & 8 \\
\hline A fair amount & 31 & 28 & 42 & 33 \\
\hline Not very much & 42 & 43 & 35 & 39 \\
\hline Nothing at all & 14 & 15 & 7 & 13 \\
\hline Don't know & 1 & * & - & 5 \\
\hline Not stated & 2 & 2 & 1 & 1 \\
\hline
\end{tabular}

Q22. How important, if at all, do you think your school's role is in preventing violent extremism?

SINGLE CODE

\begin{tabular}{r|cccc} 
& $\begin{array}{c}\text { All } \\
\text { Schools }\end{array}$ & $\begin{array}{c}\text { Primary } \\
\text { Schools } \\
\%\end{array}$ & $\begin{array}{c}\text { Secondary } \\
\text { Schools } \\
\%\end{array}$ & $\begin{array}{c}\text { Special } \\
\text { Schools } \\
\%\end{array}$ \\
Very important & 41 & 42 & 43 & 33 \\
\hline Fairly important & 33 & 33 & 40 & 25 \\
\hline Not very important & 16 & 17 & 11 & 23 \\
\hline Not at all important & 3 & 3 & 3 & 12 \\
\hline Don't know & 4 & 4 & 2 & 6 \\
\hline Not stated & 2 & 2 & 1 & 1 \\
\hline
\end{tabular}


Q23. In which of the following, if any, is your school building the resilience of your pupils to violent extremism? MULTICODE OK

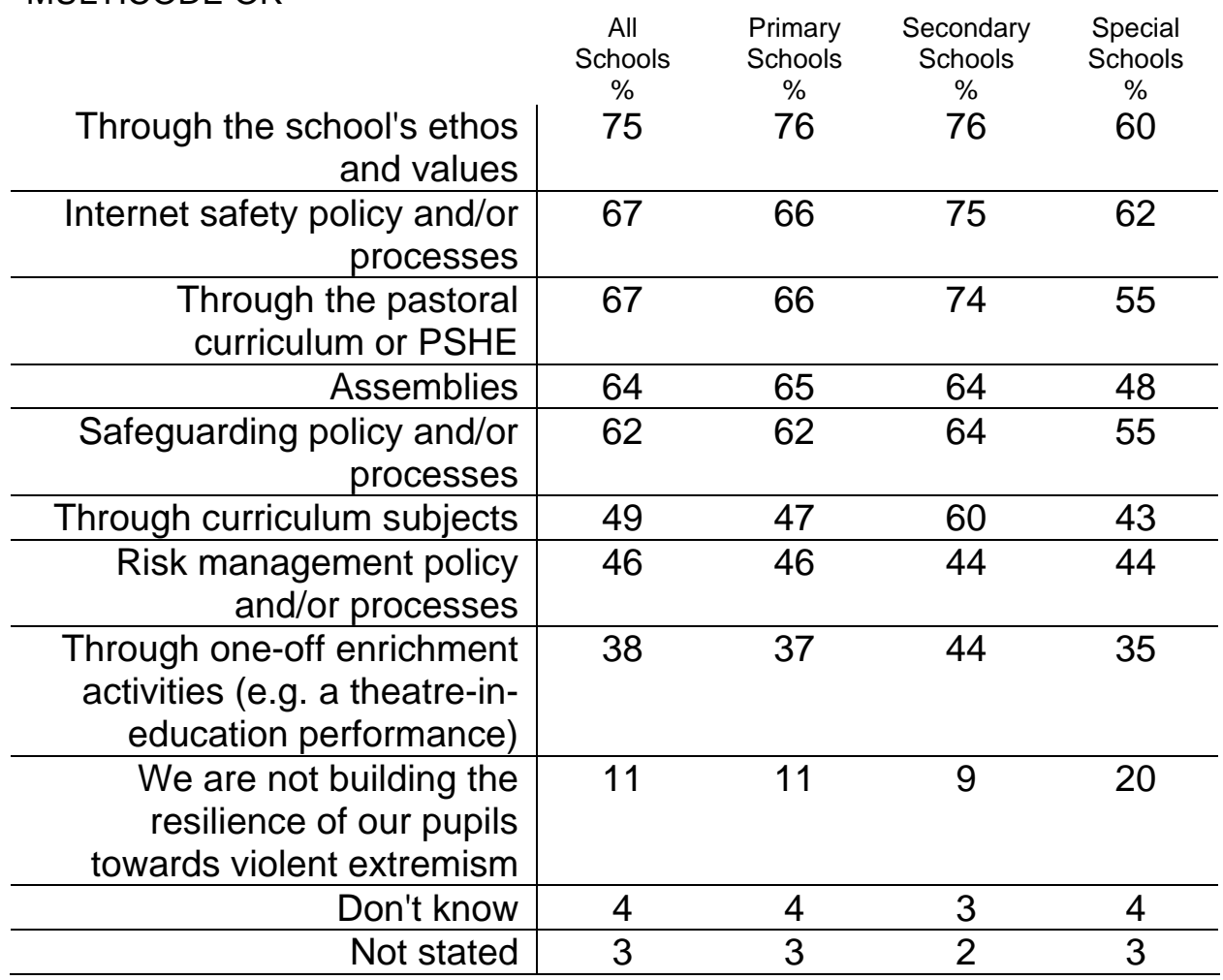


Q24. Where have you obtained information and/or support about preventing violent extremism? MULTICODE OK

\begin{tabular}{|c|c|c|c|c|}
\hline Published DCSF auidance & $\begin{array}{c}\text { All Schools } \\
\% \\
48\end{array}$ & $\begin{array}{l}\text { Primary } \\
\text { Schools } \\
\% \\
46\end{array}$ & $\begin{array}{l}\text { Secondary } \\
\text { Schools } \\
\% \\
58\end{array}$ & $\begin{array}{l}\text { Special } \\
\text { Schools } \\
\% \\
43\end{array}$ \\
\hline $\begin{array}{r}\text { Published local authority } \\
\text { guidance }\end{array}$ & 32 & 30 & 40 & 35 \\
\hline $\begin{array}{l}\text { The media (including } \\
\text { Teachers' TV, TES) }\end{array}$ & 30 & 29 & 33 & 40 \\
\hline The Police & 26 & 22 & 48 & 21 \\
\hline $\begin{array}{r}\text { Teaching unions, } \\
\text { professional bodies, subject } \\
\text { associations and/or national } \\
\text { organisations in the } \\
\text { education sector }\end{array}$ & 24 & 25 & 22 & 24 \\
\hline Local authority advisory staff & 22 & 21 & 26 & 15 \\
\hline Senior leadership team & 21 & 19 & 36 & 20 \\
\hline Colleagues in other schools & 18 & 18 & 16 & 16 \\
\hline $\begin{array}{r}\text { Training providers (local } \\
\text { authority or private) }\end{array}$ & 15 & 15 & 17 & 9 \\
\hline $\begin{array}{r}\text { Other colleagues in my } \\
\text { school }\end{array}$ & 14 & 13 & 22 & 10 \\
\hline Governors & 11 & 11 & 8 & 5 \\
\hline $\begin{array}{l}\text { Local community groups } \\
\text { and/or local charities or } \\
\text { voluntary organisations }\end{array}$ & 8 & 7 & 16 & 9 \\
\hline Local religious leaders & 7 & 6 & 14 & 7 \\
\hline $\begin{array}{r}\text { National charities or voluntary } \\
\text { organisations }\end{array}$ & 7 & 6 & 12 & 7 \\
\hline Other local partners & * & * & 1 & - \\
\hline Other & 2 & 1 & 5 & - \\
\hline $\begin{array}{r}\text { We have not obtained } \\
\text { information about preventing } \\
\text { violent extremism }\end{array}$ & 26 & 28 & 17 & 26 \\
\hline Don't know & 1 & 1 & 2 & 2 \\
\hline Not stated & 2 & 2 & 2 & 2 \\
\hline
\end{tabular}


Q25. Which of the following best describes the amount of information your school has received about its contribution to preventing violent extremism?

SINGLE CODE

\begin{tabular}{|c|c|c|c|c|}
\hline We would like a lot more & $\begin{array}{c}\text { All } \\
\text { Schools } \\
\% \\
30\end{array}$ & $\begin{array}{c}\text { Primary } \\
\text { Schools } \\
\% \\
30\end{array}$ & $\begin{array}{c}\text { Secondary } \\
\text { Schools } \\
\% \\
30\end{array}$ & $\begin{array}{c}\text { Special } \\
\text { Schools } \\
\% \\
26\end{array}$ \\
\hline information & & & & \\
\hline $\begin{array}{r}\text { We would like a little more } \\
\text { information }\end{array}$ & 41 & 40 & 48 & 34 \\
\hline $\begin{array}{r}\text { We have received enough } \\
\text { information }\end{array}$ & 18 & 18 & 16 & 24 \\
\hline $\begin{array}{r}\text { We have received too much } \\
\text { information }\end{array}$ & * & * & * & 2 \\
\hline Don't know & 8 & 8 & 5 & 13 \\
\hline Not stated & 3 & 4 & 1 & 1 \\
\hline
\end{tabular}

Q26. And which of the following organisations, if any, would you like to provide more help in developing your school's approaches to building pupils' resilience to violent extremism? MULTICODE OK

\begin{tabular}{|c|c|c|c|c|}
\hline Your local authority & $\begin{array}{l}\text { All } \\
\text { Schools } \\
\% \\
68\end{array}$ & $\begin{array}{l}\text { Primary } \\
\text { Schools } \\
\% \\
70\end{array}$ & $\begin{array}{l}\text { Secondary } \\
\text { Schools } \\
\% \\
63\end{array}$ & $\begin{array}{l}\text { Special } \\
\text { Schools } \\
\% \\
52\end{array}$ \\
\hline The DCSF & 53 & 53 & 58 & 46 \\
\hline The Police & 45 & 45 & 49 & 35 \\
\hline $\begin{array}{l}\text { Local community groups } \\
\text { and/or local charities or } \\
\text { voluntary organisations }\end{array}$ & 38 & 38 & 41 & 31 \\
\hline Local religious leaders & 37 & 36 & 43 & 34 \\
\hline $\begin{array}{r}\text { Teaching unions, } \\
\text { professional bodies, subject } \\
\text { associations and/or national } \\
\text { organisations in the } \\
\text { education sector }\end{array}$ & 35 & 36 & 35 & 27 \\
\hline $\begin{array}{r}\text { National charities or voluntary } \\
\text { organisations }\end{array}$ & 29 & 30 & 31 & 21 \\
\hline We have enough information & 1 & 1 & 1 & - \\
\hline We don't need it/not relevant & 1 & 1 & - & 3 \\
\hline Other & * & * & 1 & 1 \\
\hline $\begin{array}{r}\text { We are not developing } \\
\text { approaches to building pupils' } \\
\text { resilience towards violent } \\
\text { extremism }\end{array}$ & 8 & 8 & 6 & 16 \\
\hline Nothing/none & * & * & 1 & 2 \\
\hline Don't know & * & * & * & - \\
\hline Not stated & 4 & 3 & 4 & 3 \\
\hline
\end{tabular}


Q27. In the last year, which of the following, if any, have received continuing professional development/training on your school's contribution to preventing violent extremism?

All Primary

Schools Schools

Secondary Special Schools Schools

\begin{tabular}{r|c|c|c|c} 
You personally & 23 & 23 & 25 & 12 \\
\hline $\begin{array}{r}\text { Your school's senior } \\
\text { leadership team }\end{array}$ & 15 & 14 & 22 & 13 \\
\hline Your school's governors & 7 & 7 & 6 & 5 \\
\hline Your school's teaching staff & 6 & 6 & 10 & 6 \\
\hline Your school's support staff & 6 & 6 & 6 & 3 \\
\hline None of these & 65 & 66 & 58 & 74 \\
\hline Don't know & 3 & 3 & 4 & 5 \\
\hline Not stated & 3 & 4 & 2 & 1 \\
\hline
\end{tabular}


Q28. On the whole, which of the following best describes the amount of training received by ...

A. You personally

B. Colleagues on your school's senior leadership team

C. Colleagues on your school's teaching staff

... on your school's contribution to preventing violent extremism? SINGLE CODE PER STATEMENT

\begin{tabular}{|c|c|c|c|}
\hline $\begin{array}{r}\text { A lot more training is still } \\
\text { needed } \\
\text { All Schools }\end{array}$ & $\begin{array}{c}\text { A } \\
\text { You } \\
\text { personally } \\
\%\end{array}$ & $\begin{array}{c}\mathbf{B} \\
\text { Colleagues on } \\
\text { the senior } \\
\text { leadership } \\
\text { team } \\
\%\end{array}$ & $\begin{array}{c}\text { C } \\
\text { Colleagues on } \\
\text { the teaching } \\
\text { staff } \\
\%\end{array}$ \\
\hline Primary Schools & 36 & 36 & 39 \\
\hline Secondary Schools & 33 & 33 & 39 \\
\hline Special Schools & 30 & 30 & 33 \\
\hline $\begin{array}{r}\text { A little more training is still } \\
\text { needed } \\
\text { All Schools }\end{array}$ & 39 & 39 & 35 \\
\hline Primary Schools & 38 & 38 & 34 \\
\hline Secondary Schools & 45 & 45 & 41 \\
\hline Special Schools & 36 & 35 & 32 \\
\hline $\begin{array}{r}\text { Enough training has been } \\
\text { received } \\
\text { All Schools }\end{array}$ & 13 & 10 & 11 \\
\hline Primary Schools & 12 & 10 & 11 \\
\hline Secondary Schools & 12 & 9 & 7 \\
\hline Special Schools & 19 & 18 & 17 \\
\hline $\begin{array}{r}\text { Too much training has been } \\
\text { received } \\
\text { All Schools }\end{array}$ & 1 & 1 & 1 \\
\hline Primary Schools & 1 & 1 & 1 \\
\hline Secondary Schools & - & - & - \\
\hline Special Schools & - & - & - \\
\hline $\begin{array}{r}\text { Don't know } \\
\text { All Schools }\end{array}$ & 8 & 10 & 10 \\
\hline Primary Schools & 8 & 10 & 10 \\
\hline Secondary Schools & 6 & 7 & 7 \\
\hline Special Schools & 5 & 13 & 13 \\
\hline $\begin{array}{l}\text { Not stated } \\
\text { All Schools }\end{array}$ & 4 & 5 & 5 \\
\hline Primary Schools & 4 & 5 & 5 \\
\hline Secondary Schools & 4 & 6 & 6 \\
\hline Special Schools & 5 & 3 & 5 \\
\hline
\end{tabular}


Finally, some questions about your role in the school...

Q29. Which of the following best describes your most senior role?

\begin{tabular}{|c|c|c|c|c|}
\hline Headteacher & $\begin{array}{l}\text { All } \\
\text { Schools } \\
\% \\
77\end{array}$ & $\begin{array}{l}\text { Primary } \\
\text { Schools } \\
\% \\
85\end{array}$ & $\begin{array}{l}\text { Secondary } \\
\text { Schools } \\
\% \\
42\end{array}$ & $\begin{array}{l}\text { Special } \\
\text { Schools } \\
\% \\
64\end{array}$ \\
\hline Deputy/assistant headteacher & 11 & 5 & 40 & 21 \\
\hline $\begin{array}{r}\text { Deputy/assistant head of } \\
\text { department/head of subject/ } \\
\text { curriculum co-ordinator }\end{array}$ & 2 & 2 & 2 & 4 \\
\hline $\begin{array}{r}\text { Class teacher or subject teacher } \\
\text { (with additional curricular, non- } \\
\text { curricular and/or cross-school } \\
\text { responsibilities) }\end{array}$ & 2 & 2 & 2 & 2 \\
\hline $\begin{array}{l}\text { Head of department/head of } \\
\text { subject/curriculum co-ordinator }\end{array}$ & 1 & 1 & 2 & 1 \\
\hline Business/admin manager & 1 & 1 & 1 & $?$ \\
\hline $\begin{array}{r}\text { Deputy/assistant head of year/ } \\
\text { key stage co-ordinator }\end{array}$ & 1 & 1 & 1 & 2 \\
\hline $\begin{array}{r}\text { Classroom or subject teacher } \\
\text { (with no additional } \\
\text { responsibilities) }\end{array}$ & 1 & 1 & - & - \\
\hline $\begin{array}{r}\text { Head of year/key stage co- } \\
\text { ordinator }\end{array}$ & 1 & 1 & * & - \\
\hline Community Manager/Director & * & - & 2 & - \\
\hline $\begin{array}{r}\text { Director/Manager/Co-ordinator } \\
\text { of Extended Services }\end{array}$ & * & - & 2 & - \\
\hline $\begin{array}{r}\text { Community cohesion manager/ } \\
\text { co-ordinator }\end{array}$ & * & * & 1 & - \\
\hline Inclusion/inclusion co-ordinator & * & * & - & - \\
\hline Other & 2 & 1 & 2 & 3 \\
\hline
\end{tabular}

ASK ALL EXCEPT DEPUTYIASSISTANT HEADTEACHER OR HEADTEACHER AT Q29 Q30. Are you a member of your school's senior leadership team?

Base: All except deputy headteachers and headteacher (All schools 116, primary schools 37 , secondary schools 60 , special schools 19)

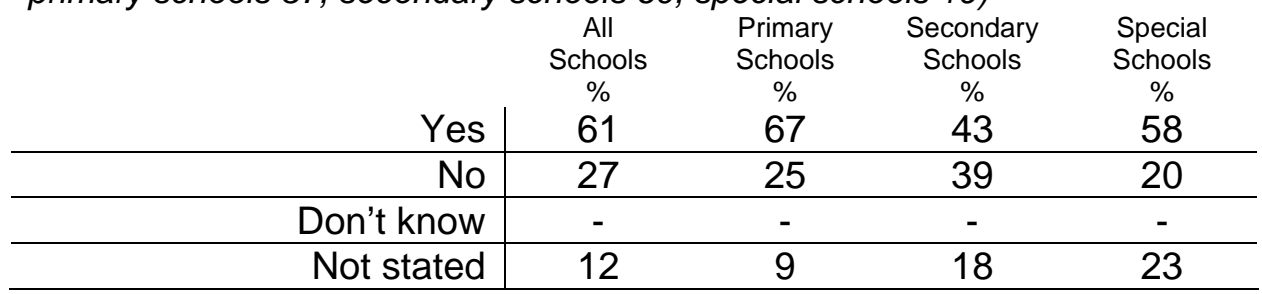


Q31. Who, if anyone, has formal/named/lead responsibility for your school's work related to promoting community cohesion?

Answers of $2 \%$ or below not shown

$\begin{array}{ccc}\text { All } & \text { Primary } & \text { Secondary } \\ \text { Schools } & \text { Schools } & \text { Schools }\end{array}$

\begin{tabular}{r|cccc} 
I have this responsibility & 70 & 74 & 51 & 63 \\
\hline Deputy Head/Assistant & 11 & 9 & 25 & 9 \\
Principal & & & & \\
\hline Other & 3 & 3 & 3 & 5 \\
\hline No-one has this responsibility & 3 & 3 & 3 & 5 \\
\hline Don't know & $\star$ & $*$ & 1 & 1 \\
\hline Not stated & 2 & 2 & 2 & 1 \\
\hline & & & &
\end{tabular}

Q32. Who, if anyone, has formal/named/lead responsibility for your school's work related to preventing violent extremism?

\begin{tabular}{|c|c|c|c|c|}
\hline Answers of $2 \%$ or below not & $\begin{array}{c}\text { All } \\
\text { Schools }\end{array}$ & $\begin{array}{l}\text { Primary } \\
\text { Schools }\end{array}$ & $\begin{array}{l}\text { Secondary } \\
\text { Schools }\end{array}$ & $\begin{array}{l}\text { Special } \\
\text { Schools }\end{array}$ \\
\hline I have this responsibility & $\begin{array}{r}\% \\
45\end{array}$ & $\begin{array}{r}\% \\
49\end{array}$ & $\begin{array}{l}\% \\
29\end{array}$ & $\%$ \\
\hline $\begin{array}{r}\text { Deputy Head/Assistant } \\
\text { Principal }\end{array}$ & 4 & 3 & 12 & 3 \\
\hline Headteacher & 3 & 3 & 8 & 4 \\
\hline Other & 2 & 2 & 3 & 1 \\
\hline No-one has this responsibility & 35 & 35 & 35 & 44 \\
\hline Don't know & 2 & 2 & 3 & 4 \\
\hline Not stated & 2 & 2 & 2 & 2 \\
\hline
\end{tabular}




\section{Statistical reliability}

Respondents represent only samples of total populations, so we cannot be certain that the figures obtained are exactly those we would have if everybody had taken part ("true values"). However, we can predict the variation between the sample results and the true values from a knowledge of the size of the samples on which results are based and the number of times a particular answer is given. The confidence with which we make this prediction is usually chosen to be $95 \%$ - that is, the chances are 95 in 100 that the true value will fall within a specified range (the "95\% confidence interval").

Strictly speaking the tolerances shown here apply only to random samples; in practice good quality quota sampling has been found to be as accurate. An indication of approximate sampling tolerances for the survey of schools is given in the table below.

\section{All schools}

\begin{tabular}{|c|c|c|c|}
\hline \multirow[t]{2}{*}{$\begin{array}{l}\text { Size of sample on which } \\
\text { survey result is based }\end{array}$} & \multicolumn{3}{|c|}{$\begin{array}{c}\text { Approximate sampling tolerances } \\
\text { applicable to percentages at or near } \\
\text { these levels }\end{array}$} \\
\hline & $10 \%$ or $90 \%$ & $30 \%$ or $70 \%$ & $50 \%$ \\
\hline & + & \pm & + \\
\hline 804 (without design effect) & 2.1 & 3.2 & 3.5 \\
\hline $\begin{array}{l}804 \text { (with design effect: } \\
\text { effective base size }=397 \text { ) }\end{array}$ & 2.9 & 4.5 & 4.9 \\
\hline
\end{tabular}

For example, with a sample size of 804 (and allowing for the design effect) where $30 \%$ give a particular answer, the chances are 19 in 20 that the true value (which would have been obtained if the whole population had been interviewed) will fall within the range of \pm 5 percentage points from the sample result (i.e. between $25 \%$ and $35 \%$ ).

\section{Schools by phase}

\begin{tabular}{|c|c|c|c|}
\hline \multirow[t]{2}{*}{$\begin{array}{l}\text { Size of sample on which } \\
\text { survey result is based }\end{array}$} & \multicolumn{3}{|c|}{$\begin{array}{c}\text { Approximate sampling tolerances } \\
\text { applicable to percentages at or near } \\
\text { these levels }\end{array}$} \\
\hline & $10 \%$ or $90 \%$ & $30 \%$ or $70 \%$ & $50 \%$ \\
\hline & \pm & + & + \\
\hline Primary schools & \multirow{3}{*}{$\begin{array}{l}3.3 \\
3.6\end{array}$} & \multirow{3}{*}{$\begin{array}{l}5.0 \\
5.5\end{array}$} & \multirow{3}{*}{$\begin{array}{l}5.4 \\
6.0\end{array}$} \\
\hline 321 (without design effect) & & & \\
\hline $\begin{array}{l}321 \text { (with design effect: } \\
\text { effective base size }=263 \text { ) }\end{array}$ & & & \\
\hline Secondary schools & \multirow{3}{*}{$\begin{array}{l}3.0 \\
3.1\end{array}$} & \multirow{3}{*}{$\begin{array}{l}4.6 \\
4.7\end{array}$} & \multirow{3}{*}{$\begin{array}{l}5.0 \\
5.1\end{array}$} \\
\hline 348 (without design effect) & & & \\
\hline $\begin{array}{l}348 \text { (with design effect: } \\
\text { effective base size }=332 \text { ) }\end{array}$ & & & \\
\hline Special schools & \multirow{3}{*}{$\begin{array}{l}4.8 \\
4.8\end{array}$} & \multirow{3}{*}{$\begin{array}{l}7.3 \\
7.3\end{array}$} & \multirow{3}{*}{$\begin{array}{l}7.9 \\
8.0\end{array}$} \\
\hline 135 (without design effect) & & & \\
\hline $\begin{array}{l}135 \text { (with design effect: } \\
\text { effective base size }=132 \text { ) }\end{array}$ & & & \\
\hline
\end{tabular}


When results are compared between separate groups within a sample, the difference may be "real" or it may occur by chance (because not everyone in the population has been interviewed). To test if the difference is "statistically significant" (i.e. a real, not just apparent, difference), we again have to know the size of the samples, the percentage of respondents giving a certain answer and the degree of confidence chosen. If we assume a "95\% confidence interval", the differences between the results of two groups must be greater than the values given in the table below:

\begin{tabular}{|c|c|c|c|}
\hline \multirow[t]{2}{*}{$\begin{array}{l}\text { Size of sample on which } \\
\text { survey result is based }\end{array}$} & \multicolumn{3}{|c|}{$\begin{array}{l}\text { Approximate sampling tolerances } \\
\text { applicable to percentages at or near } \\
\text { these levels }\end{array}$} \\
\hline & $10 \%$ or $90 \%$ & $30 \%$ or $70 \%$ & $50 \%$ \\
\hline & \pm & \pm & \pm \\
\hline $\begin{array}{l}321 \text { primary versus } 348 \\
\text { secondary schools }\end{array}$ & $\begin{array}{c}4.6 \\
\text { (without DE) } \\
4.7 \\
\text { (with DE) }\end{array}$ & $\begin{array}{c}7.0 \\
\text { (without DE) } \\
7.2 \\
\text { (with DE) }\end{array}$ & $\begin{array}{c}7.6 \\
\text { (without DE) } \\
7.9 \\
\text { (with DE) }\end{array}$ \\
\hline $\begin{array}{l}321 \text { primary versus } 135 \text { special } \\
\text { schools }\end{array}$ & $\begin{array}{c}6.0 \\
\text { (without DE) } \\
6.0 \\
\text { (with DE) }\end{array}$ & $\begin{array}{c}9.2 \\
\text { (without DE) } \\
9.1 \\
\text { (with DE) }\end{array}$ & $\begin{array}{c}10.1 \\
\text { (without DE) } \\
9.9 \\
\text { (with DE) }\end{array}$ \\
\hline $\begin{array}{l}348 \text { secondary versus } 135 \\
\text { special schools }\end{array}$ & $\begin{array}{c}5.6 \\
\text { (without DE) } \\
5.6 \\
\text { (with DE) }\end{array}$ & $\begin{array}{c}8.5 \\
\text { (without DE) } \\
8.6 \\
\text { (with DE) } \\
\end{array}$ & $\begin{array}{c}9.3 \\
\text { (without DE) } \\
9.4 \\
\text { (with DE) }\end{array}$ \\
\hline
\end{tabular}




\section{Key driver analysis}

Key driver analysis, using multiple regression techniques, examines the relationships between many factors (or variables) in order to identify the most important factors. Those which are the most influential, or have the most impact, are called "key drivers". This method of analysis is useful when there is an outcome of interest that we would like to predict or explain using other information. Linear multiple regression is used to account for the variance in an outcome, based on combinations of demographics and attitudes. It can uncover demographics and attitudes which explain some of the variance in an outcome at a significant level ${ }^{161}$, and can establish the relative predictive importance of the independent variables by comparing beta weights (standardised beta coefficients).

All variables from the community cohesion questions were included in the model, along with local area and school characteristics. If a code at a multi-coded question was mentioned by less than $5 \%$ or more than $95 \%$ of respondents it was excluded from the analysis. The linear multiple regression process identifies the most important drivers of the dependent variable, so there is no need to group different types of variables together during the analysis. In practice this can sometimes produce some drivers which are difficult to interpret (such as the curriculum subjects used to promote cohesion), but these do not tend to be the largest drivers.

While it is generally true that a larger number of cases will make any statistical technique more reliable, the number of cases included in this analysis can still be considered to be enough for the analysis to be useful. Similarly, although most respondents have answered the top two options on the scale for each of the dependent variables, key driver analysis is still a valid technique to use, and still provides some useful insights.

It should also be noted that "key driver" analysis reveals only a correlation, not causality.

For this study, key drivers were examined for four questions:

- knowledge about community cohesion;

- confidence about community cohesion;

- understanding since the duty became statutory; and

- $\quad$ activity since the duty became statutory.

Detailed findings are presented below for each of these questions for primary, secondary and special schools.

Before discussing the findings in more detail, it is worth noting several broad patterns that apply across the modelling of all four questions for primary, secondary and special schools:

- It has not been possible to construct models where a small number of factors explain a large amount of the variation in outcomes ${ }^{162}$. This suggests that many factors are at work: for example, variations in confidence about community cohesion cannot be largely explained by differences in one or two local factors, attitudes or behaviours.

- $\quad$ Some of the key drivers for a particular question are similar for primary, secondary and special schools.

- Some of the same factors are key drivers for primary schools across several of the questions (and the same is true for both secondary and special schools), in particular,

\footnotetext{
${ }^{161}$ This done using a significance test of the $\mathrm{R}^{2}$ ( the percentage of the variation in the outcome that can be explained using the statistical model).

${ }^{162}$ In most cases the models have an $\mathrm{R}^{2}$ of approximately $36 \%$ or less, meaning that they explain around only a third or less of the variation in the dependent variable.
} 
senior leadership team knowledge of socio-economic groups in the school and local area.

- The models are generally stronger and contain fewer drivers in special schools than in primary or secondary schools.

- School and local area contextual factors (such as perceptions of community cohesion in the local area, ethnic fractionalisation and profiles in the school, settlement type/ location, levels of deprivation and attainment measured through Contextual Value Added or CVA scores ${ }^{163}$ ) have been included in the modelling, but are weaker drivers than might perhaps be expected.

\section{Reading the charts}

Each model is presented graphically in the same format. The following chart shows the model for knowledge of the statutory duty in primary schools. The key things to note on this chart (and the others that follow) are:

- The $\mathbf{R}^{2}$ figure show in the central box. This is the percentage of the variation in the outcome (in this case knowledge of the statutory duty) that can be explained using the statistical model. In this case it is $28.7 \%$.

- Positive drivers shown on the left hand side. As each of these increase, the dependent variable also increases. They are shown in descending order of importance, along with the percentage of the model that they make up. In this example, senior leadership team knowledge of the socio-economic groups accounts for $18 \%$ of the variation in the model that has been constructed for knowledge of the duty. Since the model itself explains $28.7 \%$ of the variation, SLT knowledge actually explains $18 \%$ of $28.7 \%$ of the variation, which comes to approximately $5 \%$. The other positive drivers have a weaker effect.

- Negative drivers are shown on the right hand side. Again these are shown in descending order of importance, along with a percentage that reflects the amount of the model they account for. The outcome moves in the opposite direction from these drivers, so the more likely a school is to associate community cohesion with "citizenship", the less knowledge it is likely to claim about community cohesion.

\footnotetext{
${ }^{163}$ CVA scores measure attainment of pupils in comparison to pupils with similar prior attainment and are discussed in more detail at http://www.standards.dfes.gov.uk/performance/1316367/CVAinPAT2005/
} 


\section{Drivers of knowledge and confidence - primary schools}

In primary schools, positive drivers of knowledge and confidence include senior leadership team knowledge of the local area and continuing professional development/training. It is not possible to construct particularly strong models of drivers: both the models shown account for slightly above a quarter of the variation in the outcome.

The key conclusions to note are that: the low $\mathrm{R}^{2}$ suggests many factors are at work, senior leadership team knowledge about socio-economic groups is twice as strong as any of the other drivers, and finally, contextual factors seem relatively weak drivers.

\section{Knowledge of duty (primary schools)}

Q1a. Before today, how much, if anything, would you say you knew about ...? Schools' duty to promote community cohesion

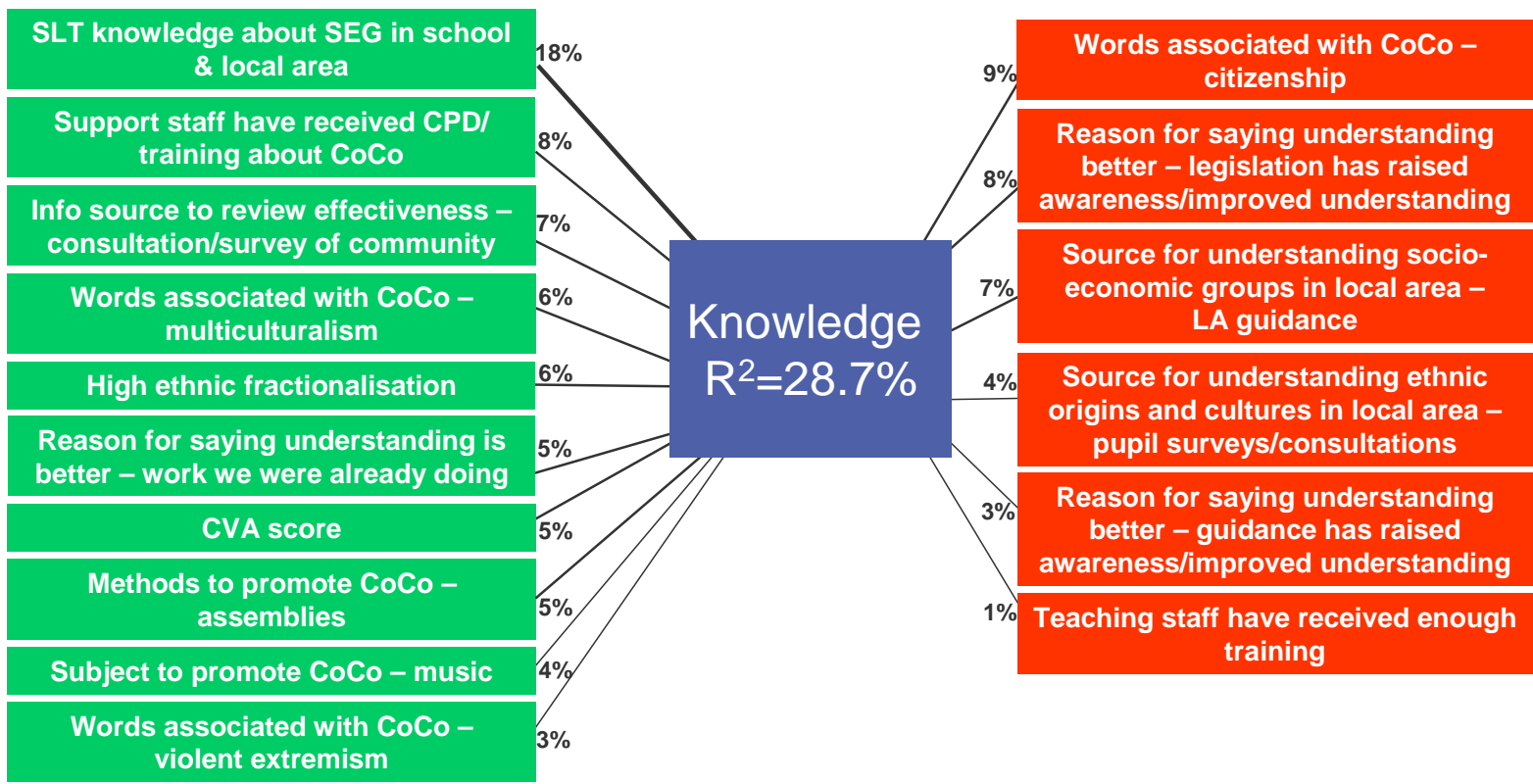

The model for confidence about the duty in primary schools is shown next. It has a similar $\mathrm{R}^{2}$, but contains far fewer variables, each of which explains more of the variation than was the case for the knowledge model.

Senior leadership team knowledge of socio-economic groups is again the biggest driver, but the analysis also reveals the importance of the school having a plan or policy for promoting community cohesion. Similarly, primary schools which review effectiveness through pupil surveys and consultations tend to be more confident about the duty. 


\section{Confidence about duty (primary schools)}

Q2a. And how confident would you say you feel about ...? Schools' duty to promote community cohesion?

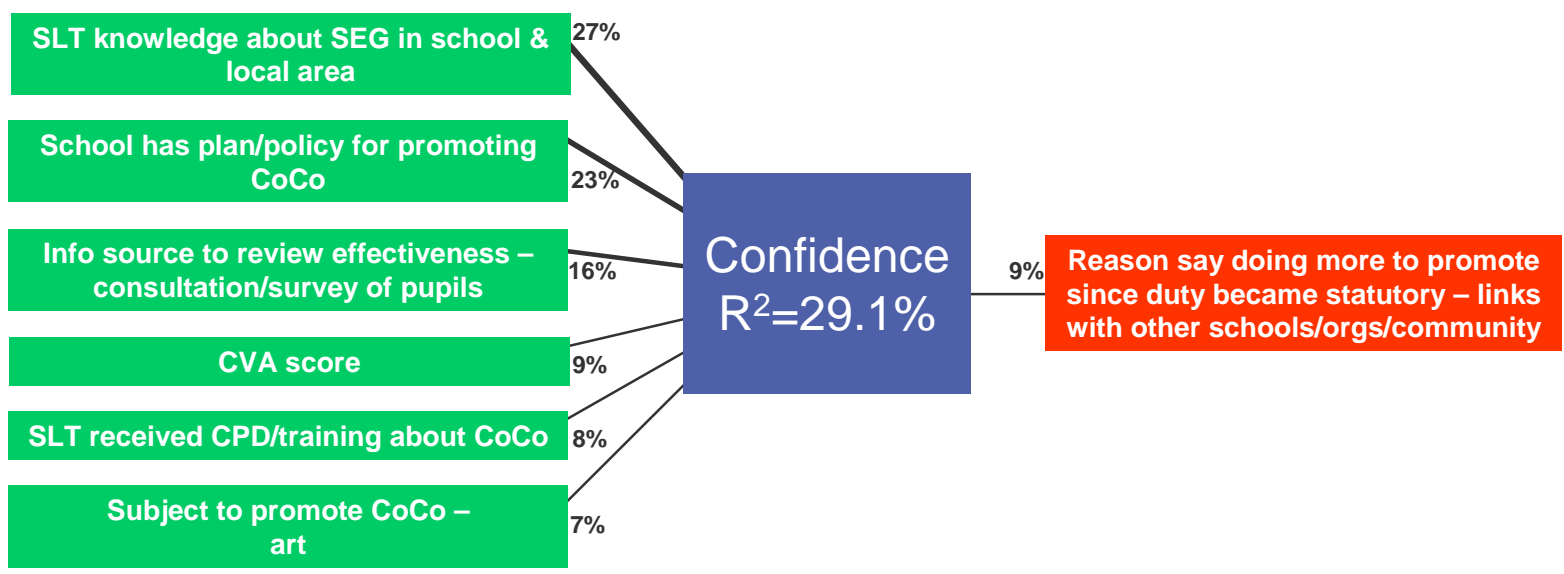

\section{Drivers of knowledge and confidence of duty - secondary schools}

The pattern in drivers of knowledge and confidence in secondary schools is similar to that seen in primary schools:

- The knowledge and confidence models are not especially strong, suggesting that many factors are at work. The knowledge model contains many drivers so the contribution of each driver is fairly small. By contrast, the confidence model contains fewer drivers, meaning that each driver has a larger role.

- $\quad$ Senior leadership team knowledge again appears important for both knowledge and confidence .

- The existence of a school plan for promoting community cohesion is again a key driver of confidence in secondary schools, as was the case in primary schools.

- Contextual factors are not significant drivers. CVA score appears, but is fairly far down the list of drivers. Faith status, levels of deprivation and settlement type do not appear as key drivers. 


\section{Knowledge of duty (secondary schools)}

Q1a. Before today, how much, if anything, would you say you knew about ...? Schools' duty to promote community cohesion

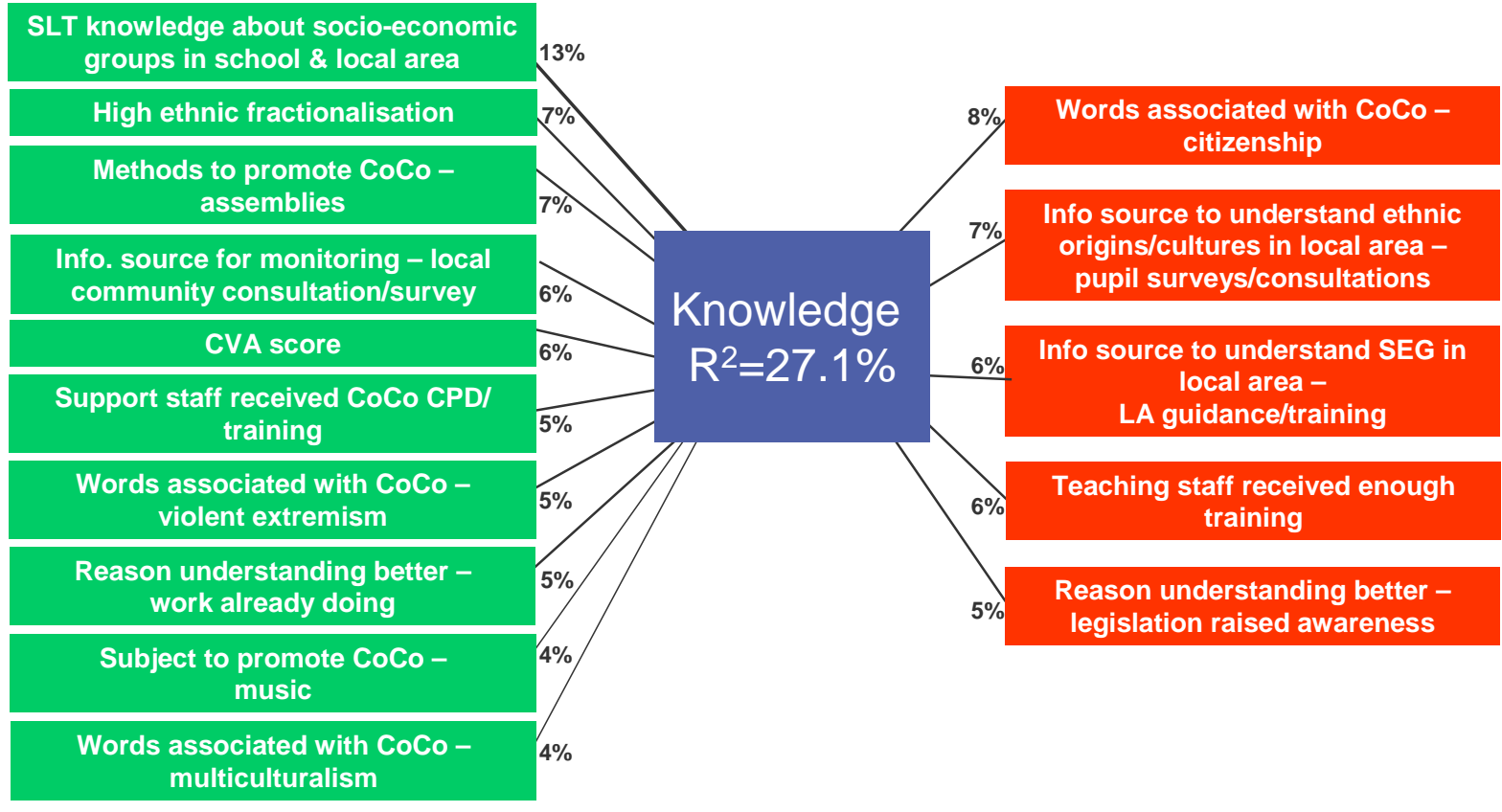

\section{Confidence about duty (secondary schools)}

Q2a. And how confident would you say you feel about ...? Schools' duty to promote community cohesion

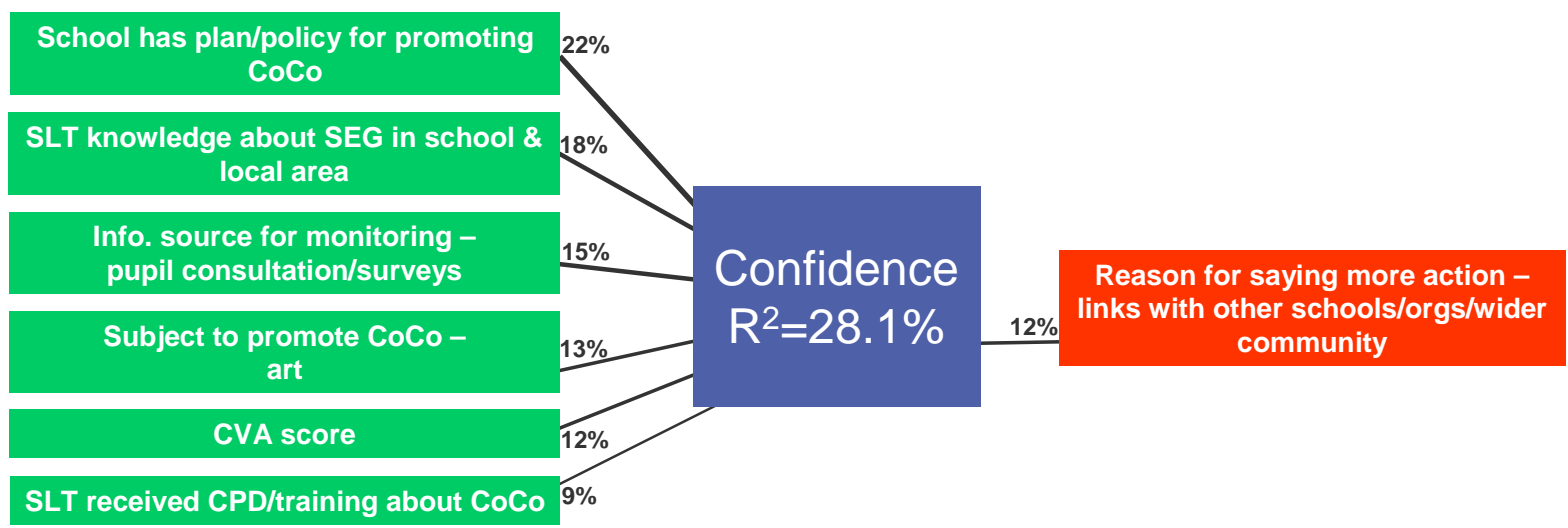




\section{Drivers of knowledge and confidence of duty - special schools}

The models for special schools are noticeably different from those just explored for primary and secondary schools. For primary and secondary schools, the key drivers appear to be senior leadership team knowledge and whether the school has a plan or policy for promoting cohesion. By contrast, in special schools senior leadership team knowledge is not a key driver and a strategic approach seems even more important than was the case for primary or secondary schools.

Plans for promoting cohesion, and integration into the school improvement plan, are both key drivers of knowledge, while integration into the school improvement plan is a key driver of confidence.

\section{Knowledge of duty (special schools)}

Q1a. Before today, how much, if anything, would you say you knew about ... ? Schools' duty to promote community cohesion?

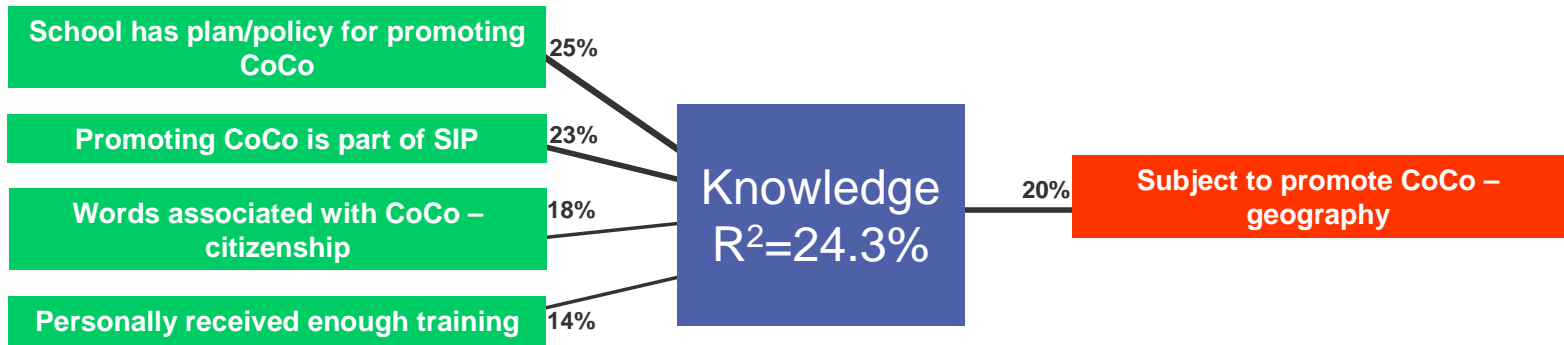

\section{Confidence about duty (special schools)}

Q2a. And how confident would you say you feel about ... ? Schools' duty to promote community cohesion?

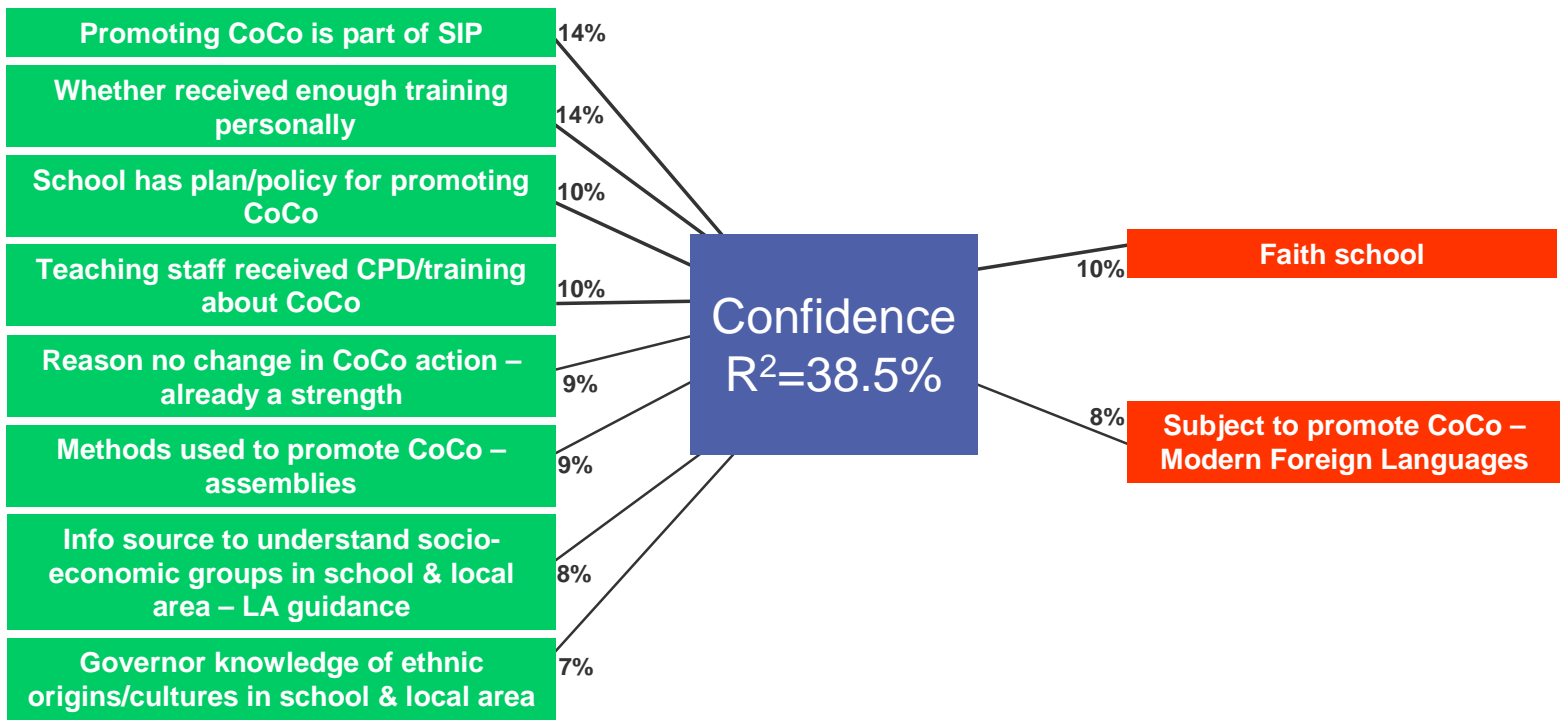


As the low $\mathrm{R}^{2}$ statistics and high number of factors on both charts show, it is not possible to produce very strong models for primary schools of the key drivers of changes since the duty became statutory. It appears that many factors are at work.

\section{Change in understanding (primary schools)}

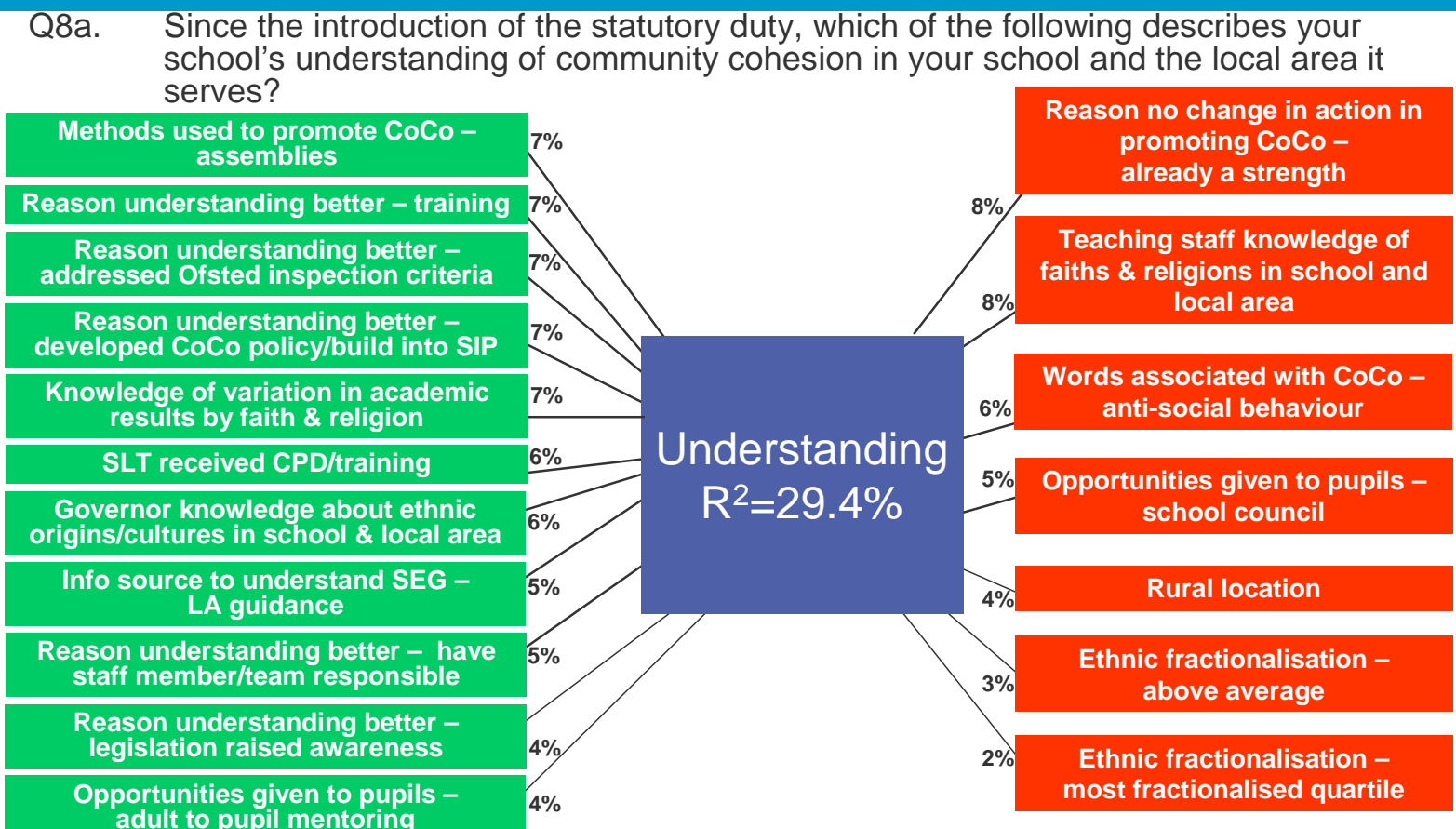




\section{Change in activity (primary schools)}

Q9a. Since the introduction of the statutory duty, which of the following describes how much your school is doing to promote community cohesion?

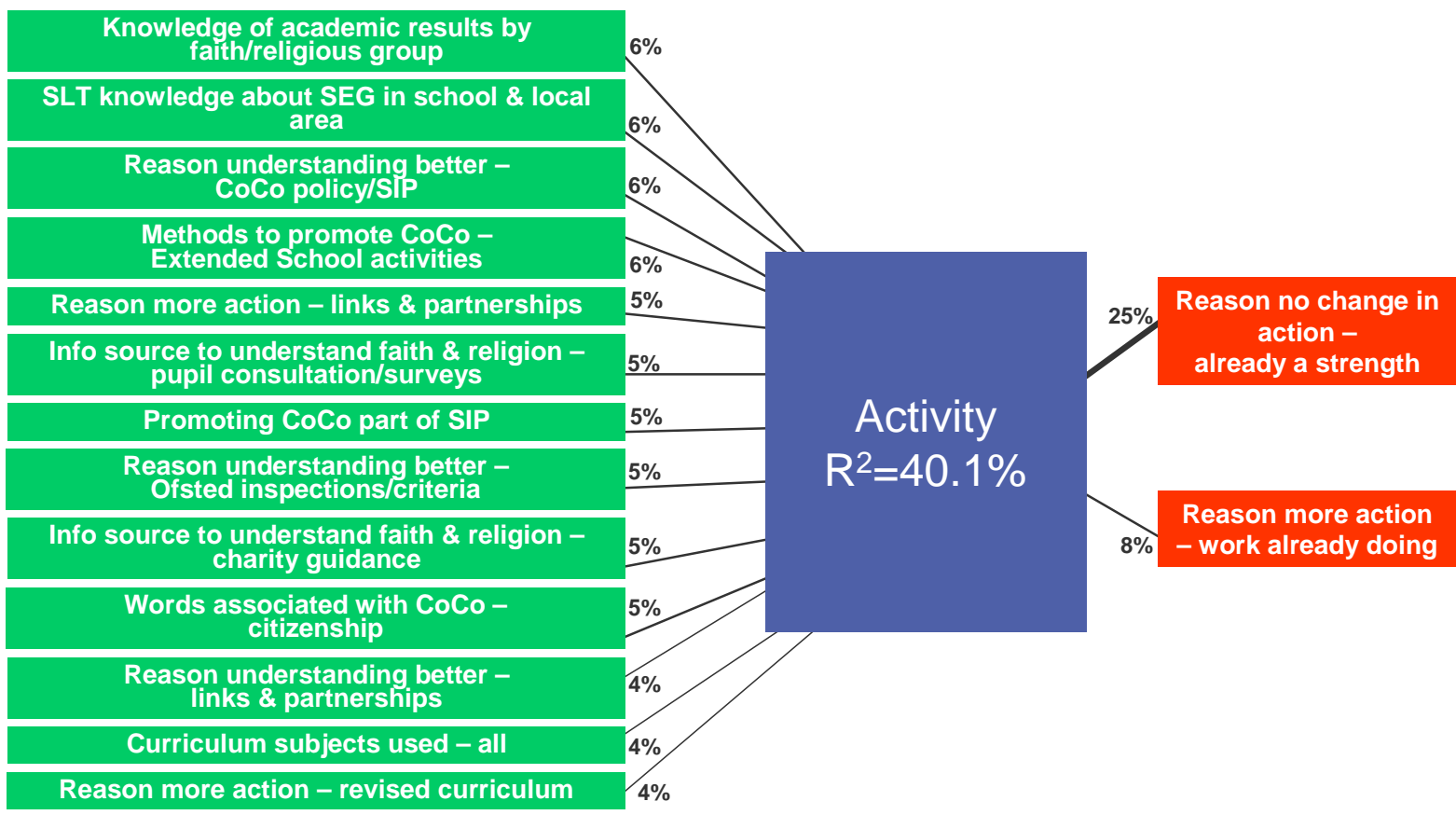

Key drivers of changes since the duty - secondary schools

For secondary schools (as for primary) it is not possible to single individual key influencers which explain much of the variation in changes since the duty became statutory. This suggests that change since the duty became statutory has not been confined to particular groups of schools. 


\section{Change in understanding (secondary schools)}

Q8a. Since the introduction of the statutory duty, which of the following describes your school's understanding of community cohesion in your school and the local area it serves?

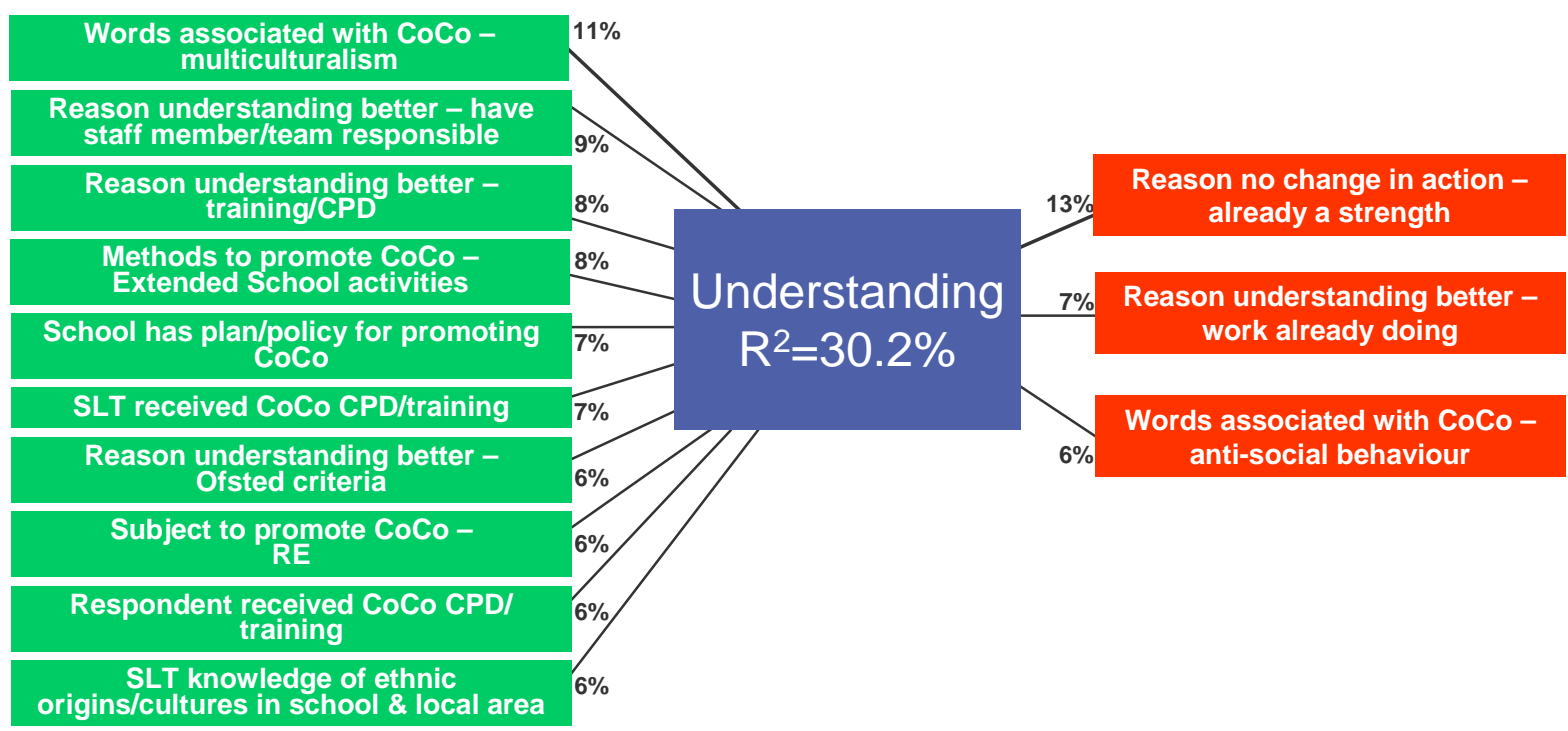

\section{Change in activity (secondary schools)}

Q9a. Since the introduction of the statutory duty, which of the following describes how much your school is doing to promote community cohesion?

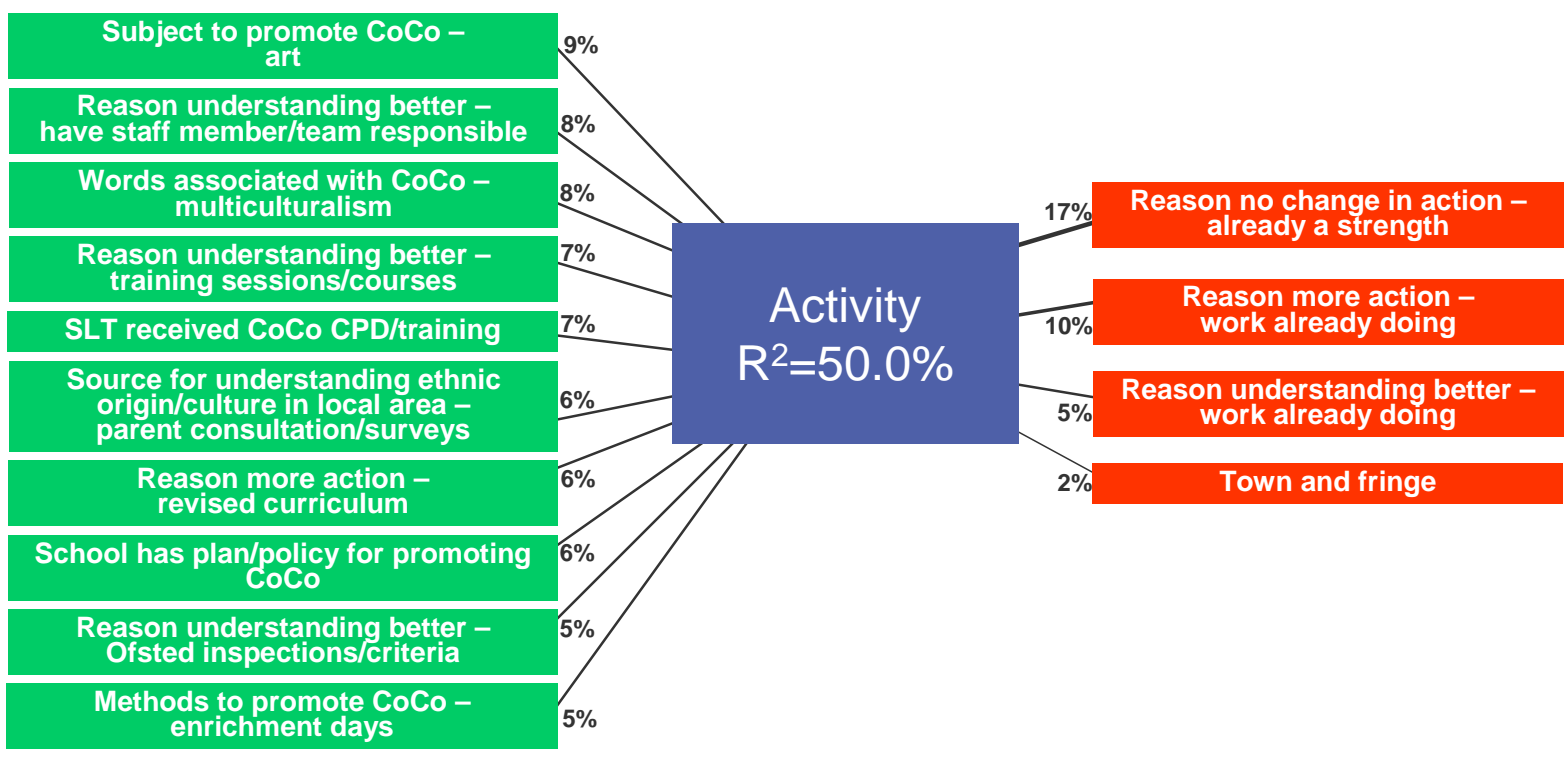




\section{Key drivers of changes since the duty - special schools}

As the chart shows, changes in knowledge since the duty became statutory vary most with knowledge of bullying rates for different faith or religious groups. Special schools which are faith schools are less likely to feel their understanding has improved. Similarly, use of parent/carer surveys for knowledge of faith and religious groups is another negative driver.

\section{Change in understanding (special schools)}

Q8a. Since the introduction of the statutory duty, which of the following describes your school's understanding of community cohesion in your school and the local area it serves?

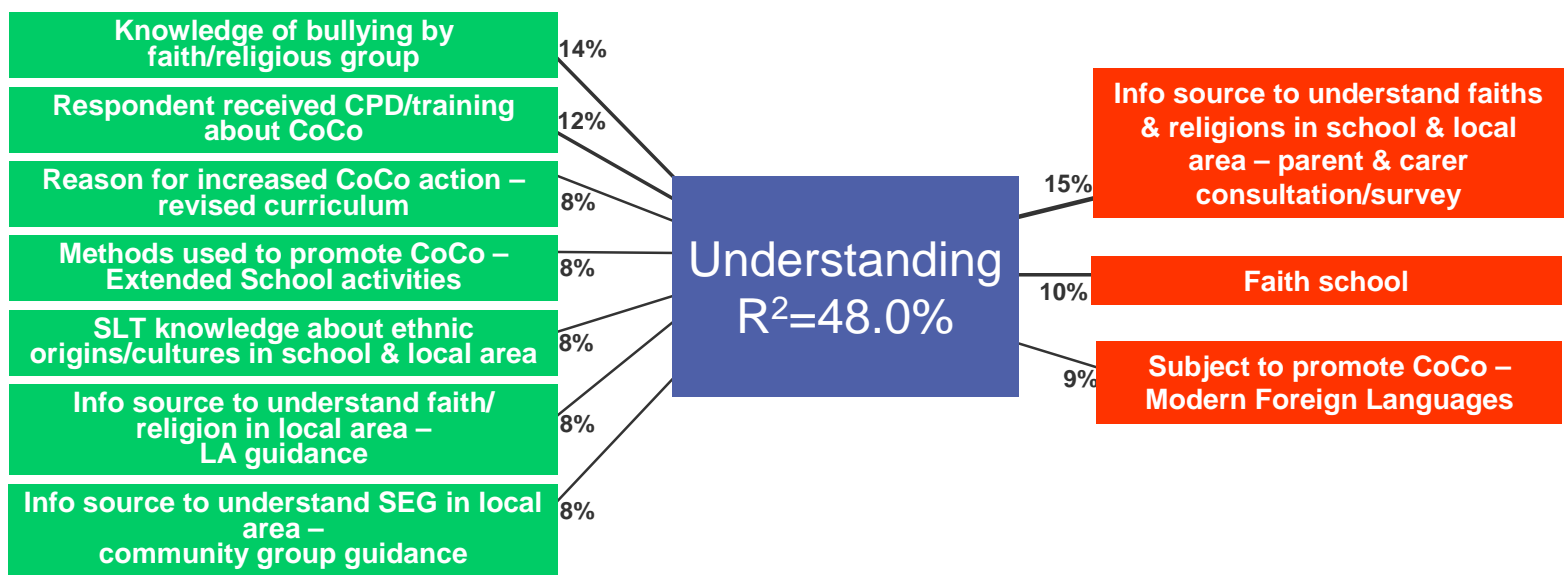

In special schools, the factors most strongly associated with increased activity since the statutory duty are the use of community consultations or surveys, integrating promotion of cohesion into the school improvement plan and senior leadership knowledge of faith and religion in the school are local area. Between them, these three factors are associated with around a fifth of the change in activity since the duty became statutory.

\section{Change in activity (special schools)}

Q9a. Since the introduction of the statutory duty, which of the following describes how much your school is doing to promote community cohesion?

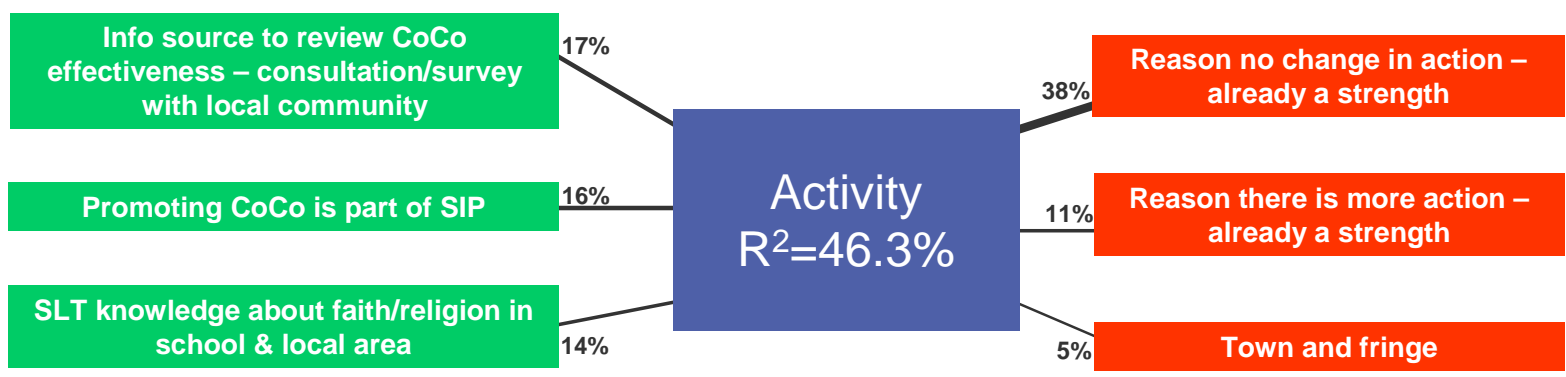


Ref: DFE-RR085

ISBN: 978-1-84775-857-6

(C) Department for Education

February 2011 